Social and Cognitive Influences on a Teacher Candidate's choice to pursue Math Education
A Dissertation
presented to

the Faculty of the Graduate School

at the University of Missouri-Columbia

In Partial Fulfillment

of the Requirements for the Degree

Doctor of Education

by

REBECCA CALLAWAY

Dr. Tim Wall, Dissertation Supervisor

May, 2018 
The undersigned, appointed by the dean of the Graduate School, have examined the dissertation entitled

\title{
SOCIAL AND COGNITIVE INFLUENCES ON A TEACHER CANDIDATE'S CHOICE TO PURSUE MATH EDUCATION
}

\author{
presented by Rebecca R. G. Callaway \\ a candidate for the degree of doctor of education, \\ and hereby certify that, in their opinion, it is worthy of acceptance.
}

Dr. Tim Wall

Dr. Jenni Wall

Dr. Carol Edmonds

Dr. Linda Smith 


\section{DEDICATION}

I dedicate this research to all the future math teachers. To all those students who have been discouraged in math but persevered. To those teachers with a growth mindset that believe all students can learn mathematics. To the problem solvers and out of the box thinkers. 


\section{ACKNOWLEDGEMENTS}

I want to thank the Lord, my family and my friends. Without the grace of God, I would not have persevered through this program. It was the Lord's compassion that gave me the time to complete the many readings and papers. The Lord's strength that gave me the strength to be a mom, a teacher and a student without losing my mind.

I want to thank my husband Jason Callaway for taking the kids on fun adventures so I could have a quiet house within to work. I want to thank him for spending a summer in Columbia and bringing Jane to me every few hours so I could nurse her as baby and still go to class. Not many dads would have been as supportive. Thank you to Jasmine for cooking for her brothers and babysitting her sister many Sundays so I could write and Wednesdays so I could go to class. Thank you to whole crew that gave up a spring break in 2017 so I could write and never complained about my mess on the kitchen table.

I want to thank my dear friends Angela Dorsey, Vicky Bryan, and Luanne Haggard. Thank you to Vicky and Angela for carpooling for two years with me. I loved the time we spent together discussing life and our studies. Thank you for collaborating on projects with me. I learned a great deal from your expertise. A special thank you to Angela for always looking out for me. You talked me into applying for this program and saved me on several emails I missed near the end due to taking a new position in another district. Your passion for learning and for students has always inspired me. I also want to thank my editor Luanne Haggard. She dedicated so much time to helping me complete my papers, not only on grammar and APA, but on evaluating whether I really answered the prompt. Your compassion and willingness to serve is un-paralleled. 


\section{TABLE OF CONTENTS}

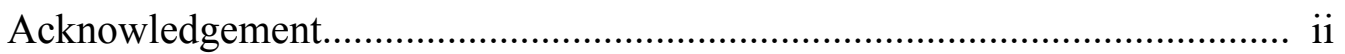

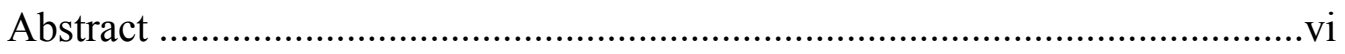

\section{SECTION ONE: INTRODUCTION TO THE DISSERTATION IN PRACTICE........1}

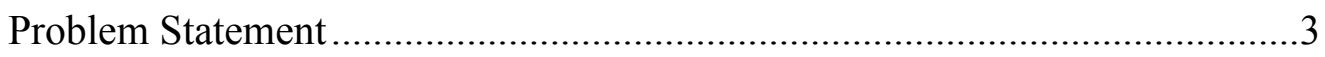

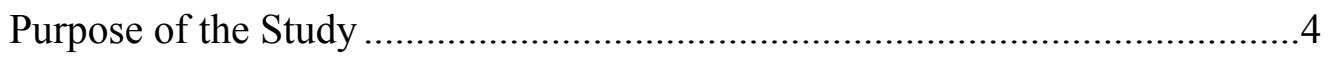

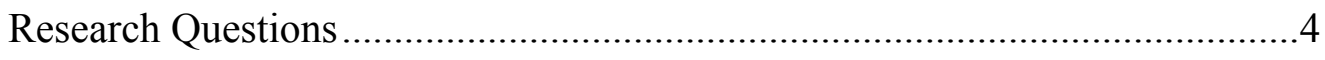

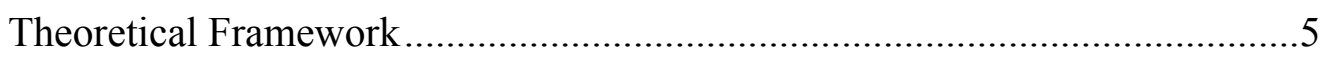

Math Education Preparation ..............................................................6

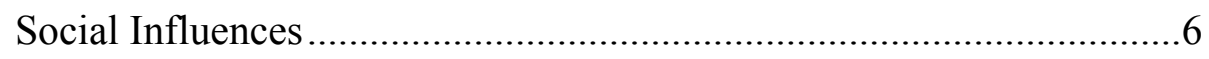

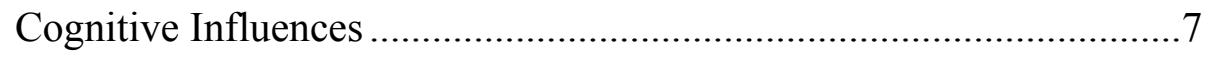

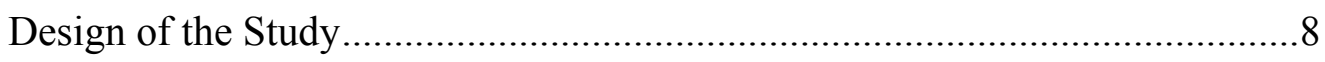

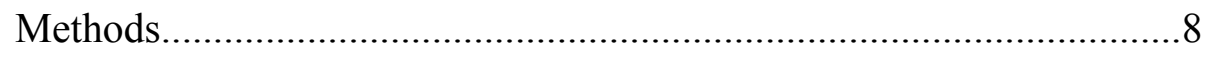

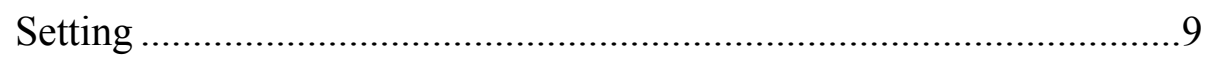

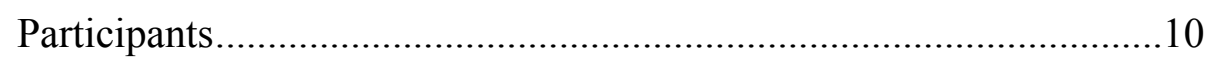

Data-Collection Tools ....................................................................10

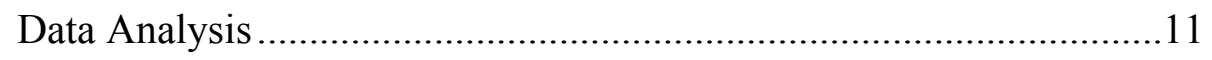

Limitations, Delimitations and Assumptions..................................................13

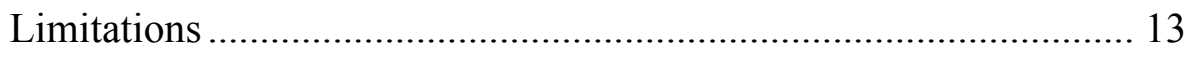

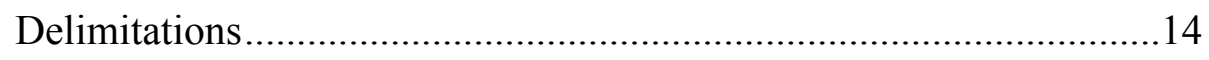

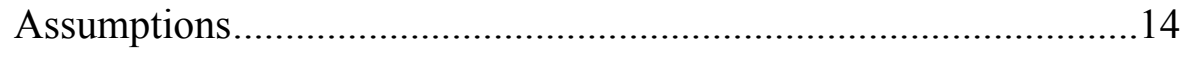

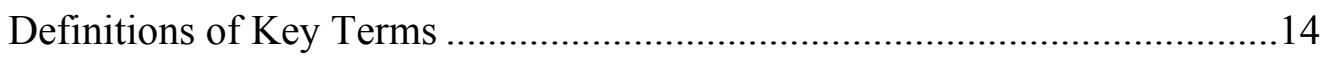

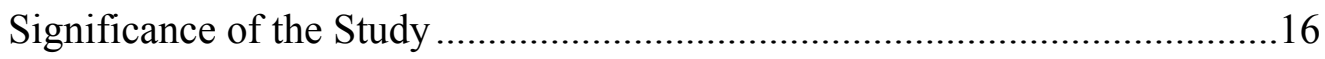


Practice

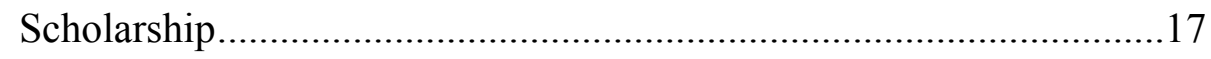

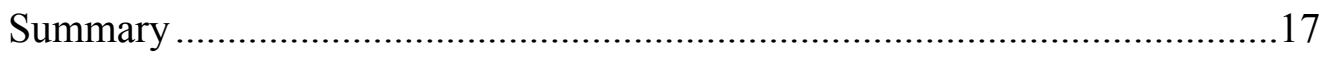

SECTION TWO: PRACTITIONER SETTING FOR THE STUDY ...........................19

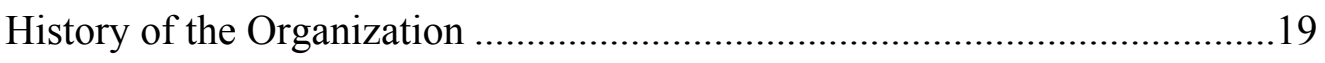

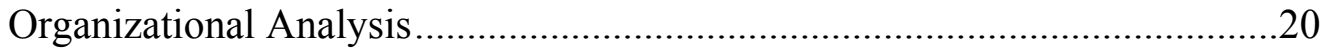

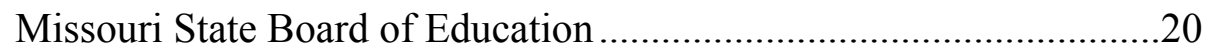

Department of Elementary and Secondary Education ..........................22

Office of Career and College Readiness ..............................................24

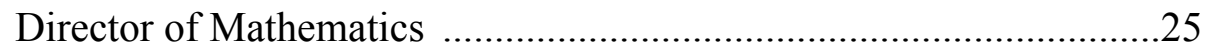

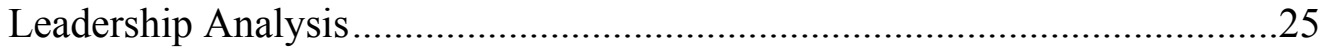

Implications for Research in the Practitioner Setting ......................................26

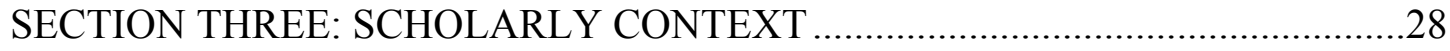

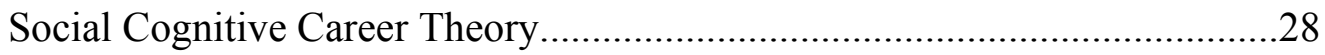

Math Education Preparation .........................................................................

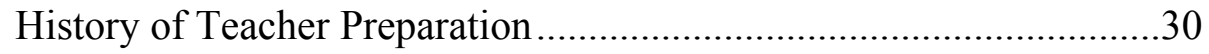

History of Math Teacher Preparation ...................................................31

Current Teacher Preparation for Math Education.................................33

Influences on selecting Math Education ..............................................34

Social Influences on Career Choices ……………….....................................

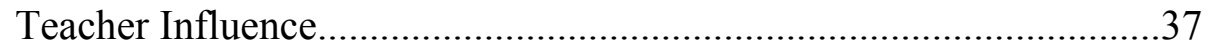

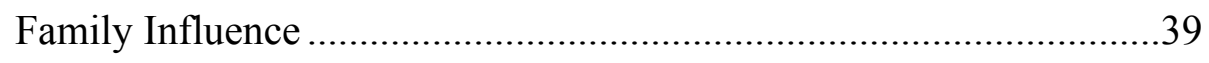

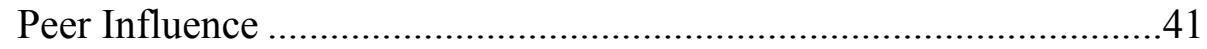


Cognitive Influences on Career Choices ...............................................42

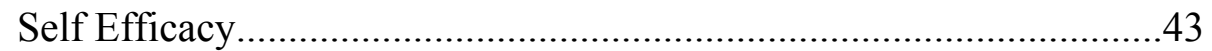

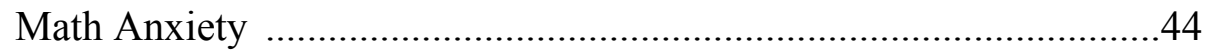

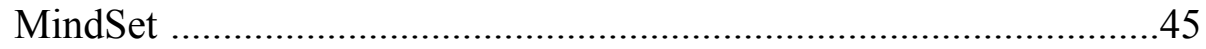

Outcome expectations ...........................................................47

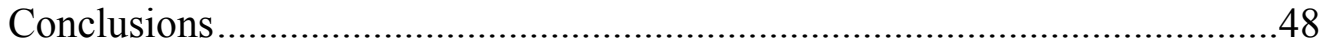

SECTION FOUR: CONTRIBUTION TO PRACTICE …......................................51

Plan for Dissemination of Practitioner Contribution ...................................51

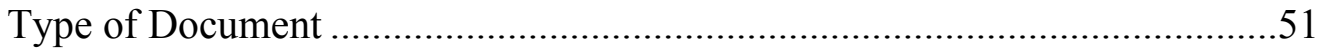

Rationale for this Contribution Type ..................................................51

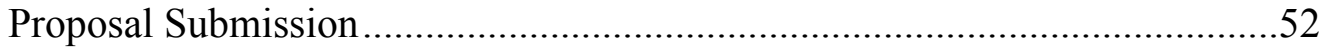

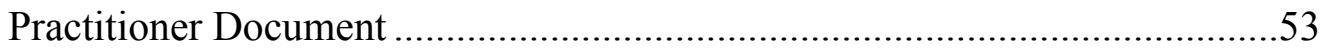

SECTION FIVE: CONTRIBUTION TO SCHOLARSHIP ..................................67

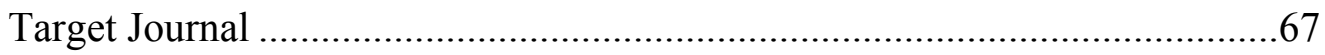

Rationale for this Target ................................................................6

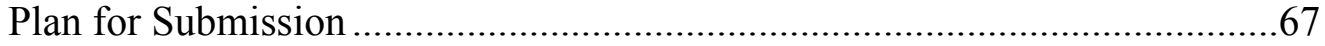

Submission-Ready Journal Article ......................................................68

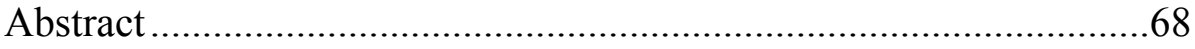

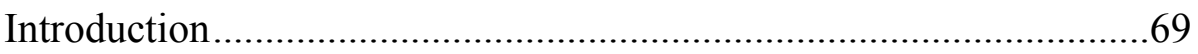

Purpose of the study .............................................................. 71

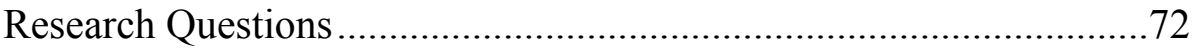

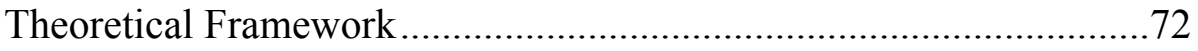

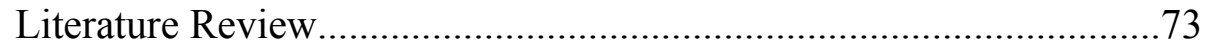


Research Design.

Results . .77

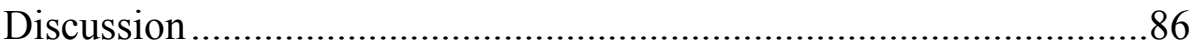

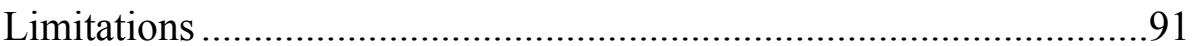

Implications for Practice and Contributions to Math Education ........91

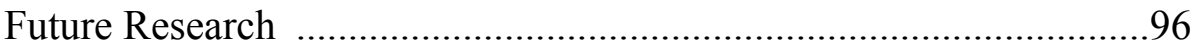

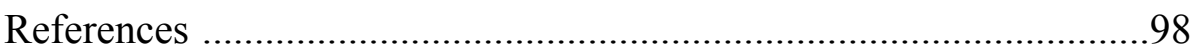

SECTION SIX: SCHOLARLY PRACTITIONER REFLECTION ............................105

Dissertation Influencing Practice as an Educational Leader...........................105

Changes in Practice related to self-efficacy ........................................106

Changes in Practice related to growth mindset...................................107

Dissertation Process Influencing Scholarship................................................108

Researcher as Learner ...................................................................109

Researcher as Scholar ...............................................................110

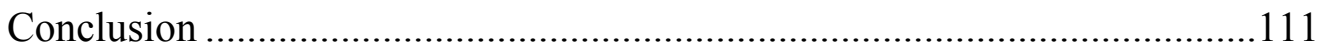

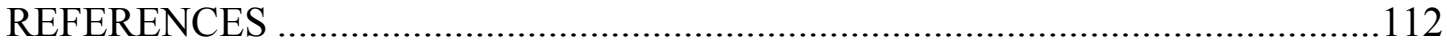

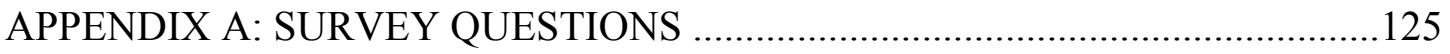

APPENDIX B:RECRUITMENT LETTERS FOR FACULTY .................................129

APPENDIX C:RECRUITMENT LETTERS FOR STUDENTS …............................130

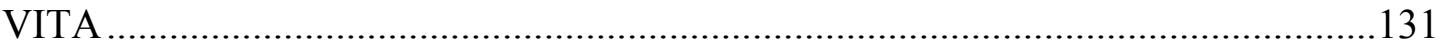




\begin{abstract}
There is a crisis across the United States as schools are seeing a shortage of mathematics teachers. While school districts are working on new ways to recruit teacher candidates, the heart of the problem lies in the decline in students entering secondary mathematics teacher preparation programs. This study evaluates the social and cognitive influences on a student's choice to pursue a degree in secondary mathematics education. An electronic survey was given to 63 students across the state of Missouri in the first three years of a math teacher preparation program. In the survey, students ranked the level of social influences (teacher encouragement, family support, and peer influences) and the level of cognitive influences (self-efficacy, growth mindset, and outcome expectations). Self-efficacy was the largest influence by a statistically significant difference. Teacher encouragement was significantly found to be the largest social influence. This is important because it implies that schools have the largest opportunity to increase the number of secondary math teachers.
\end{abstract}




\section{SECTION ONE: INTRODUCTION TO THE DISSERTATION IN PRACTICE}

Across the United States mathematics classes are finding themselves without a teacher. Forty-two states reported teacher shortages in mathematics in the 2015-2016 school year (Sutcher, Darling-Hammond, \& Carver-Thomas, 2016). For the 2017-2018 school year, forty-eight states and the district of Columbia report a shortage of secondary math teachers (Ostroff, 2017). Administrators in school districts would like to find highly qualified teachers who fit with their communities and philosophies so their students will be the most successful. However, what do schools do if there are not enough candidates to fill the positions? Schools hire uncertified candidates or leave positions unfilled (Ostroff, 2017). For example, Clark County in Nevada had over 900 teaching positions unfilled for the 2015-2016 school year (Ryan, 2016). Districts like Clark County are forced to place permanent substitutes (not certified in the field) in classrooms (DeNisco, 2015; Ryan, 2016). Other districts are increasing class sizes to take in the students; for example, in California class sizes have reached 35 students per teacher (Ostroff, 2017). Fetler's research on high school math teachers' characteristics and math student performance (1999) found there is a shortage of qualified math teachers and that shortage is associated with low student achievement. According to Sutcher, Darling-Hammond, and Carver-Thomas (2016) "evidence shows that shortages historically have disproportionately impacted our most disadvantaged students" where "high-minority schools had four times as many uncertified teachers as low-minority schools" (p. 5).

While school districts are working on new ways to recruit teacher candidates, the heart of the problem lies in the decline in students entering teacher preparation programs. 
In the 2008-2009 school year, there were 719,081 teacher candidates enrolled in teacher preparation programs. However, in the 2013-2014 school year this number dropped 35\% down to 464,250 students enrolled (Sutcher, Darling-Hammond, \& Carver-Thomas, 2016). This is coupled with the increase in the number of teachers retiring. The National Center for Education Statistics (NCES) predicts student enrollment will increase in the next decade by three million students (NCES, 2012). This increase in students will lead to an increased need for teachers.

To further aggravate the shortage of teachers in the United States, there is an increased need for teachers of color and disadvantaged race because of the changing demographics. Student population is becoming more and more diverse, and role models are becoming fewer (Branch, 2001; Estes, 2017; Schmitz, Nourse, \& Ross, 2012; Sutcher, Darling-Hammond, \& Carver-Thomas, 2016). In 2004, only 6\% of teachers in the United States were Hispanic, while $21 \%$ of the students were Hispanic and only $7.9 \%$ of teachers were black, while $17 \%$ of the students were black (Estes, 2017; NCES, 2012). Many believe minority students are more likely to succeed academically when taught by a teacher of their own race (Dee, 2004). This success could be due to the fact they share a cultural framework which helps make instruction culturally relevant (Branch, 2001). It could also be connected to how the teacher allocates time and expectations to the students (Dee, 2004). Test scores for minorities are traditionally lower in mathematics, and so there is an even larger need for qualified effective teachers (Branch, 2001; Schmitz, Nourse, \& Ross, 2012). 


\section{Problem Statement}

The overarching problem is there is a shortage of math teachers caused by a shortage of students entering the field of math education (Sutcher et al., 2016; Ingersoll \& Perda, 2010). Specifically, the problem is a lack of research on influences on a teacher candidate's choice to pursue math education. Ingersoll and Perda (2010) found in their research that the content areas of math and science have more of a shortage of teachers than English classrooms. Curtis (2012) who completed a qualitative study on why teachers go into education, found that math teachers entered the profession because of their desire to work with young people, make a difference, and a love for math. But what influences led to a desire to work with young people, or created a love for math? Lent and Brown's (2013) research states there are social and cognitive influences that impact how one chooses a career. There is a need to find the social and cognitive influences that positively or negatively influence a teacher candidate's choice to become a math teacher.

The shortage of students pursuing degrees in science, technology, engineering, and mathematics (STEM) could be similar to the shortage seen in students pursuing math education. Researchers state there is a decline in students pursuing STEM fields (Moakler \& Kim, 2014). The mathematics referred to in STEM is students studying purely mathematics; however students pursuing math education would have similar characteristics and influences. According to the National Science Board, as the need for STEM careers has increased there has been a decline in the number of students entering STEM fields of study in higher education (2005). Furthermore, the interest in STEM has declined at the high school level which means fewer students pursuing a degree in a STEM field (National Academy of Sciences, 2007). Wang's (2013) research found the 
largest influence on students pursuing a degree in a STEM field was mathematical selfefficacy and exposure to math and science courses at the high school level. So how does this compare to lack of students pursing math education? A connection between the shortage of math teachers and the lack of students interested in math seems logical, but what is influencing this loss of interest in math education?

\section{Purpose of the Study}

The purpose of this study was to contribute to the literature on why teacher candidates pursue math education. This may increase the number of students entering into the math education profession. This research investigated what social and cognitive factors influence a teacher candidate to select a specific field of education. Specifically, is the choice influenced by people around them, or emotions and beliefs? If people, then is it teachers, family members or peers that influence students the most to choose a career in education? Or are there other perceptions like self-efficacy, mindset, or outcome expectations that influence their choice? If these factors are found, then researchers can begin to look at how to increase the positive influences and decrease the negative influences so the number of students entering the field of math education can be increased.

\section{Research Questions}

The main research question guiding this study was: What factors influence a student to select mathematics? The sub-questions investigated are:

- Is there a difference between social and cognitive influences on a student's choice to pursue a degree in mathematics education? 
- Is there a difference between the social influences (teacher encouragement, family support, and peer influence) on a student's choice to pursue a degree in mathematics education?

- Is there a difference between the cognitive influences (self-efficacy, mindset, and expectations) on a student's choice to pursue a degree in mathematics education?

\section{Theoretical Framework: Social Cognitive Career Theory}

This study used the Social Cognitive Career Theory (SCCT) that integrates career interests, goals, and intentions with self-efficacy and outcome expectations. This theory was initially presented in 1994 by Lent, Brown, and Hackett as three interconnected theories. The goal was to explain the interest development, choices in career paths, and performance in education relating to vocational training. In 2006, a fourth overlapping model was adopted to discuss wellbeing or satisfaction (Lent \& Brown, 2013). "People do not operate as autonomous agents. Nor is their behavior wholly determined by situational influences. Rather, human functioning is a product of a reciprocal interplay of intrapersonal, behavioral, and environmental determinants. .." (Bandura, 2006, p.165). SCCT views students as living within a social world, with ever-present opportunities to be influenced. Specifically, the SCCT choice model is concerned with the self, experiential, and contextual factors that promote pursuit of careers paths (Lent \& Brown, 2013). This study will be applying the model to teacher candidates' choice of teaching area, specifically focused on those that selected math education. 


\section{Math Education Preparation}

The history of teacher preparation influences a teacher candidate's choice to pursue math education. One example of this influence is the loss of prestige of the teaching profession. This began with teacher preparation being in normal schools and not originally in the universities (Larabee, 2008). The teaching certificate did not hold the prestige that other university degrees held. Another example of this influence is in the stereotypes of education being women's work, but math being a male field. Seventy-five percent of teachers, kindergarten through $12^{\text {th }}$ grade, are females (Allgretto, Corcoran $\&$ Mishel, 2004). This stereotype is encouraged further by statistics like men get higher SAT scores in math than women or science and technology careers are predominantly male disciplines (McCarthy, 2011). Females also report higher levels of math anxiety and lower levels of math self-concept (Else-Quest, Minew, \& Higgins, 2013). The combination of the stereotypes causes every teacher candidate that selects math education to have to fight society biases. Furthermore, there are cultural stereotypes that certain ethnic groups are better suited for mathematics while others are less suited for mathematics (Hrabowski, 2011). This is not helped by the statistic that many states are adding more testing for licensure, and these tests have shown to be biased to students of color (Branch, 2001).

\section{Social Influences}

There are many influences in a person's life that guides them to a career choice. Social influences like teachers, parents, and peers have a strong impact especially in the adolescent years (Alika, 2012; Hsiao \& Nova, 2015). During adolescence is when many students select their career and begin taking courses to pursue that career. The emotional 
support needed for a career choice often comes from peers (Pereira \& Garcia, 2007). Researchers suggest social relationships "act as a pipe to channel the flow of information and resources" about career choices (Easley \& Wang, 2017, p. 636). Social relationships can also influence the choice with expectations and perceptions (Guerra \& BraungartRieker, 1999; Hsiao \& Nova, 2015). This study evaluated three types of social influence: teachers, family, and peers.

\section{Cognitive Influences}

Career choices are often influenced by cognitive factors such as self-efficacy, anxiety, mindset, and outcome expectations. Mathematical self-efficacy is the belief students hold in their mathematics capabilities, and it is predictive of student's achievement and motivations in mathematics (Bates, Latham \& Kim, 2011; Brown \& Lent, 2006; Moakler \& Kim, 2014). Researchers have found that mathematics selfefficacy is increased when students experience academic success specific to math such as solving math problems (Campbell \& Hackett, 1986; Len, Brown, \& Hackett, 1994). There have been many studies that show a significant relationship between self-efficacy and performance (Ayontolah \& Adedeji, 2009; Bates, Latham, \& Kim, 2011; Peters, 2012; Stevens, Olivarez, Lan, \& Tallent-Runnels, 2004; Williams \& Williams 2010). A negative correlation has also been found between mathematics anxiety and mathematical self-efficacy (Azar \& Mamoudi 2014; Hackett \& Betz, 1989). Students with high math anxiety tend to avoid situations involving mathematics and are therefore less likely to pursue math related careers (Beilock \& Willingham, 2014; Supekar, 2015). While selfefficacy focuses on what a student thinks they can do, mindset focuses on their ability to learn. A fixed mindset is when students believe they are either smart or not, good at 
something or not good at it (Boaler, 2016). A student with a growth mindset is more willing to take on hard work and view mistakes as a challenge and motivation to work harder (Duckworth \& Quinn, 2009; Dweck, 2016). This study looked at the cognitive influences of self-efficacy, mindset, and outcome expectations on a teacher candidate's career choice.

\section{Design of the Study}

The research question was looking for a difference so a quantitative study was selected (Creswell, 2014). The independent variables were social influences of teacher encouragement, family support, or peer influence and cognitive influences of selfefficacy, mathematical mindset, and outcome expectations. It will be a non-experimental design because the variables of teacher encouragement, parental support, and peer influence cannot ethically be restricted from participants (Creswell, 2014). Furthermore, the variable of self-efficacy and growth mindset cannot be controlled.

\section{Methods}

A survey was used to generalize results from a sample of the population (Creswell, 2014). The population was all secondary math education teacher candidates in their first or second year of course work attending a college or university in Missouri and pursing a middle or secondary teaching position. An electronic survey was emailed out to participants through math professors at various Missouri universities with teacher preparation programs. The researcher does not work at a college or university and is therefore considered an outsider (Merriam \& Tisdell, 2016). However, the researcher is a secondary math teacher and so must be careful of bias toward personal influences to select math education. The data collected were cross sectional as it was collected over 
one year (Creswell, 2014). Descriptive statistics including mean, median, mode and standard deviation were used to interpret the data. Then hypothesis mean paired $t$-tests were used to determine significant differences between influences.

\section{Setting}

The population was all secondary math teacher candidates attending a teacher preparation program in Missouri in the United States of America. This state has had a steadily increasing population around six million (US census, 2017). Missouri is composed of $83 \%$ white population, $12 \%$ black population, and a growing $4 \%$ Hispanic population (US census, 2017). Eighty-eight percent of individuals over 25 years of age have a high school diploma, but only $27 \%$ have a Bachelor's degree or higher (US census, 2017). All children between the ages of seven and seventeen are required to regularly attend either public, private, parochial, or homeschool by state law (Education, 2017). Missouri's public elementary and secondary schools employed 69,683 teachers in 2015-2016 school year of which 78.4\% are female (MDESE, 2017).

There is a Department of Elementary and Secondary Education that administers the primary and secondary public schools in the state and a Department of Higher education to administrate the colleges and universities. Missouri has 13 public four-year universities, 14 public two-year colleges, and 25 independent colleges (MDHE, 2017). Many of the four-year universities began as normal schools designed for teacher preparation and then in the early twentieth century turned into fine arts universities (Education 2017). Missouri certified 5,615 teachers in 2009-2010 (Brock, 2012). In 2015, Missouri published a plan to "recruit, prepare and retain effective teachers for all public schoolchildren in the state, especially in high-poverty, high-minority, or rural 
districts" (MDESE). The new plan included revising the standards and assessments for teacher candidates to become certified. The new standards for the preparation of educators went into full implementation in 2017.

\section{Participants}

The exact size of the population was unknown and so a sample will be used to estimate the population. The sample (survey participants) were math education majors from Missouri colleges and universities in their first or second year. The survey was emailed out to all secondary math teacher candidates, and because it was not mandatory the sample is considered self-selected (Creswell, 2014). The survey was given in the first and second year and not the final years so that it is measuring the influences that caused a teacher candidate to pursue a degree in math education instead of measuring if they are able to complete the degree.

\section{Data collection tool}

The survey was an online questionnaire using Survey Monkey. The online aspect allowed it to be emailed out across the state and record the data accurately and quickly (Creswell, 2014). It also gave quick descriptive statistics. The survey used a 4-point Likert scale causing a "forced choice" for each question (Fink, 2009 p. 26). Most previous research on self-efficacy used a Likert-type response scale (Toland \& Usher, 2016). Only four points were used because cognitive psychologists have stated participants have a hard time holding too many categories in working memory at a time (Cowan, More, Chen, Gilchrist, \& Saults, 2008). Furthermore, Toland and Usher's research (2016) found that the four-point scale was optimal for measuring self-efficacy because it increased the reliability and validity. 
The survey questions were written by the researcher. They were tested on 10 secondary teachers from various fields of education and years of experience. The pretest provided feedback if the online format was working properly and if the questions provided the needed information (Fink, 2009). The next step was to email the survey questions to math professors across the state at the thirteen public universities. Then they emailed the survey to their students. The survey would stay open for one month to give teacher candidates a chance to respond on their own time line.

\section{Data analysis}

The independent variables were teacher encouragement, parental support, peer influence, self-efficacy, mindset, and outcome expectations. The following table shows the variables and to which questions each one aligns.

Table 1

Variable Alignment to Questions

\begin{tabular}{lll} 
Variable & Type & Question Number \\
\hline Teacher Encouragement & Social & $7 \mathrm{~b}, 7 \mathrm{f}$ \\
Family support & Social & $7 \mathrm{a}, 7 \mathrm{c}, 7 \mathrm{~d}$ \\
Peer Influence & Social & $7 \mathrm{e} 8 \mathrm{f}$ \\
Self-efficacy & & \\
$\quad$ General academic & Cognitive & $4 \mathrm{a}, 4 \mathrm{e}$ \\
$\quad$ Content specific & Cognitive & $8 \mathrm{a}, 8 \mathrm{~b}, 4 \mathrm{~b}, 4 \mathrm{c}, 4 \mathrm{~d}$ \\
Mindset & Cognitive & $5,6,8 \mathrm{c}$ \\
Outcome expectancy & Cognitive & $8 \mathrm{~d}, 8 \mathrm{e}, 8 \mathrm{~g}$ \\
\hline
\end{tabular}

The data analysis began with descriptive statistics comparing the results from each survey question. Descriptive statistics were used because they "give us a manageable and meaningful summary of the underlying phenomenon" (Wheelen, 2013, p. 17). The descriptive statistics consisted of the mean, median, mode and standard 
deviation. After comparing the data from each question, the data were grouped into the variables: teacher encouragement, parental support, peer influence, self-efficacy, mindset, and outcome expectations and the descriptive statistics analyzed. Next the data were grouped into the social influence and cognitive influence and compared through descriptive statistics. Finally, bar graphs were created to compare the mean, median and mode for the variables (Field, 2013).

After the charts were analyzed the data were evaluated for statistical differences using a paired t-test. A t-test focuses on whether the difference between two groups' averages is because of random chance in sample selection or another factor. Statwing (2017) states that to get a meaningful difference one needs a large sample size, small standard deviation and a large difference between averages. It is a paired t-test because the data is from the same candidate just different questions (Field, 2013).

Below are listed the null- hypotheses tested to go with the research questions: Is there a difference between social and cognitive influences on a student's choice to pursue a degree in mathematics education?

1. There is no significant difference between the social and cognitive influences on a teacher candidate's choice to select mathematics.

Is there a difference between the social influences (teacher encouragement, family support, and peer influence) on a student's choice to pursue a degree in mathematics education?

2. There is no significant difference between the teacher's influence and the parent's influence on a teacher candidate's choice to select mathematics. 
3. There is no significant difference between the parent's influence and the peers' influence on a teacher candidate's choice to select mathematics.

4. There is no significant difference between the teacher's influence and the peers' influence on a teacher candidate's choice to select mathematics.

Is there a difference between the cognitive influences (self-efficacy, mindset, and expectations) on a student's choice to pursue a degree in mathematics education?

5. There is no significant difference between content self-efficacy and outcome expectations on a teacher candidate's choice to select mathematics.

6. There is no significant difference between content self-efficacy and growth mindset on a teacher candidate's choice to select mathematics.

7. There is no significant difference between the growth mindset and the outcome expectations on a teacher candidate's choice to select mathematics.

The statistical significance was found, the implications were analyzed and reported.

\section{Limitations, Delimitations and Assumptions}

The study's limitations, delimitations and assumptions are important to keep in mind as one evaluates the results and will influence the future research. Conditions that are out of the researcher's control are limitations, whereas delimitations are conditions caused by choices made by the researcher (Creswell, 2014). Assumptions are factors the researcher assumed to be true.

\section{Limitations}

One limitation is the number of teacher candidates in the state of Missouri is not diverse in race or gender and so the sample will not be diverse. Majority of teacher candidates are Caucasian and female (Estes, 2017). Another limitation is some students 
interested in pursuing math education may have been kept out of college due to low entrance exams or financial strain. Therefore, the data are limited to those who qualify for the college. Finally, students often change their mind on what career to pursue, so there may be some teacher candidates who change their mind about math education.

\section{Delimitations}

The data were collected through a voluntary survey and so the sample size was small and lacking diversity. Therefore, the reader should be cautioned that the results lack generalization because they only reflect those whom choose to participate. Since there is only a small number of teacher candidates pursuing math education at each university, it was important to pull from teacher preparation programs all over the state. However, that required relying on professors at those other programs to encourage their teacher candidates to participate. This encouragement was not consistent across the state. Therefore, some areas were more represented then others. Furthermore, the questions were written by the author and only field tested with teachers already in the profession, therefore, the strength of the validity and reliability could be questioned.

\section{Assumptions}

The surveys were anonymous leading to one major assumption that the teacher candidates answered honestly. Another assumption is the professors shared the survey with all teacher candidates and all had the opportunity to participate. Since, the survey was given using Survey Monkey, it is also assumed all students had access to electronic devices with internet and could participate.

\section{Definition of Key Terms}

To better grasp an understanding of the research and findings, the following 
section includes necessary definitions of key terms defined in direct relation to this study. Diversity. Diversity is the differences among groups of people and individuals based on ethnicity, race, socioeconomic status, gender, exceptionalities, language, religion, sexual orientations, and geographical area and types of diversity necessary for addressing the effects of candidate's interactions with diverse faculty, candidates, and students (Estes, 2017).

Fixed mindset. People who believe intelligence is unchangeable have a fixed mindset (Dweck, 2006).

Growth mindset. People who believe intelligence is malleable and can be developed through learning have a growth mindset (Dweck, 2006).

Math Anxiety. Math anxiety is a feeling of tension, apprehension or fear about one's ability to do math, which subsequently interferes with performance thereof (Segen's Medical Dictionary, 2011).

Self-efficacy. Self-efficacy is described as how a teacher candidate views self in regard to the ability to exercise control over their own level of functioning and over events that affect their lives. Self-efficacy is a by-product of confidence and beliefs on how one feels, thinks about self in regard to accomplishing a given task (Estes, 2017).

Teacher Candidate. A teacher candidate is a college student who is participating in a teacher preparation program and preparing to become a certified teacher, but is not yet graduated (Estes, 2017). 


\section{Significance of the Study}

\section{Practice}

The need to recruit quality math teachers has never been more pronounced and therefore, the need to recruit teacher candidates in the field of mathematics is significant (Sutcher et al., 2016). Moreover, if math teachers are hard to find, then finding good math teachers is even harder to find (Ostroff, 2017). This research will analyze what factors draw teacher candidates to math education and what social and cognitive influences are impacting their choices. Through this research, teachers and school administrators can learn how to increase the interest in math education degrees. For example, if teacher influence is found to be strong, then teachers will be encouraged to increase this influence through student conferencing and career counseling. However, if family influence is found to be higher, then schools can increase the use of programs that educate families about future careers in mathematics. Furthermore, if self-efficacy or growth mindset are found to have a strong influence, then teachers can strive to use more activities that build self-efficacy and growth mindsets. On the other side, if it is outcome expectations that have the greatest influence, then districts may look for ways to publicize the positive outcome expectations or even work to improve the outcome expectations for teachers.

This increase in interest in math would increase the number of math education candidates. Therefore, this research will help find factors related to alleviating the shortage of math teachers, which would then increase the quality of math instruction by increasing the number of qualified teacher candidates to hire. School district administrators will be curious about the results, as well as universities with teacher prep 
programs and policy makers. Furthermore, math teachers will be interested in these results as they are the first line of influence on future teacher candidates.

\section{Scholarship}

This research will also add to the literature on the Social Cognitive Career Theory (SCCT) by evaluating the influences of teacher candidates pursuing a degree in math education. The SCCT has been used to see how mathematical self-efficacy influences individuals' pursuit of careers in STEM fields which is similar to math education (Fouad \& Santana, 2017; Wang, 2004). STEM fields differ from math education in outcome expectations which is an important feature of cognitive influences. This research will extend the SCCT to the specific field of math education. Furthermore, the SCCT has been extended to various client groups based on racial diversity (Byars-Winston, Estrada, Howard, Davis, \& Zalapa, 2010), persons with disabilities (Fabian, 2000) and gay and lesbian workers (Morrow, Gore, \& Campbell, 1996), but not directly to teacher candidates. Teacher candidates may include some of the above group, but they also have their own characteristics as a sub group. This research would extend the theory to how teacher candidates select the field in which they study and more specifically what social and cognitive influences made the most impact on their decision.

\section{Summary}

There is a shortage of teacher candidates pursuing a degree in math education causing there to be a shortage of math teachers (Sutcher et al., 2016). Using the Social Cognitive Career Theory (SCCT), the researcher investigated the relationship between social influences such as teacher encouragement, family support, and peer recommendations along with cognitive influences such as self-efficacy, mindset, and 
outcome expectations to teacher candidate's choice to pursue math education. The research consisted of an electronic survey to first and second year teacher candidates across Missouri in the United States of America. The analysis consisted of descriptive statistics and t-tests to look for differences between the various influences. The research contributes to the literature on the career influences of teacher candidates and the use of the SCCT in the field of education. Finally, these results will help guide high schools and universities to find ways to encourage an increase in teacher candidates pursuing math education. "Schools are there to give students the most rigorous education they can, but without quality teachers they can't do that" (Ostroff, 2017). 


\section{SECTION TWO: PRACTITIONER SETTING FOR THE STUDY}

The Missouri Department of Elementary and Secondary Education's (DESE)

mission is to guarantee the superior preparation and performance of every child in school and in life (Missouri Department of Elementary and Secondary Education, 2017). They have three strategic priorities that address access for all students to high quality

educational opportunities: efficiency of business operations, effective programming, and teacher. The setting of this study is DESE because their focus is on education. More specifically this section will focus on the director of mathematics that works for DESE. Beginning with the history of the organization, the study completes an organizational analysis and a leadership analysis.

\section{History of the Organization}

In 1945, the Missouri Constitution created the State Board of Education with the addition of Article IX, Section 2a (Missouri Department of Elementary and Secondary Education, 2017). The state assigned the first commissioner of Education in 1947. He was a former teacher and administrator in the state. Since that time, there have been six commissioners; all being former teachers and administrators in the state. The creation of the Department of Elementary and Secondary Education (DESE) became the name for the entire department under the leadership of the commissioner. In 2009, there was a reorganization and the Office of College and Career Readiness was formed. In 2015, Missouri published a plan to "recruit, prepare and retain effective teachers for all public schoolchildren in the state, especially in high-poverty, high-minority or rural districts" (Missouri Department of Elementary and Secondary Education, 2017). 
The Office of College and Career Readiness is in charge of the guiding standards for education and the Missouri Assessment Program (MAP) (Missouri Department of Elementary and Secondary Education, 2017). The standards are not a specific curriculum school districts have to follow, but a set of standards to move students to college and career readiness. The first set of Show Me Standards were written by teachers across the state and adopted in 1996. The math standards were influenced and aligned to the National Council of Teacher of Mathematics (NCTM) standards. Furthermore, the standards were an answer to the call from the Education Summit attended by President Bush and the Missouri Governor to make United States students first in the world in mathematics (Klein, 2003). In 2010, the Missouri State Board of Education adopted the Common Core State Standards (CCSS) after much encouragement from the nation's leadership. Yet, there was much debate about the assessments and in 2016, the Missouri Learning Standards were written with the guidance of teachers and replaced of the Common Core Standards. The director of math assessment and curriculum is appointed by the commissioner and has a large role in the organization of the math standards. There have been six directors since the beginning of the creation of this position.

\section{Organizational Analysis}

\section{Missouri State Board of Education}

According to the Missouri Constitution, "The supervision of instruction in the

public schools shall be vested in a state board of education ..." (Article IX, Section 2a). This provision gives the State Board of Education general authority for public education, within limits set by the General Assembly (Missouri Department of Elementary and Secondary Education, 2017). The State Board is made up of eight citizens appointed by 
the Governor and confirmed by the Senate. Members serve staggered, eight-year terms with one term expiring each year. No more than four members of the State Board may belong to the same political party. No more than one member of the State Board may reside in the same county or Congressional district. When terms expire, members continue to serve until being replaced or reappointed. The State Board elects its own officers each year.

The State Board's duties and responsibilities range from preschool to the postsecondary and adult levels (Missouri Department of Elementary and Secondary Education, 2017). It does not have direct authority over higher education institutions. However, the State Board sets standards for and approves courses and professional programs for teachers and school administrators in Missouri's public and private higher education institutions. Under federal law, the State Board serves as the state-level governing body for career and technical education programs provided by local school districts, community colleges, and four-year institutions. The State Board's major duties include: appointing the Commissioner of Education and setting policies for the Department of Elementary and Secondary Education (DESE), defining academic performance standard and assessment requirements for public schools, and accrediting local school districts. It accredits school districts through the "Missouri School Improvement Program," which includes minimum standards for high school graduation, curriculum, student testing, support services, and other areas of school operations (Missouri Department of Elementary and Secondary Education, 2017). The State Board also establishes requirements for the education, testing, assessment, certification, and recertification of all public-school teachers and administrators, oversees federal education 
programs and the distribution of federal funds to school districts, and establishes regulations for school bus safety and for fiscal management in local school districts. Finally, they are responsible for submitting annual budget recommendations for education to the Missouri Legislature and administering the state's Vocational Rehabilitation and Sheltered Workshop program, which provide services for adult Missouri citizens with disabilities.

\section{Department of Elementary and Secondary Education}

The Department of Elementary and Secondary Education (DESE) became the name for the whole organization and is led by the Commissioner of Education (Missouri Department of Elementary and Secondary Education, 2017). The law states the Commissioner shall "seek in every way to elevate the standards and efficiency of the instruction given in the public schools of the state" (Missouri Department of Elementary and Secondary Education, 2017). Under the commissioner, there are two divisions led by deputy commissioners; Financial and Administrative Services and Learning Services. This research study will focus on the division of Learning Services. The division of Learning Services is responsible for all DESE's activities related to educational success of students, educators, and schools. It includes offices which manage quality schools, college and career readiness, special education, educator quality, early and extended learning, adult learning and rehabilitative services, and the data system management. 


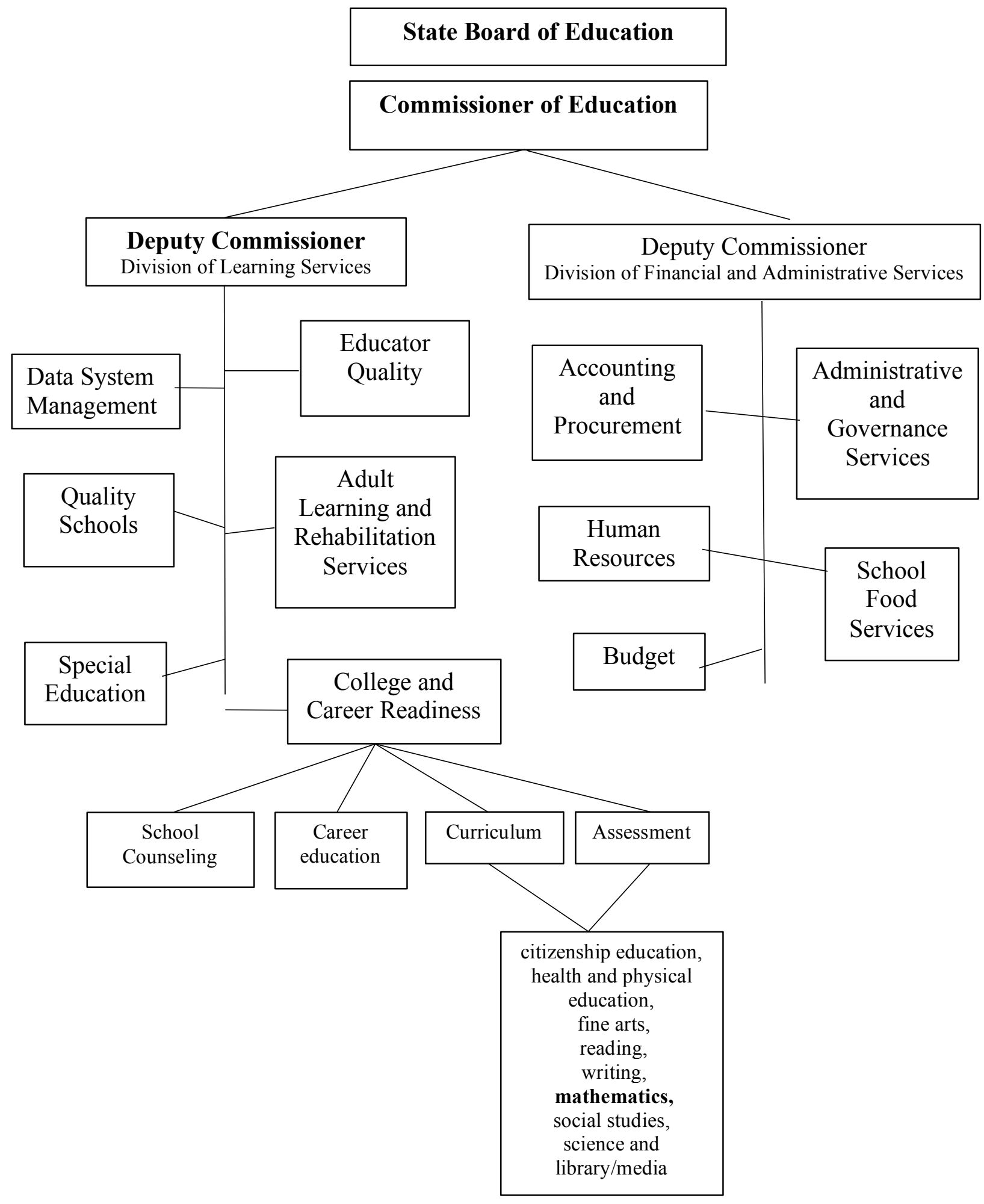

Figure 1.

Organizational chart for DESE 


\section{Office of College and Career Readiness}

This research will examine the Office of College and Career Readiness as we examine the influences on a student's choice of career. College readiness means a high school graduate has the necessary English and mathematics knowledge and skills to qualify for and succeed in two- or four-year college courses without the need for remedial coursework (Missouri Department of Elementary and Secondary Education, 2017). Career readiness means a high school graduate has the necessary skills to succeed in workforce training programs for his/her chosen career. These skills include, but are not limited to, reading, writing, communications, teamwork, critical thinking, and problem solving. The Office of College and Career Readiness consists of four areas: assessment, curriculum services, career education, and school counseling. The assessment section manages test development, on-going test maintenance, and oversees the test administration for statewide, large-scale assessments. The curriculum services section provides professional services related to the development and implementation of improved curricula in the schools of the state. Career education combines academics and occupational skill training to prepare students of all ages. Training programs are offered in Agriculture, Business, Health Sciences, Family and Consumer Sciences, Skilled Technical Sciences, Technology and Engineering, Marketing, and Cooperative Education. The school counseling section provides resources and technical assistance to help school counselors fully implement comprehensive school counseling programs in their schools. 


\section{Director of Mathematics}

Within the Office of College and Career Readiness, there is a director of mathematics who oversees curriculum and assessment pertaining to mathematics. The goal of the mathematics director is to provide assistance to all stakeholders in the education of all Missouri students in mathematics (Missouri Department of Elementary and Secondary Education, 2017). The position provides resources to assist educators in preparation of reaching the goal of all students graduating college and career

ready. These resources include the Missouri Learning Standards, model curriculum, math presentations, and grade and course level expectations. The curriculum is not mandated, just given as an example (Jeremy Ellis, personal communication). The director encourages school districts to develop their own rigorous, coherent, and focused standards-based mathematics curriculum that continually improves classroom instruction (Missouri Department of Elementary and Secondary Education, 2017).

\section{Leadership Analysis}

The State Board of Education leadership is like a district school board (Jeremy Ellis, personal communication). The Board members are appointed by the Governor with half from each party to keep the politics balanced. The Commissioner is like a superintendent hired by the Board members. The Commissioner is supported by two Deputy Commissioners, followed by several Assistant Commissioners, then Coordinators, Directors, Assistant directors, and finally supervisors when needed. The directors, assistant directors, and supervisors communicate with the school districts either directly or through regional offices. They are there for support, not to enforce compliance. So, their power is more reverent or expert, then positional (French \& Raven, 
1959/2005). Most of DESE's employees are former teachers and administrators of the Missouri school system and have experience and expertise they bring to their leadership. Their goal is to convince school districts to follow the suggested standards and guide them in educating students. This aligns with Northouse's definition that leadership is "a process whereby an individual influences a group of individuals to achieve a common goal" (2011, p. 3).

The math standards have seen many changes over the years and the director of math assessment and curriculum has overseen those changes. As Jansson (2013) indicates, "change does not just happen, it is interactive by nature" (p.1005). Therefore, the math directors have included representatives from across the state in collaborative teams to make these changes. They have aimed for diverse groups as categorized in multiple ways: demographic, psychological, and organizational (Levi, 2014).

\section{Implications for Research in the Practitioner Setting}

One of the strategic priorities of the Board of Education is to "prepare, develop and support educators to ensure an effective teacher in every classroom" (MDESE, 2017). This research impacts this strategic priority, because it identifies the social and cognitive influences on a teacher candidate to select math education. By identifying these influences, the understanding of how to prepare and develop educators will be improved. Furthermore, it will give guidance on how to increase the supply of teacher candidates.

Math teachers will be interested to learn how they can help build their profession by inspiring the next generation of teachers. School administrators will be interested in this research because it will increase the pool of teachers from which to hire and this will 
allow them to select more effective teachers that fit with the climate of their building. Therefore, the director of mathematics will be interested in the research and how it can be shared across the state to increase the positive influences on future teacher candidates. 


\section{SECTION THREE: SCHOLARLY CONTEXT}

The purpose of this study is to add to the literature on why teacher candidates pursue math education. This research investigates what factors have a relationship to the shortage of college students pursing a degree in math education. Specifically, is their choice influenced by people around them, or circumstances they encounter. If people, then is it teachers, parents, or peers that influence students the most to choose a career in education? Or are there circumstances that cause changes in perceptions like self-esteem, self-efficacy, or cultural aspects that influence their choice? When these factors are found, then research can begin to look at how to increase these influences so there will be an increase in the number of students entering the field of math education.

\section{Social Cognitive Career Theory}

Social Cognitive Career Theory (SCCT) is a conceptual framework aimed at understanding the processes through which people develop educational/vocational interests and make career-relevant choices (Lent, Brown, \& Hackett, 1994). It integrates career interests, with social and cognitive factors, such as self-efficacy and outcome expectations. It was initially presented in 1994 by Lent, Brown, and Hackett as three interconnected theories. Its goal was to explain the interest development, choices in career paths, and performance in education relating to vocational training (Lent et al., 1994). In 2006, they added a fourth overlapping model of well-being or satisfaction (Lent \& Brown, 2013).

The SCCT believe influences on a student are a mixture of environmental factors, social encounters, and behavioral determinants (Bandura, 2006; Lent, Brown, Talleyrand, McPartland, Davis, Chopra, \& Chai, 2002). Specifically, the SCCT choice model is 
concerned with the self, experiential, and contextual factors that promote pursuit of careers paths (Lent \& Brown, 2013). Lent et al. (2002) showed strong influence by both cognitive factors such as self-efficacy and social factors such as support from family and peers in their qualitative research on the factors that influence college student's choice of study. The SCCT emphasizes students select careers based on their interests; and selfefficacy and outcome expectations are the most important factors in shaping interests (Lent et al., 1994).

Voldina and Nagy's (2016) research showed students form their interests based on both likes and dislikes. This means when considering factors that influence career choice, both positive and negative social and cognitive influences need to be considered. Negative influences like math anxiety discourage many individuals from choosing a career in a math related field (Beilock \& Willingham, 2014; Supekar, 2015).

Furthermore, mathematical self-efficacy was found to have a stronger relationship with mathematical career choice than actual math performance (Hacket and Betz, 1989). Researchers found students with higher levels of mathematical self-efficacy were more likely to pursue math courses that would help them prepare for a mathematical-related career, while those with low self-efficacy would avoid math courses. Self-efficacy combined with outcome expectations will lead to interest and then a career choice is a basic belief in SCCT (Lent et al., 1994). When specified to a certain field, it predicts that building mathematical self-efficacy, and positive, but realistic, outcome expectations will lead to realistic and investigative interest in mathematics, which in turn would lead to math career goals and more students entering the field of mathematics (Fouad \& Santana, 2017). 


\section{Math Education Preparation}

The history of teacher preparation influences teacher candidate's choice to pursue math education. One example of this influence is the loss of prestige of the teaching profession. This began with teacher preparation being in normal schools and not originally in the universities. Prestige did not improve when colleges choose to educate more teachers instead of being highly selective (Larabee, 2008). Another example of this influence is in the stereotypes of education being women's work, but math being a male field. The combination of the stereotypes causes every teacher candidate that selects math education to have to fight society biases.

\section{History of teacher education}

People have been teaching even before teacher education existed. Before the $20^{\text {th }}$ century, the assumption was anyone that passed a grade level could turn around and teach that same level (Larabee, 2008; Feiman, 1990). Other professions, before the $20^{\text {th }}$ century, believed in informal apprenticeships to train employees, but the teaching profession did not include pedagogical training of any sort. The first move toward teacher education was summer teacher institutes that offered classes on content and the beginnings of pedagogy. Near the end of the $19^{\text {th }}$ century as the common school movement grew, so did the need for teachers (Larabee, 2008). Not only was the demand for teachers growing, but the quality of those teachers needed to increase. To meet this demand, normal schools were built to train more teachers. The number of people going past elementary school was increasing and so normal schools began to require a high school diploma for admission (Feiman, 1990). The common school system created a 
"public responsibility for educating the nation's children" and the normal school was designed to "set the standard- the norm-for good teaching" (Larabee, 2008, p. 65). Influential men like Horace Mann, Cyrus Pierce, and Henry Barnard began to make teachers better prepared with a mix of liberal arts and pedagogical courses. The normal schools "championed the idea of teaching as a noble calling or vocation and fostered a professional spirit de corps" (Feiman-Nemser, 1990, p. 5). There were different opinions on how to prepare teachers and debates about technical theory versus professional treatment of subjects. By 1889 , the number of public and private normal schools reached just under 300, but this was still no more than one-quarter of the new teachers needed (Tyack, 1967). While the community was pressuring the normal schools to produce more teachers, the students were pressuring the normal schools to offer more degrees. To attract more students, the normal schools began to offer programs for other careers and the normal schools turned into liberal art "people's colleges" (Larabee, 2008, p. 294). Between 1911 and 1930, there were 88 official conversions from normal colleges to teacher's colleges which allowed the schools to grant bachelor's degrees in multiple fields (Tyack, 1967). Eventually the schools began to drop the word teacher from their title becoming state colleges and by 1950 the last of the normal schools were converted (Larabee, 2008). The last conversion was to earn the title of university placing teacher education as a subset of the larger university system.

\section{History of Math Teacher Preparation}

The focus of the normal schools was traditionally for preparation of elementary teachers, while secondary teachers sought liberal arts degrees (Graham, Li \& Buck, 2000). In the 19th century, students that pursued a liberal arts education were considered 
the elite leaders in the community (Feiman-Nemser, 1990). The secondary teachers in a community usually came from this group of liberal arts students. However, many people thought there was a large difference between a liberal arts education and useful vocational training. In the $20^{\text {th }}$ century, as knowledge grew and the number of people going to school increased, students started specializing in their study, "The liberal arts tradition underscores the special ties that link intellectual arts, academic content, and teaching" (Feiman-Nemser, 1990, p. 7). The liberal arts education included philosophy courses, but not much pedagogical help for the secondary teachers. This did not improve when the normal school joined the universities, because the secondary teachers still had to balance their courses in content with their courses in education.

Mathematics teacher preparation has varied through time and across the various programs, but one consistent theme is a large number of courses in mathematics. In 1911, the American subcommittee of the International Commission on the Teaching of Mathematics released a recommendation for all secondary math teachers to take courses in pure mathematics, applied mathematics, surveying, and a "strong course on the teaching of secondary mathematics" (International Commission on the Teaching of Mathematics, 1911, pp. 13-14). This expectation grew in 1935, as six credit hours of calculus, Euclidean geometry, theory of equations, and history of math were recommended by the Mathematical Association of America's Commission on the Training and Utilization of Advanced Students of Mathematics (Commission on the Training and Utilization of Advanced Students of Mathematics, 1935).

With the launching of Sputnik in 1957, the nation increased its attention on math and science which influenced teacher preparation programs across the United States 
(Graham, Li \& Buck, 2000). By 1960, many groups were calling for secondary math teachers to be required to have a major in mathematics along with their education courses (American Association for the Advancement of Science, 1959; Committee on the Undergraduate Program in Mathematics, 1961; National Council of Teachers of Mathematics, 1959). In 1983, the recommendation was 13 courses of mathematics which for several institutions is more than a major (Committee on the Undergraduate Program in Mathematics, 1983). Furthermore, the NCTM's Agenda for Action (1980) included pedagogical content recommendations such as involving students in meaningful problemsolving activities and the use of diverse instructional strategies. The new recommendation was that math teachers needed to have both a solid mathematical background and a solid understanding of how students learned (Graham, Li \& Buck, 2000). The Professional Standards for Teaching Mathematics was released in 1991 and presented teaching in a new light with teachers responsible for creating and selecting mathematical tasks that encourage thinking, creating a classroom environment that supported learning, stimulating mathematical discourse in the classroom, and analyzing student learning through the use of data.

\section{Current Teacher Preparation for Mathematics}

Today, teachers are typically certified through a college or university teacher preparation program, then licensed through the licensing arm of their state's board of education. Although the process may vary from state to state, the minimum education requirement for a math teacher is a bachelor's degree in mathematics along with courses in pedagogy, mathematics competency testing, and a student teaching component (Math teacher education, 2017). Some states certify math teachers for all grade levels (K-12), 
while others certify math teachers for specific student populations (elementary, middle, secondary). In states where math teachers are certified to teach a particular student population or grade range, colleges and universities offer teacher preparation programs specific to those populations or grade ranges (Missouri Department of Elementary and Secondary Education, 2017). Teacher preparation programs are often completed as part of specially designed bachelor's programs that combine mathematics and pedagogy. However, many teacher preparation programs are also available at the post-bachelor's and master's level for aspiring math teachers that have already completed undergraduate work in mathematics.

Math courses are an important part of math teacher preparation. Math curriculum is considered "static with knowledge viewed as cut and dry and subject to little change" (Stoldolsky \& Grossman, 2000). Therefore, math teacher preparation contains a set of math courses that include topics like algebra, trigonometry, calculus, statistics, and geometry. Math teachers' main focus is on content mastery and less on the social growth (Stoldolsky \& Grossman, 2000) so pedagogy is about conceptual development of the content. Critics argue keeping the content and pedagogy separate can cause teacher candidates to lack pedagogical content knowledge (Ferrini-Mundy \& Findell, 2010). One fix to this is the belief in practice based learning that might include microteaching, or field experience (Whitford, \& Villaume, 2014).

\section{Influences on selecting math education}

"We need to recruit, reward, train, learn from, and honor a new generation of talented teacher" (Duncan, 2009, p.15). Since the beginning of normal schools, teacher preparation has battled with quality versus quantity of teachers prepared (Larabee, 2008). 
Do schools train a few highly selective model teachers or the large number of teachers needed for the expanding school systems? Schools in the United States are facing critical shortages as Baby Boomers retire and the number of students increase (Duncan, 2009). Most schools choose to train a larger number with a minimal professionalism at the sacrifice of the reputation of teacher preparation programs (Larabee, 2008). However, if they had chosen the higher quality, then it would have left even more classes without trained teachers. Furthermore, there is much debate on what higher quality means. Many states are adding more testing for licensure, but these tests have shown to be biased to students of color (Branch, 2001). Does raising quality really mean finding effective teachers for the schools?

One current fix to teacher shortage is the alternative certification programs (Feiman, 1990) that is enlarging this choice of quantity over quality. It allows college graduates without educational training on-the-job help. Mentoring teachers offer support and advice while the teacher is teaching. However, what does this choice of quantity over quality do to the reputation of teachers? Larabee (2008) states that this choice lowers the level of respect for teachers and therefore, lowers the number of students who want to pursue it as a career.

Seventy-five percent of teachers, kindergarten through $12^{\text {th }}$ grade, are females (Allgretto, Corcoran \& Mishel, 2004). Many view teaching as women's work because of the stereotype that women are best at nurturing the young (Larabee, 2008). Furthermore, Larabee (2008) mentions women were willing to work for half the pay. However, there is a social stereotype that men are significantly stronger in mathematics than women. This stereotype is encouraged by statistics like men get higher SAT scores in math than 
women or science and technology careers are predominantly male disciplines (McCarthy, 2011). Females also report higher levels of math anxiety and lower levels of math selfconcept (Else-Quest, Minew, \& Higgins, 2013). These opposing stereotypes encourage a shortage of math teachers. If teaching is a woman's job and math is a male field, then every math teacher is having to fight one or the other stereotype. Either the male for choosing to work for a lower salary or the female for being seen as less feminine for studying mathematics. These stereotypes are encouraged through teacher preparation programs for math education as the courses are taught in two different colleges of the university. Courses in pedagogy are taught in the college of education, while math courses are taught in the math department.

Another set of stereotypes that discourage students from pursing a teaching career is that, many people believe teaching is a natural skill a candidate either has or does not have (Larabee, 2008). This is similar to a stereotype about mathematic being hard, "we too often suggest that few people have the skill to excel in these subjects" (Hrabowski, 2011, p. 293). However, learning to read is a very difficult process and many students struggle with it, but culture expects all people to master reading without excuse. While in math, it is acceptable to say, "I am just not a math person" (Rattan, Good \& Dweck, 2012). Furthermore, there are cultural stereotypes that certain ethnic groups are better suited for math, while others are less well suited (Hrabowski, 2011). In response to negative stereotypes, students who are members of stigmatized groups may disengage from academic domains affected by stereotype threat (Scott \& Martin, 2014). These stereotypes are influencing who is pursing math education. 


\section{Social Influences on Career Choice}

There are many influences in a student's life that guides them to a career choice. Social influences like teachers, parents, and peers have a strong impact especially in the adolescent years (Alika, 2012; Hsiao \& Nova, 2015). During adolescence is when many students select their career and begin taking courses to pursue that career. Research suggests social relationships "act as a pipe to channel the flow of information and resources" about career choices (Easley \& Wang, 2017, p. 636). Social relationships can also influence the choice with expectations and perceptions. This research evaluates three types of social influence: teachers, family, and peers.

\section{Teacher's Influence}

More than half of the American public believe teachers have the greatest influence on a student's learning (NEA, 1999). Many believe that "A great teacher can change the course of a student's life" (Duncan, 2009, p. 15). This influence can be positive or negative based on the teacher's perceptions. Teachers that encourage students through affirmation of their academic abilities give students a sense of self-efficacy (Fries-Britt, Villlarreal, McAllister \& Blacknall, 2012). Discrimination, neglect, and avoidance can also be very powerful negative influences on students.

Students' academic outcomes are shaped by their teacher's perceptions of their academic effort and potential (Blanchard \& Muller, 2014; Fries-Britt et al, 2012). Teachers' perceptions connect to students' academic ability but are also effected by bias and outside influence. "Teachers' views of their students may be limited by their ability to understand who their students are and to connect with them" (Blanchard \& Muller, 2014, p. 262). The Meyerhoff Scholars program has had great success in raising retention 
rates of minorities in STEM fields because they build in relationships. Students that had a relationship to the faculty were graduating, but those without strong relationships often left without much notice (Hrabowski, 2011). Dee (2004) discusses the impact on student achievement when students are "matched with teachers who share their race or ethnicity" (p. 195). He found that white teachers give black students less praise, less attention, and more scolding than the white students in the same class (Dee, 2004). Schmitz, Nourse, and Ross (2012) state that teacher discrimination corrodes African American student's math beliefs, achievement, and respect of teachers. Holding lower expectations was very detrimental to the encouragement of math careers (Schmitz, Nourse \& Ross, 2012). Jussim and Harber (2005) believe that teachers' perceptions are generally accurate, meaning that differences in perceptions based on background (race, ethnicity) correspond to measurable differences in motivation and achievement. However, other research states that a teacher's stereotypical beliefs about race influence children's selfperceptions, motivations, and achievement in school (McKown \& Weinstein, 2008; Nurnberger \& Nerb 2016; Blanchard \& Muller, 2014). There is much debate about whether a teacher's expectations will influence a student's success. The Pygmalion study by Rosenthal and Jacobson in 1968 was one of the first to state they found a significant relationship between a teacher's positive expectation and a student's growth in IQ (Jussim \& Harber, 2005). However, after reviewing the data and findings, Jussim and Harber (2005) stated "the study's actual findings ranged from nil to quite modest" (p. 135). This then leads into the debate about whether teachers are good predictors of a student's success or does their expectation affect the student's outcome. 
Another area in which a teacher's expectations influences a student's ability to succeed is their tracking for future study. Teachers guide the evaluating and sorting into college preparatory coursework (Blanchard, \& Muller, 2014). Teachers facilitate students' upward mobility through their high expectations and encouragement or alternatively act as the gatekeepers for higher level courses. Ethnic bias can influence teacher recommendations as African Americans and Latinos are the target for negative stereotypes about intellectual ability and European Americans and Asian Americans have positive stereotypes about intellectual ability (Bobo, 2001). Furthermore, research found that boys are being recommended for math and science while, girls are being recommended for language arts at higher rates (Nernberger et al., 2016). The students most at-risk for implicit biased influence are the ones in the middle academically (Blanchard, \& Muller, 2014; Glock et al, 2013; Nernberger et al., 2016). This means students that are on the bubble between the college preparatory track and the non-college track are the ones most affected by bias and therefore their future is most determined by their ethnicity or sex. Finally, the belief that a student is less academically capable can cause a teacher to place that student in lower-level courses, possibly taught by less experienced teachers or with lower expectations (Blanchard \& Muller, 2014).

\section{Family Influence}

Family support has a strong influence on a child's motivation to seek a career and to be successful in school. Career decisions are influenced by parent expectations and support (Guerra \& Braungart-Rieker, 1999; Hsiao \& Nova, 2015). Of a survey of students, “...96\% reported that family members expected them to get high grades, whereas only $18 \%$ reported that people in school held these expectations" (Blanchard, \& 
Muller, 2014). The family expectations can have a large influence or a small influence depending on the relationship between the student and family (Alika, 2012). In Aaltonen's study (2015), many of the young people when asked about parental influence, insisted that "they make the decisions concerning their future education and career independently and do not accept any dictates from their parents" (p. 4). However, in that same study, they found evidence that siblings often played a role in the decision-making process. Overall, they found evidence that family discussions and advice played a large role in career decisions.

Choice of a particular field of study is also connected to the educational resources at home, and the parental knowledge about higher education. Students with highly educated parents will have more information not only on the working of the higher education systems, but also on the economic returns of different fields of study (Vergolini \& Vlach, 2017). The addition of fees and loans only add to the perplexity of higher education for working class families unfamiliar with the system (Reay, Davies, David \& Ball, 2001). Furthermore, the socioeconomic class of the family influences the college and career choice. There are persistent inequalities among students enrolled in universities based on socioeconomic class. For example, the lower social classes had less students furthering their education while the upper class have majority going into the universities (Reay et al., 2001). The National Center for Educational Statistics found that $96 \%$ of students in a high socioeconomic status obtain some postsecondary education and $72 \%$ earn a degree. Meanwhile, $71 \%$ of students in a low socioeconomic status obtain some postsecondary education, however only 35\% earn a degree (NCES, 2017). Elite universities have a disproportionate number of upper class students, while less selective 
universities have a disproportionate number of lower socioeconomic students (Kettley \& Whitehead, 2012).

Furthermore, the socioeconomic class of the parents influences the parent's expectations of the students. Parents have hopes and expectations of their children's future careers being better than their own, but that better can differ among the classes (Irwin \& Elley, 2012). For example, it could be the difference of unskilled labor to skilled labor or from a high school diploma to an associate degree. No matter what the expectation, there is strong evidence the family has influence on student's career choice.

\section{Peer influence}

A student's peer culture and friends have strong influence on the career they select. Peers are defined as "those individuals in the immediate social context of similar rank and similar attributes to the focal individual" (Tartari, Perkmann, \& Salter, 2014, p. 1190). Specifically, the emotional support needed for a career choice comes mainly from these peers (Pereira \& Garcia, 2007). Similarly, "peer effects" influence academic engagement and behavior (Tartari et al., 2014) which in turn influences academic success and career interest.

Peers can have a positive and/or negative influence on a student's career choice. They may be inspired by their peers that are achieving success, or they might compare their goals and behaviors to their peers (Tartari et al., 2014). Cultures that are involuntarily a minority (African Americans brought to United States by slave trade, or Native Americans forced out of their land) form oppositional identity to form a sense of ethnic authenticity (Eglash et al., 2013). Only 9\% of STEM professionals are African Americans, Hispanics or Native Americans while they make up 26\% of the population 
(National Science Board, 2012). Why is there such a discrepancy between the numbers? There is a great disparity between the academic culture in mathematics compared to disadvantage minority culture. Fryer and Torelli (2010) provided quantitative support to the "acting White" hypothesis by showing that black student popularity was inversely proportionate to academic success. Other research has found student performance is impacted negatively when students worry about fitting it or feel threatened by stereotypes about their race (Harackiewicz, Canning, Tibbetts, Priniski, \& Hyde, 2015). Unwelcoming academic culture in science and math departments can cause further problems with academic success (Tolven-Lindsey, Levis-Fitzgerald, Barber, \& Hasson, 2015). Sixty percent of black students who start in non-STEM field graduate in five years and only $31 \%$ of black students who start in a STEM field graduate in five years (Hrabowski, 2014). According to Scott and Martin's research (2014), the minorities they surveyed overwhelmingly felt they had to face barriers due to their race when pursuing STEM fields.

\section{Cognitive Influences on Career Choice}

Career choices are often influenced by cognitive factors such as self-efficacy, anxiety, mindset, and outcome expectations. Personal motivation or personal belief in what someone is good at or enjoys guides behavior (Bandura, 1993). The old cliché of "doing what makes you happy" is connected to these cognitive influences. This may come from intrinsic motivation like self-efficacy or a growth mindset that influence what a student will study in college. 


\section{Self-Efficacy}

Self-efficacy is the belief students hold in their mathematics capabilities, and it is predictive of student's achievement and motivations in mathematics (Bates, Latham, \& Kim, 2011; Brown \& Lent, 2006; Moakler \& Kim, 2014). Bandura (1993) states that self-efficacy is not about the skills one has, but what one thinks they can do with the skills one possesses. Even when an activity is challenging, self-efficacy can be the factor that helps a student persevere (Pajares, 2003; Stevens, Olivarez, Lan, \& TallentRummels, 2004). Self-efficacy can change a student's perception about a difficult task from something to avoid into a challenge that can be mastered (Williams \& Williams 2010). Motivation is influenced by self-efficacy (Bandura, 1993; Ball, Huang, Cotton, Rikard, \& Coleman, 2016) often changing it from extrinsic to intrinsic motivation. For example, a student with strong math self-efficacy will have intrinsic motivation to continue working on tasks when they are not required, which will lead them to taking higher level math courses than are required and then possibly pursuing a career related to mathematics (Stevens et al, 2004; Ball et al, 2016).

Research has found mathematics self-efficacy is increased when students experience academic success specific to math such as solving math problems (Campbell \& Hackett, 1986; Len, Brown, \& Hackett, 1994). Experiences of success and failure, are often the foundation of self-efficacy along with verbal persuasion (Williams \& Williams, 2010). Classroom climate can also be an important factor in building self-efficacy in mathematics (Peters, 2012). While academic self-efficacy predicted overall grade performance, domain specific mathematics self-efficacy had a greater connection to mathematical career choice (Lent, Brown, \& Gore, 1997). Specifically, "students who do 
well in mathematics feel good about their ability to do mathematics and therefore are more likely to choose a major that requires the use of mathematics" (Bates et al, 2011, p. $325)$.

There have been many studies that show a direct relationship between selfefficacy and performance (Ayontolah \& Adedeji, 2009; Bates et al, 2011; Peters 2012; Stevens et al, 2004; Williams \& Williams 2010). Other studies categorized it differently; for example, King's (2015) study found students that were high in positive affect were more likely to report high levels of engagement and decreased disaffection. Villavicencia's (2015) study found there was a positive correlation between enjoyment and pride, which explained a significant amount of the variance between the students' grades, self-regulation, and self-efficacy. Azar and Mamoudi (2014) found a relationship between mathematical self-efficacy, anxiety, attitude, and the progress of students in statistics. Their model accounted for 30\% of the change in student scores. Peters' (2013) research found a relationship between classroom climate and mathematic self-efficacy along with the connection to performance. However, there is a lack of research on how mathematical self-efficacy influences the career selection of math education.

\section{Math Anxiety}

A negative correlation has been found between mathematics anxiety and mathematical self-efficacy (Azar \& Mamoudi, 2014; Hackett \& Betz, 1989). Math anxiety is defined as "a negative emotional reaction that is characterized by feelings of stress and anxiety in situations involving mathematical problem solving" (Supekar et al., 2015, p. 12574). Negative emotions such as anxiety, lowers students' perception of their ability to problem solve and/or study math further (Beilock, Gunderson, Ramirez, \& 
Levine, 2010). Math anxiety affects nearly $50 \%$ of grade-school children in the United States (Beilock \& Willingham, 2014). Furthermore, it is more common in women than men (Beilock, Gun, 2010; Peters, 2012) and pre-service teachers report higher levels than any other undergraduate major (Harper \& Daane, 1998). Students with high math anxiety tend to avoid situations involving mathematics and are therefore less likely to pursue math related careers (Supekar, 2015; Beilock \& Willingham, 2014). Research has found students high in negative affect were more likely to report low levels of engagement and increased disaffection (King, McInery, Fraide, \& Villarosa, 2015). In contrast, Aspinwall (1998), noted that if the primary goal in learning was to feel good, this goal would make students lazy thinkers and not appreciate the negative information. The argument is that negative emotions can encourage students to work harder, learn from mistakes, or grow through disappointment. Mathematical anxiety may make a student work harder, but it is doubtful that it will encourage a student to take more challenging math classes or pursue a degree in mathematics. Furthermore, the root of the anxiety may go back to the student's mindset about mathematics and challenges.

\section{Mindset}

As self-efficacy and anxiety influence what a student believes they can do, mindset influences how a student believes their intelligence can grow or change. Is intelligence fixed and unchangeable or can it be improved and developed? A fixed mindset is when students believe they are either smart or not, good at something or not good at it (Boaler, 2016). A student with a growth mindset is more willing to take on hard work and they view mistakes as a challenge and motivation to work harder (Duckworth \& Quinn, 2009; Dweck, 2016). Fixed mindsets can be very damaging 
because the fear of making a mistake and not being smart any more can keep students from taking challenging courses or attempting a challenging project (Boaler, 2016). Students with a growth mindset are not as worried about looking intelligent, and so they take on more challenges and are more resilient to setbacks (Dweck, 2016). High achieving girls are the most affected by the fixed mindset (Dweck, 2006). The high number of girls with a fixed mindset is one reason girls avoid careers in the STEM fields (Boaler, 2016).

"No one is born knowing math, and no one is born lacking the ability to learn math" (Boaler, 2016, p. 5). The fixed mindset is most prevalent in mathematics especially at the collegiate level. Math professors were found to have a fixed mindset about their students more than any other department (Leslie, Cimpian, Meyer, \& Freeland, 2015). There is also a traditional line of thinking that students are either naturally good at mathematics or not (Boaler, 2016). Dweck's research (2016) found students that favored a growth mindset had higher levels of academic achievement than those with a fixed mindset no matter their economic background. Other research showed the difference in performance happened in high school math classes where students with a growth mindset formed learning goals versus performance goals (Bahnik, \& Vranka, 2017). These learning goals allow students to persevere toward success of their goals in the future, while a performance goal requires immediate success or failure of that one event. Boaler's (2017) research found the highest-achieving students in the world are those with a growth mindset and they outrank the other students by the equivalent of more than a year of mathematics. Moreover, research suggests that mindset influences 
student success in mathematics, but there is a lack of research on how it influences career choice.

\section{Outcome Expectations}

Outcome expectations are the personal beliefs about what one thinks will happen (Lent, Brown, \& Hackett, 1994). The expectations can be grouped into physical, social, and self-evaluative (Bandura, 1993). Physical outcomes would include salary, benefits, working conditions, and paid time off. Summers off and job flexibility would be positive influences to encourage students to pursue education (Allgretto, Corcoran, \& Mishel, 2004). However, the salary and working conditions are often the reason teachers leave the profession (Branch, 2001; Curtis, 2012; DeNisco, 2015). Allgretto et al.’s (2004) research showed teacher's weekly wage was $12.2 \%$ lower than workers with comparable skill requirements. Furthermore, they found teachers worked more hours putting the hourly wage comparison lower by $14.1 \%$. They also found teachers have less paid leave and fewer wage bonuses (Allgretto et al., 2004). Working conditions can include violence and drugs that interfere with teaching (Branch, 2001). These physical outcome expectations have a negative influence on student's career selection to become teachers.

Social and self-evaluative outcome expectations could be positive or negative depending on personal history. Curtis (2012) found many students go into the field of education to make a difference. This shows a belief that teaching has a positive social influence. Payne's (2005) research found that respect for teachers and the profession is dependent upon social class. Middle class students respect teachers because schools are set up with middle class values and social norms, therefore they are more likely to consider it a socially acceptable career option. However, students in poverty often view 
teachers and schools as oppressors because of the difference in middle class expectations and so the teaching profession may not seem socially acceptable (Payne, 2005).

Economic class is not the only cultural division. Research indicates students show more interest in careers they perceive hire more members of their own gender or race (Else-Quest et al., 2016). Furthermore, researchers are predicting in the next two to three decades, the majority of students will belong to a racial-ethnic minority (Schmitz, Nourse, \& Ross, 2012). The majority of teachers are white and so role models of color are severely insufficient (Branch, 2001; Dee, 2004, Schmitz, Nourse, \& Ross, 2012). Research suggests students of color do not find schools to be culturally relevant to them (Branch, 2001; Diemer, Marchland, McKellar, \& Malanchuk, 2016). This is connected to Schmitz et al.'s (2016) research that white teachers do not always have the experiences needed to understand their students. Teachers' discrimination has been found to cut the bond between a student and the school, ending trust or any sense of belonging (Schmitz et al, 2016). Social outcome expectations are discouraging students that face poverty and students of color from pursuing a career in education.

\section{Conclusion}

When selecting the field of study, teacher candidates are influenced by both social and cognitive factors. Figure 2 shows how both the social and cognitive influences are each made up of multiple factors. They join to guide a teacher candidate's interest which then leads to the selection of what they will study in college. 


\section{Social Influence}

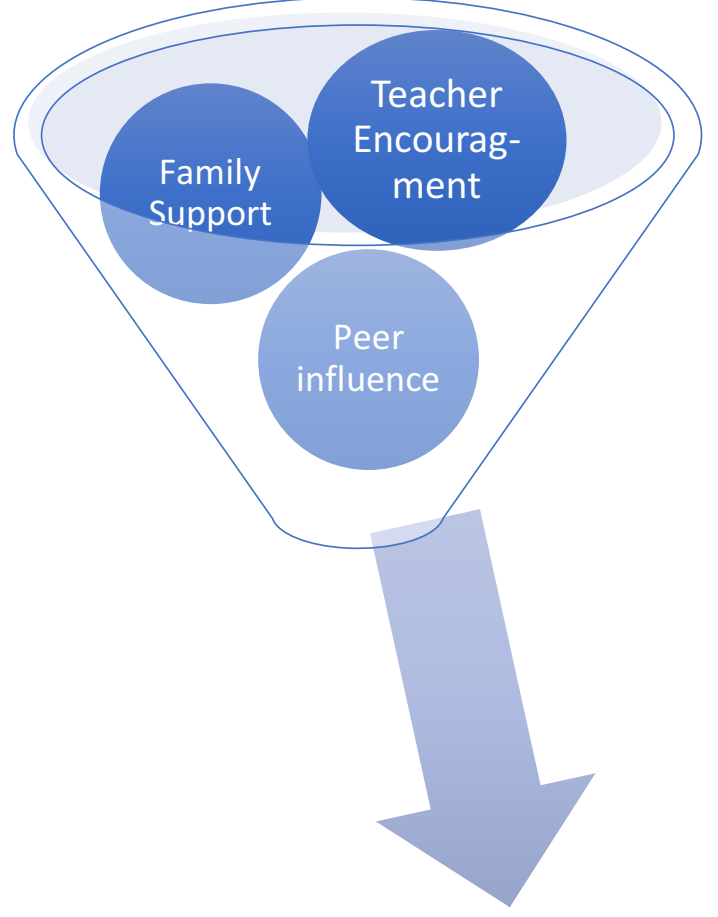

\section{Cognitive} Influence

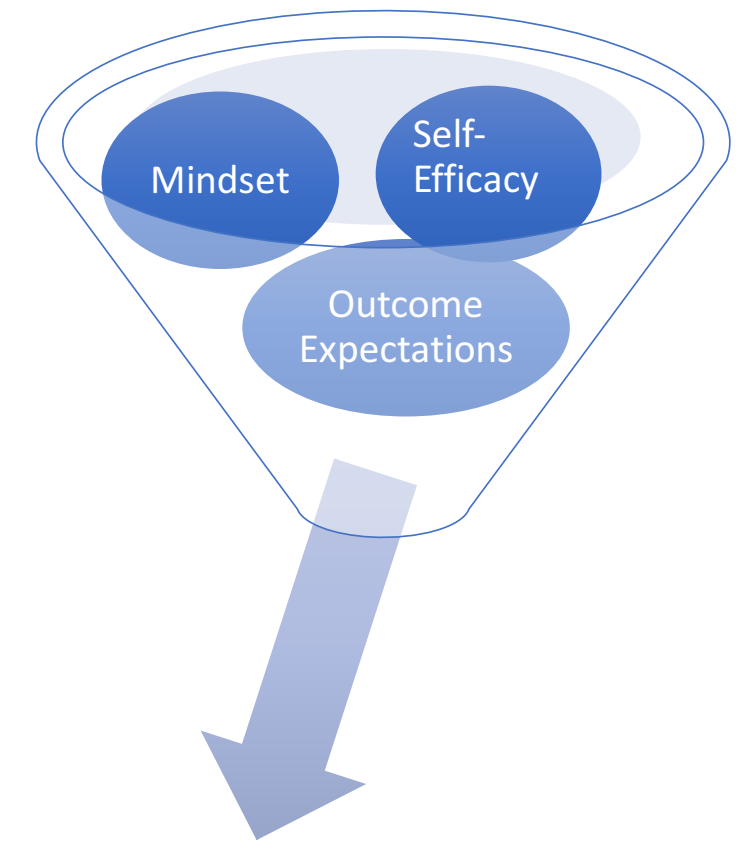

Outcome

Expectations

\section{Interests}

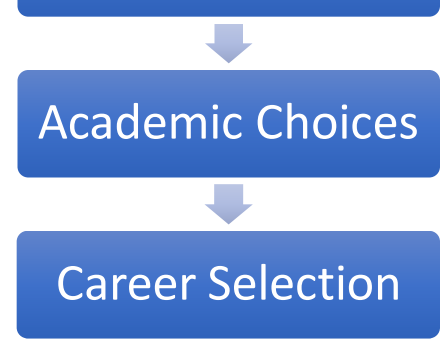

Figure 2. Social and Cognitive Influence on Career Selection

Research indicates there is a decline in students pursuing science, technology, engineering, and mathematics (Moakler \& Kim, 2014; National Academy of Sciences, 2007). Research also indicates there is a shortage of math teachers (Sutcher et al., 2016; Ingersoll \& Perda, 2010). A connection between the shortage of math teachers and the lack of students interested in math seems logical, but there is a lack of research on the influences on a teacher candidate's choice to pursue math education. 
The SCCT theory states individuals select careers based on what they believe they are good at and which they believe will bring them positive outcomes (Lent \& Brown, 2013). However, it also includes the fact there are both positive and negative influences in an individual's life that influence their choices (Voldina \& Nagy, 2016). The influences can be grouped as social or cognitive. For teacher candidates, the social influences include teacher encouragement, family support, and peer influence. The cognitive influences include self-efficacy, math anxiety, mindset, and outcome expectations. The SCCT has been used to see how mathematical self-efficacy influences individuals' pursuit of careers in STEM fields, which is similar to math education, but not the same (Wang, 2004; Fouad \& Santana, 2017). STEM fields differ from math education in outcome expectations which is an important feature of cognitive influences. So, this research will extend the SCCT to the specific field of math education. The SCCT has been extended to various client groups based on racial diversity (Byars-Winston et al, 2010), persons with disability (Fabian, 2000) and gay and lesbian workers (Morrow et al, 1996), but not to teacher candidates. Therefore, there is a gap in the literature regarding the use of the SCCT directly toward teacher candidates' selection of their field of study. 


\section{SECTION 4: CONTRIBUTION TO PRACTICE \\ Plan for Dissemination of Practitioner Contribution}

The target for dissemination for practitioner contribution is a presentation at the Regional Conference for National Council of Teachers of Mathematics (NCTM) on November 1-3, 2018 in Kansas City MO. Proposal will be submitted online by December $1^{\text {st }}$ of 2017.

\section{Type of Document}

Presenters develop oral presentations and handouts that provide a brief overview of their work and facilitate discussion with participants. Presentation specifications will be provided upon acceptance. The proposal should include the conference topic area; abstract; session description, including a review of relevant literature and aim of the session; three to five learner outcomes based on the aim and objectives of the session; and a description of audience participation. The proposal will fit under the strand of Celebrating Differences: Access, Equity, and Empowerment. The topic strand for this contribution will be Social and Cognitive Influences on teacher candidate's choice to pursue math education. The format would be a 30 -minute Burst presentation.

\section{Rationale for this Contribution Type}

The regional conference for NCTM is attended by thousands of math teachers and math coordinators across the nation. It is the place to discuss math education and how to improve instruction. Math teachers influence future teacher candidates by their actions and their classroom environments. Math coordinators are affected by the shortage of math teachers and will be interested in how to improve the pool of teacher candidates. The proposal will fit under the strand of Celebrating Differences: Access, Equity, and 
Empowerment because it will be addressing how to encourage diverse students to consider careers in mathematics.

\section{Proposal Submission}

Title: Social and Cognitive Influences on Teacher Candidates choice to select Math Education

\section{Description of presentation:}

There is a shortage of teachers across the state in the field of math, and it is due in large part to a lack of students pursuing math education. The presenter will discuss results from a survey collected across the state of Missouri on the factors that influence a teacher candidate choice to pursue math education. Specifically, the social influences (teachers, parents and peer) and cognitive influences (self-efficacy, anxiety, growth mindset, and outcome expectations) were compared.

\section{Participant Learning:}

1. How teacher influence affects student's choice to pursue education.

2. How self-efficacy and anxiety influence a student's choice to pursue math.

3. How teachers and schools can help encourage more students to pursue math education as a career.

\section{Focus on Math:}

The purpose of the research was to find influences that will increase the number of teacher candidates pursuing math education. Therefore, mathematical self-efficacy, math anxiety, and outcome expectation for a career in math education will be discussed. Session Audience: Research 
Topic: Access and Equity for Students

Practitioner Document

\section{WHAT INFLUENCED YOUR CHOICE TO PURSUE MATH EDUCATION?}

SOCIAL AND COGNITIVE INFLUENCES ONA TEACHER CANDIDATE'S CHOICE TO PURSUE MATH EDUCATION

In the 2017-2018 school year, forty-eight states and the district of Columbia report a shortage of math teachers (Ostroff, 20I7).

In the 2008-2009 school year, there were 719,08I teacher candidates enrolled in teacher preparation programs but in the 2013-2014 school year this number dropped $35 \%$ down to 464,250 students enrolled (Sutcher, Darling-Hammond, \& Carver-

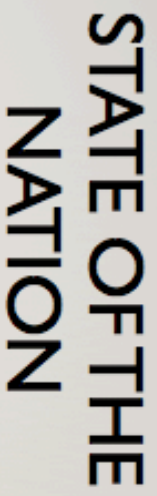
Thomas, 2016). 


\section{PROBLEM STATEMENT}

The overarching problem is there is a shortage of secondary math teachers caused by a shortage of students entering the field of math education (Sutcher, et al..., 2016; Ingersoll \& Perda, 2010).

\section{SOCIAL COGNITIVE CAREER THEORY}

1994 by Lent, Brown and Hackett

"People do not operate as autonomous agents. Nor is their behavior wholly determined by situational influences. Rather, human functioning is a product of a reciprocal interplay of intrapersonal, behavioral, and environmental determinants. .." (Bandura, 2006, p.165). 


\section{SOCIAL COGNITIVE CAREER THEORY}

1994 by Lent, Brown and Hackett

SCCT views students as living within a social world, with ever-present opportunities to be influenced. Specifically, the SCCT choice model is concerned with the self, experiential, and contextual factors that promote pursuit of careers paths (Lent \& Brown, 2013).

\section{SOCIAL INFLUENCES}

Social influences like teachers, parents, and peers have a strong impact especially in the adolescent years (Alika, 20I2; Hsiao \& Nova, 20I5).

Research suggests social relationships "act as a pipe to channel the flow of information and resources" about career choices (Easley \& Wang, 2017, p. 636).

This study looked at the social influences of teacher encouragement, family support and peer influence on a student's choice to pursue secondary math education as a profession. 


\section{COGNITIVE INFLUENCES}

Mathematical self-efficacy is the belief a student holds in their mathematics capabilities, and it is predictive of student's achievement and motivations in mathematics (Bates, Latham \& Kim, 20I I; Brown \& Lent, 2006; Moakler \& Kim, 2014).

A fixed mindset is when students believe they are either smart or not, good at something or not good at it (Boaler, 2016).

\section{COGNITIVE INFLUENCES}

A student with a growth mindset is more willing to take on hard work and view mistakes as a challenge and motivation to work harder (Duckworth \& Quinn, 2009; Dweck, 2016).

This study looked at the cognitive influences of self-efficacy, mindset and outcome expectations on a student's choice to pursue secondary math education as a profession. 


\section{WHAT FACTORS INFLUENCE A STUDENT TO SELECT SECONDARY MATHEMATICS EDUCATION AS A PROFESSION?}

I. Is there a difference between social and cognitive influences on a student's choice to pursue a degree in mathematics education?

2. Is there a difference between the social influences (teacher encouragement, family support, and peer influence) on a student's choice to pursue a degree in mathematics education?

3. Is there a difference between the cognitive influences (self-efficacy, mindset, and expectations) on a student's choice to pursue a degree in mathematics education?

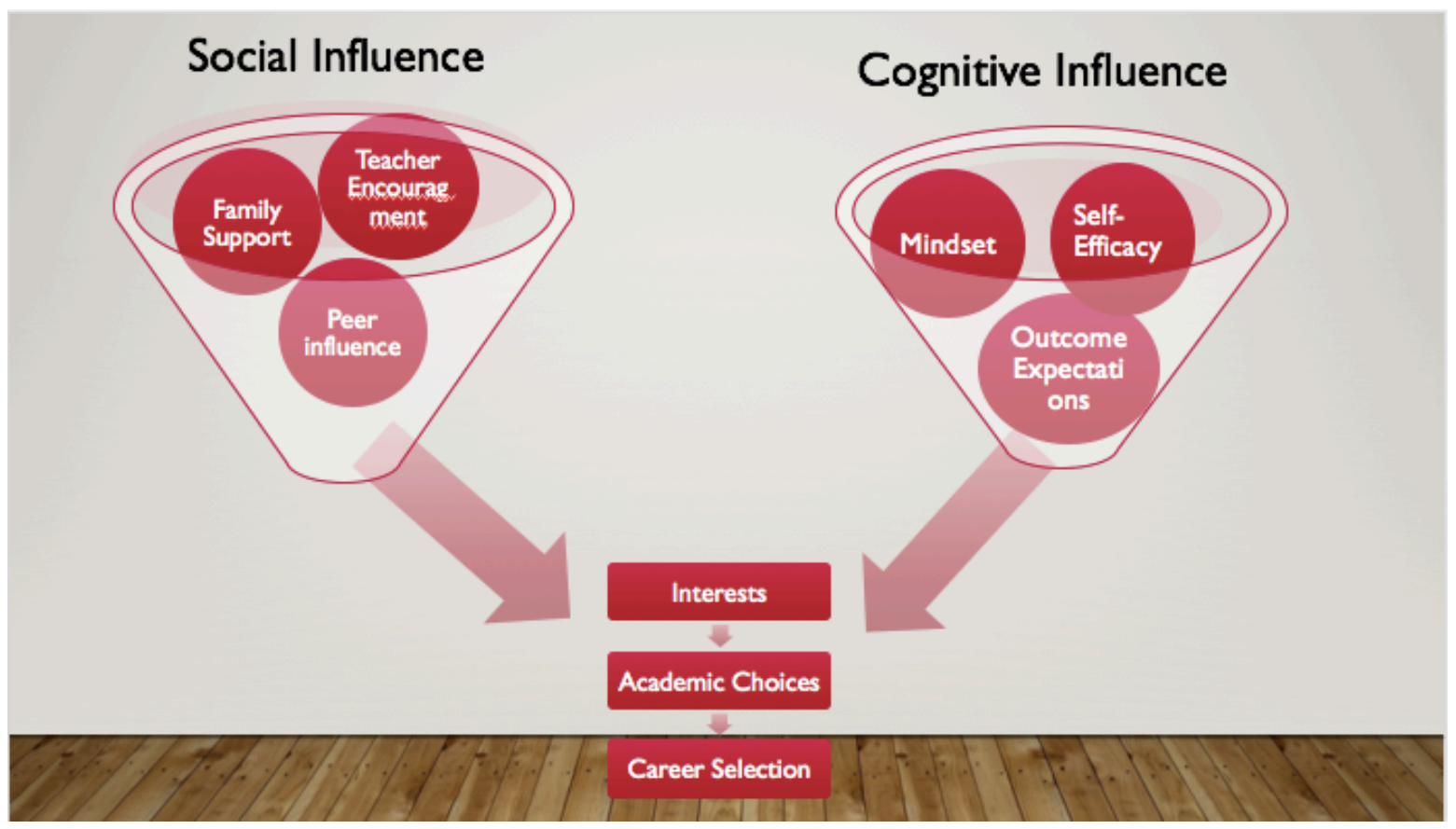




\section{STUDY DESIGN}

Non experimental Quantitative Study

Population: all secondary mathematics teacher candidates attending a teacher preparation program in Missouri.

Electronic survey was emailed out to participants through math professors at various Missouri universities with teacher preparation programs.

\section{STUDY DESIGN}

Cross sectional data collected over one year from across the state of Missouri.

Sample size was 63 students in their first three years of secondary math teacher preparation

Descriptive statistics and hypothesis mean paired $t$-tests were used to in the data. 
Figure 1. Descriptive Statistics comparing Social and Cognitive Influences
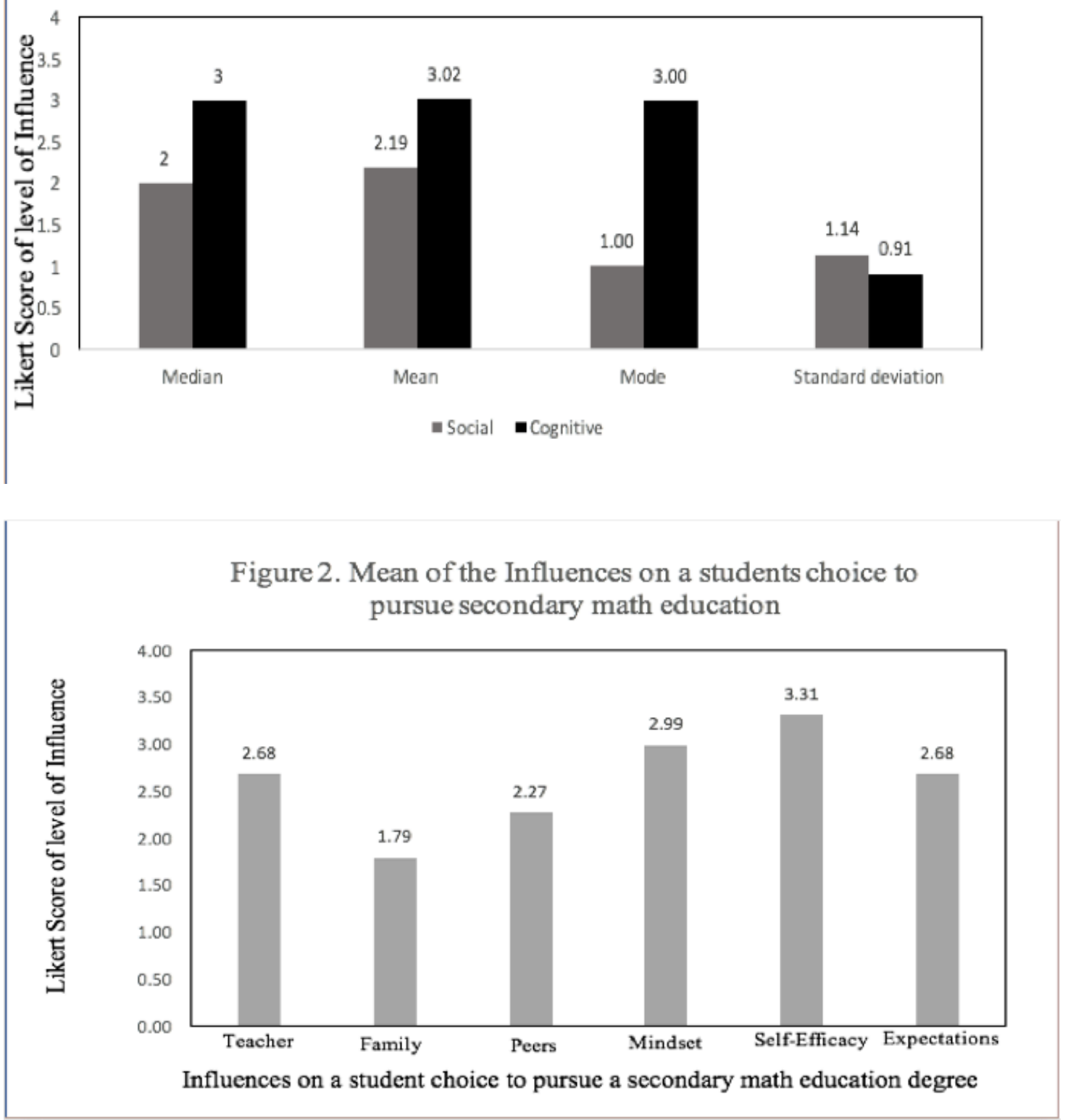
Figure 3. Median of the Influences on a students choice to pursue secondary math education

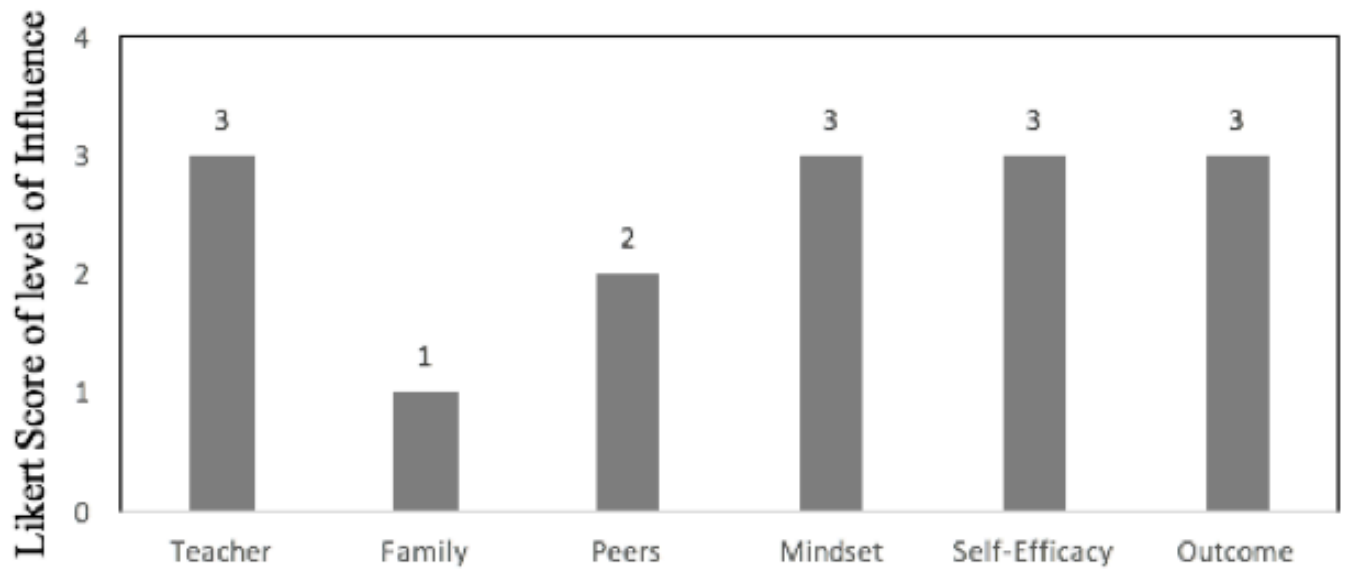

Influences on a student's choice to pursue a math education degree

Figure 4. Mode of the Influences on a students

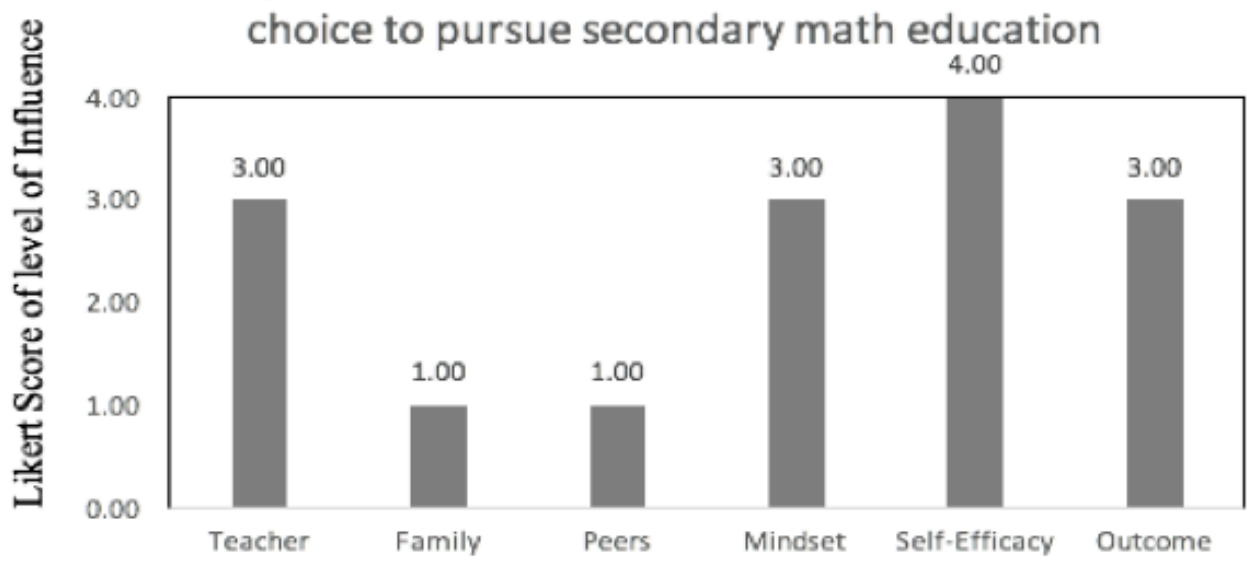

Influences on a student choice to pursue a secondary math education degree 


\section{HYPOTHESIS MEAN PAIRED T-TESTS}

Null Hypothesis

There is no significant difference between the social and cognitive influences on a teacher candidate's choice to select mathematics. $p=.000 * * * \quad$ Reject Null Hypothesis with $\mathbf{9 9 . 9 \%}$ confidence Mean Difference $\mathbf{0 . 8 4} \quad$ Test Statistic $\mathrm{t}=\mathrm{II} . \mathrm{I}$

\section{TABLE I. HYPOTHESIS MEAN PAIRED $T$-TESTS FOR SOCIAL INFLUENCES}

\begin{tabular}{cccc} 
Social Influences being compared & P value & Mean difference & test statistic \\
\hline Teacher vs Family & $.0000^{* * *}$ & .89 & 7.79 \\
in Paired t-tests for amily & $.0000^{* * *}$ & .49 & 4.46 \\
leacher vs Peers & $.005^{* *}$ & .39 & 2.91
\end{tabular}

Note. all null Hypothesis were rejected $* p<.05, * * p<.01, * * * p<.001$. 


\section{TABLE 2. HYPOTHESIS MEAN PAIRED $T$-TESTS FOR COGNITIVE INFLUENCES}

Influences being compared $\quad \mathrm{P}$ value mean difference test statistic

Self-efficacy vs Mindset $\quad .0002 * * * \quad .34 \quad 4.04$

Self- efficacy vs Expectations $.0000 * * * \quad 1.59 \quad 18.40$

$\begin{array}{llll}\text { Mindset vs Expectations } & .0000 * * * & 1.25 & 13.17\end{array}$

Note. all null Hypothesis were rejected $* p<.05, * * p<.01, * * * p<.001$.

\section{IMPLICATIONS}

Mathematical Self-Efficacy has the strongest influence on a student's choice to pursue a secondary mathematics education degree.

Therefore, building students' belief in their mathematical skills is the most important way to increase the number of future math teachers.

Aligns with Social Cognitive Career Theory that careers are selected based on our interests and our belief in our skills [Lent \& Brown, 2013]. This agrees with Wang's research (2013) that self-efficacy had the largest influence on student's choice to pursue STEM majors. 


\section{IMPLICATIONS}

The three largest influences on a teacher candidates' choice are self-efficacy, mindset and teacher influence.

Self-efficacy and Growth mindset can be impacted by the tasks teachers select and the climate in the classroom.

Teachers have a significantly larger influence on a student's choice than their family or peers.

\section{WAYS TO IMPROVE SELF-EFFICACY}

Research has found mathematics self-efficacy is increased when students experience academic success specific to math such as solving math problems (Campbell \& Hackett, 1986; Lent, Brown, \& Hackett, 1994).

Kirk (2018) lists four main ways of building self-efficacy: Mastery experiences, Vicarious experience,Verbal persuasion and Emotional State or classroom climate Tasks need to be at the correct difficulty level (Margolis \& McCabe, 2006).

Collaborative learning, Inquiry based instruction and Focusing on conceptual instead of the computational questions have also been shown to improve self-efficacy (Fenci \& Scheel, 2005).

Bandura (1993) states that self-efficacy is not about the skills one has, but what one thinks they can do with the skills one possesses. Even when an activity is challenging. self-efficacy can be the factor that helps a student persevere (Pajares, 2003; Stevens, Olivarez, Lan, \& Tallent-Rummels, 2004). 


\section{WAYS TO IMPROVE GROWTH MINDSET}

Every time the brain experiences conflict between a correct response and an error there is increased electrical activity (brain growth) (Moser, Schroder, Heeter, Moran, \& Lee, 20I I).

Mistakes are when the brain grows the most because it is challenged and struggles (Boaler, 2016; Dweck, 2016).

When students are praised for who they are as a person instead of what they have done, they get a fixed mindset about their abilities (Boaler, 2016).

\section{NEXT STEPS IN RESEARCH}

-What factors influence a student to pursue a secondary mathematics education degree? (Qualitative Study)

- Is there a difference between males and females when it comes to growth mindset?

- Is there a difference between the influence of earning a good living versus having good benefits on a student's choice to pursue education as a profession?

- What creates students' interest in mathematics?

Males had higher means in the data than females, especially on the question about mistakes. Females report higher levels of math anxiety and lower levels of math selfconcept [Else-Quest, Minew, \&. Higgins, 2013).

The data showed a mode of one (no influence) for a good living influencing their choice while good benefits had a mode of four (strong influence). Summers off and job flexibility could be positive influences to encourage students to pursue education (Allgretto, Corcoran, \& Mishel, 2004). However, the salary and working conditions are often the reason teachers leave the profession (Branch, 2001; Curtis, 2012; DeNisco, 2015). 


\section{REFERENCES}

Alika, H. (2012). Career choice in engineering: The influence of peers and parent's implication for counselling. College Student Journal, 46(3), 537-542.

Bandura, A. (2006). Toward a psychology of human agency. Perspectives on Psychological Science, 1, 164-180. doi:10.1111/j.1745-6916.2006.00011.

Bates, A. B., Latham, N., \& Kim, J. A. (2011). Linking preservice teachers' mathematics Self-Efficacy and mathematics teaching efficacy to their mathematical performance. School Science and Mathematics, 111(7), 325-333.

Boaler, J. (2016). Mathematical mindsets: Unleashing students' potential through creative math, inspiring messages and innovative teaching. San Francisco, CA: Jossey-Bass.

Brown, S.D. Lent, R.W. (2006). Preparing adolescents to make career decisions: A social cognitive perspective. Adolescence and education, 5, 201-223.

\section{REFERENCES}

Campbell, N. K., Hackett, G. (1986). The effects of mathematics self-efficacy expectations on math self-efficacy and task interest. Journal of Vocational Behavior, 28, 149-162.

Duckworth, A., \&Quinn, P. (2009). Development and validation of the short gritscale. Journal of Personality Assessment, 91(2), 166-174.

Dweck, C.S. (2016). The remarkable reach of growth mind-sets. Scientific American Mind, doi: $15552284,27(1)$.

Eesley, C., \& Wang, Y. (2017). Social influence in career choice: Evidence from a randomized field experiment on entrepreneurial mentorship. Research Policy, 46(3), 636-650.

Fenci, H., \& Scheel, K. (2005) Research and teaching: Engaging students-an examination of the effects of teaching strategies on self-efficacy and course in a nonmajors physics course. Journal of college science teaching, 35(1), 20-24. 


\section{REFERENCES}

Hsiao, J., \& Nova, S. P. D. C. C. (2016). Generational Approach to Factors Influencing Career Choice in Accounting. Revista Contabilidade \& Finanças, 27(72), 393-407.

Kirk, K. (2018) Self-efficacy: Helping students believe in themselves. Retrieved from https://serc.carleton.edu/NAGTWorkshops/affective/efficacy.html

Lent, R.W., Brown, S.D. Hackett, G. (1994). Toward a unifying social cognitive theory of career and academic interest, choice, and performance. Journal of Vocational Behavior. 45, 79-1 22.

Lent, R.W., Brown, S.D. (20I3). Social cognitive model of career self-management:Toward a unifying view of adaptive career behavior across the life span.Journal of Counseling Psychology, 60, 557-568.

Margolis, H., \& McCabe, P. (2006). Improving self-efficacy and motivation:What to do, what to say. Intervention in School and Clinic, 4 I (4), 2 I 8-227.

\section{REFERENCES}

Moakler, M.W., Kim, M. M. (2014). College major choice in stem: Revisiting confidence and demographic factors. The Career Development Quarterly, 62, 128-142.

Moser, J.,Schroder, H.S., Heeter, C., Moran, T.P., \&Lee,Y. H. (20I I). Mind your errors: Evidence for a neural mechanism linking growth mindset to adaptive post error adjustments. Psychological Science,22, I484-I 489.

Ostroff, C. (2017). Schools throughout the country are grappling with teacher shortage, data show. CNN: Health Retrieved from http://www.cnn.com/2017/08/21/health/teacher-shortage-data-trnd/index.html.

Sutcher, L., Darling-Hammond, L., Carver-Thomas, D. (2016).A coming crisis in teaching? Teacher supply, demand and shortages in the U.S. Learning Policy Institute, Research. Action. Impact. Retrieved from http://www/learningpolicyinstitute.org/products/coming-crisis-teaching.

SECTION 5: CONTRIBUTION TO SCHOLARSHIP

\section{Target Journal}

Journal for Research in Mathematics Education 


\section{Rationale for this Target}

The Journal for Research in Mathematics Education matches the focus of the research. It is read by math teachers who are the target audience for this research. Math teachers are the ones influencing the future teacher candidates and they can make the largest impact of improving the number of teacher candidates pursuing a degree in math education.

\section{Plan for Submission}

Who: Submit online at JRME Online Submission and Review System.

For questions contact

Jinfa Cai, JRME Editor

523 Ewing Hall

University of Delaware

Newark, DE 19716

USA

302-831-1879 jirme@,nctm.org

When: Fall of 2018

\section{Submission-Ready Journal Article}

A 12,000-word research report using APA formatting 


\begin{abstract}
There is a crisis across the United States as schools are seeing a shortage of mathematics teachers. While school districts are working on new ways to recruit teacher candidates, the heart of the problem lies in the decline in students entering secondary mathematics teacher preparation programs. This study evaluates the social and cognitive influences on a student's choice to pursue a degree in secondary mathematics education. An electronic survey was given to 63 students across the state of Missouri in the first two years of a math teacher preparation program. In the survey, students ranked the level of social influences (teacher encouragement, family support, and peer influences) and the level of cognitive influences (self-efficacy, growth mindset, and outcome expectations). Self-efficacy was the largest influence by a statistically significant difference. Teacher encouragement was significantly found to be the largest social influence. This is important because it implies that schools have the largest opportunity to increase the number of secondary math teachers.
\end{abstract}




\section{Introduction}

Across the United States mathematics classes are finding themselves without a teacher. Forty-two states reported teacher shortages in mathematics in the 2015-2016 school year (Sutcher, Darling-Hammond, \& Carver-Thomas, 2016). For the 2017-2018 school year, forty-eight states and the district of Columbia report a shortage of secondary math teachers (Ostroff, 2017). Administrators in school districts would like to find highly qualified teachers who fit with their communities and philosophies so their students will be the most successful. However, what do schools do if there are not enough candidates to fill the positions? Schools hire uncertified candidates or leave positions unfilled (Ostroff, 2017). For example, Clark County in Nevada had over 900 teaching positions unfilled for the 2015-2016 school year (Ryan, 2016). Districts like Clark County are forced to place permanent substitutes (not certified in the field) in classrooms (DeNisco, 2015; Ryan, 2016). Other districts are increasing class sizes to take in the students; for example, in California class sizes have reached 35 students per teacher (Ostroff, 2017). Fetler's research on high school math teachers' characteristics and math student performance (1999) found there is a shortage of qualified math teachers and that shortage is associated with low student achievement. According to Sutcher, Darling-Hammond, and Carver-Thomas (2016) "evidence shows that shortages historically have disproportionately impacted our most disadvantaged students" where "high-minority schools had four times as many uncertified teachers as low-minority schools" (p. 5). 
While school districts are working on new ways to recruit teacher candidates, the heart of the problem lies in the decline in students entering teacher preparation programs. In the 2008-2009 school year, there were 719,081 teacher candidates enrolled in teacher preparation programs. However, in the 2013-2014 school year this number dropped 35\% down to 464,250 students enrolled (Sutcher, Darling-Hammond, \& Carver-Thomas, 2016). This is coupled with the increase in the number of teachers retiring. The National Center for Education Statistics (NCES) predicts student enrollment will increase in the next decade by three million students (NCES, 2012). This increase in students will lead to an increased need for secondary mathematics teachers.

The overarching problem is there is a shortage of math teachers caused by a shortage of students entering the field of math education (Sutcher et al., 2016; Ingersoll \& Perda, 2010). Specifically, the problem is a lack of research on influences on a teacher candidate's choice to pursue math education. Ingersoll and Perda (2010) found in their research that math and science have more of a shortage than English. Curtis (2012) who completed a qualitative study on why teachers go into education, found that math teachers entered the profession because of their desire to work with young people, make a difference, and a love for math. But what influences led to a desire to work with young people or created a love for math. Lent and Brown's (2013) research states there are social and cognitive influences that impact how one chooses a career. There is a need to find the social and cognitive influences that positively or negatively influence a teacher candidate's choice to become a math teacher.

The shortage of students pursuing degrees in science, technology, engineering, and mathematics (STEM) could be similar to the shortage seen in students pursuing math 
education. Research states there is a decline in students pursuing STEM fields (Moakler \& Kim, 2014). The mathematics referred to in STEM is not necessarily secondary math education. However, students pursuing math education would have similar characteristics and influences of students studying pure mathematics. According to the National Science Board, as the need for STEM careers has increased, there has been a decline in the number of students entering STEM fields of study in higher education (2005). Furthermore, the interest in STEM has declined at the high school level which means fewer students are pursuing a degree in a STEM field (National Academy of Sciences, 2007). Wang's research on why students choose STEM majors (2013) found the largest influence on students pursuing a degree in a STEM field was mathematical self-efficacy and exposure to math and science courses at the high school level. So how does this compare to lack of students pursing math education? A connection between the shortage of math teachers and the lack of students interested in math seems logical, but what is influencing this loss of interest in math education?

\section{Purpose of the Study}

The purpose of this study is to contribute to the literature on the social and cognitive influences on a student's choice to pursue a degree in secondary mathematics education. This study can increase the number of students entering into the math education profession which would then increase the number of math teacher. It will compare the level of influence of social and cognitive influences. Specifically, is the choice influenced by people around them, or emotions and beliefs? If people, then is it teachers, family members, or peers that influence students the most to choose a career in education? Or are there other perceptions like self-efficacy, anxiety, mindset, or outcome 
expectations that influence their choice? If these factors are found, then researchers can begin to look at how to increase the positive influences and decrease the negative influences so the number of students entering the field of math education can be increased.

\section{Research Questions}

The main research question guiding this study was: What factors influence a student to select secondary mathematics education as a profession? The sub-questions investigated were:

- Is there a difference between social and cognitive influences on a student's choice to pursue a degree in secondary mathematics education?

- Is there a difference between the social influences (teacher encouragement, family support, and peer influence) on a student's choice to pursue a degree in secondary mathematics education?

- Is there a difference between the cognitive influences (self-efficacy, mindset, and expectations) on a student's choice to pursue a degree in secondary mathematics education?

\section{Theoretical Framework: Social Cognitive Career Theory}

This study is guided the Social Cognitive Career Theory (SCCT), integrating career interests, goals, and intentions with self-efficacy and outcome expectations. This theory was initially developed by Lent, Brown, and Hackett (1994) as a synthesis of three interconnected theories. The goal was to explain the interest development, choices in career paths, and performance in education relating to vocational training. In 2006, a fourth overlapping model was adopted to discuss wellbeing or satisfaction (Lent \& 
Brown, 2013). "People do not operate as autonomous agents. Nor is their behavior wholly determined by situational influences. Rather, human functioning is a product of a reciprocal interplay of intrapersonal, behavioral, and environmental determinants. .." (Bandura, 2006, p.165). SCCT views students as living within a social world, with everpresent opportunities to be influenced. Specifically, the SCCT choice model is concerned with the self, experiential, and contextual factors that promote pursuit of careers paths (Lent \& Brown, 2013). This study will be applying the model to teacher candidates' choice of teaching area, specifically focused on those that selected math education.

\section{Literature Review}

\section{Math Education Preparation}

The history of teacher preparation influences a teacher candidate's choice to pursue math education. One example of this influence is the loss of prestige of the teaching profession. This began with teacher preparation being in normal schools and not originally in the universities (Larabee, 2008). The teaching certificate did not hold the prestige that other university degrees held. Another example of this influence is in the stereotypes of education being women's work, but math being a male field. Seventy-five

percent of teachers, kindergarten through $12^{\text {th }}$ grade, are females (Allgretto, Corcoran \& Mishel, 2004). This stereotype is encouraged further by statistics like men get higher SAT scores in math than women or science and technology careers are predominantly male disciplines (McCarthy, 2011). Females also report higher levels of math anxiety and lower levels of math self-concept (Else-Quest, Minew, \& Higgins, 2013). The combination of the stereotypes causes every teacher candidate that selects math education to have to fight society biases. Furthermore, there are cultural stereotypes that certain 
ethnic groups are better suited for math while others are less (Hrabowski, 2011). This is not helped by the statistic that many states are adding more testing for licensure, and these tests have shown to be biased to students of color (Branch, 2001).

\section{Social Influences}

There are many influences in a person's life that guides them to a career choice. Social influences like teachers, parents, and peers have a strong impact especially in the adolescent years (Alika, 2012; Hsiao \& Nova, 2015). During adolescence is when many students select their career and begin taking courses to pursue that career. The emotional support needed for a career choice often comes from peers (Pereira \& Garcia, 2007). Research suggests social relationships "act as a pipe to channel the flow of information and resources" about career choices (Easley \& Wang, 2017, p. 636). Social relationships can also influence the choice with expectations and perceptions (Guerra \& BraungartRieker, 1999; Hsiao \& Nova, 2016). This study evaluated three types of social influence: teachers, family, and peers.

\section{Cognitive Influences}

Career choices are often influenced by cognitive factors such as self-efficacy, anxiety, mindset, and outcome expectations. Mathematical self-efficacy is the belief students hold in their mathematics capabilities, and it is predictive of student's achievement and motivations in mathematics (Bates, Latham \& Kim, 2011; Brown \& Lent, 2006; Moakler \& Kim, 2014). Research has found that mathematics self-efficacy is increased when students experience academic success specific to math such as solving math problems (Campbell \& Hackett, 1986; Len, Brown, \& Hackett, 1994). There have been many studies that show a significant relationship between self-efficacy and 
performance (Ayontolah \& Adedeji, 2009; Bates, Latham, \& Kim, 2011; Peters, 2012;

Stevens, Olivarez, Lan, \& Tallent-Runnels, 2004; Williams \& Williams 2010). A

negative correlation has also been found between mathematics anxiety and mathematical self-efficacy (Azar \& Mamoudi 2014; Hackett \& Betz, 1989). Students with high math anxiety tend to avoid situations involving mathematics and are therefore less likely to pursue math related careers (Beilock \& Willingham, 2014; Supekar, 2015). While selfefficacy focuses on what a student thinks they can do, mindset focuses on their ability to learn. A fixed mindset is when students believe they are either smart or not, good at something or not good at it (Boaler, 2016). A student with a growth mindset is more willing to take on hard work and view mistakes as a challenge and motivation to work harder (Duckworth \& Quinn, 2009; Dweck, 2016). This study looked at the cognitive influences of self-efficacy, mindset, and outcome expectations on a teacher candidate's career choice.

\section{Research Design}

A quantitative study was selected to research the difference between the social and cognitive influences (Creswell, 2014).

Table 1

Social and Cognitive influences grouped by survey questions

\begin{tabular}{lll} 
Variable & Type & Question Number \\
\hline Teacher Encouragement & Social & $7 \mathrm{~b}, 7 \mathrm{f}$ \\
Family support & Social & $7 \mathrm{a}, 7 \mathrm{c}, 7 \mathrm{~d}$ \\
Peer Influence & Social & $7 \mathrm{e} 8 \mathrm{f}$ \\
Self-efficacy & & \\
$\quad$ General academic & Cognitive & $4 \mathrm{a}, 4 \mathrm{e}$ \\
$\quad$ Content specific & Cognitive & $8 \mathrm{a}, 8 \mathrm{~b}, 4 \mathrm{~b}, 4 \mathrm{c}, 4 \mathrm{~d}$ \\
Mindset & Cognitive & $5,6,8 \mathrm{c}$ \\
Outcome expectancy & Cognitive & $8 \mathrm{~d}, 8 \mathrm{e}, 8 \mathrm{~g}$ \\
\hline
\end{tabular}


It will be a non-experimental design because the variables of teacher encouragement, parental support, and peer influence cannot ethically be restricted from participants (Creswell, 2014). Furthermore, the variables of self-efficacy and growth mindset cannot be controlled.

\section{Methods}

A survey was used to generalize results from a sample of the population (Creswell, 2014). The population was all secondary math teacher candidates in their first or second year of course work attending a college or university in Missouri. An electronic survey was emailed out to participants through math professors at various Missouri universities with teacher preparation programs. The researcher does not work at a college or university and is therefore considered an outsider (Merriam \& Tisdell, 2016). However, the researcher is a secondary math teacher and so must be careful of bias toward personal influences to select math education. The data collected was cross sectional as it was collected over one year (Creswell, 2014). Descriptive statistics including mean, median, mode and standard deviation were used to interpret the data. Then hypothesis mean paired $t$-tests were used to determine significant differences between influences.

\section{Setting and Participants}

In 2017-2018, Missouri reported 15 regions with a shortage of mathematics teachers. The population for this research was students attending a teacher preparation program in Missouri in the United States of America and pursing a degree in secondary mathematics education. The sample was 63 survey participants that are secondary math education majors in their first or second year of a secondary math teacher preparation 
program in Missouri. It contained 35 females (56\%) and 28 males (44\%). The sample contained 16 students $(25 \%)$ that were first generation college students. The survey was emailed out to secondary math education teacher candidates, and because it was not mandatory the sample is considered self-selected (Creswell, 2014). The survey was given in the first and second year and not the final years so that it is measuring the influences that caused a teacher candidate to pursue a degree in math education instead of measuring if they are able to complete the degree.

\section{Results}

The survey was collected from 63 candidates and the data were first analyzed per question. The data analysis began with descriptive statistics about the characteristics of those pursing a degree in math education. Descriptive statistics were used because they "give us a manageable and meaningful summary of the underlying phenomenon" (Wheelen, 2013, p. 17). For each question the mean, median, mode, and standard deviation were calculated. The majority of the questions were answered by a 4-point Likert scale where a 1 represents no influence, a 2 represents little influence, a 3 represents moderate influence, and a 4 represents strong influence. Questions 4, 5 and 6 were also on a 4 point Likert Scale but the levels were worded differently to match the questions (see appendix for exact wording of questions).

Overall the social influences scored in the (2) little to (1) no influence while the cognitive influences scored in the (3) moderate to (4) strong influence. Questions 8a and $8 \mathrm{~b}$ scored the highest of all the questions. Specifically, both questions have a four for the median and the mode. Therefore, a student's interest and belief in their skill are the strongest influence on their choice to pursue a secondary math education degree. 
Table 2

Descriptive statistics for each question on the survey grouped by social and cognitive influences.

\begin{tabular}{|c|c|c|c|c|c|}
\hline Variables & Questions & Mean & Median & Mode & Std dev \\
\hline Social Influe & & 2.19 & 2 & 1 & 1.14 \\
\hline Teach & ncouragement & 2.68 & 3 & 3 & 1.09 \\
\hline & 7b) A teacher encouraged me to & 2.41 & 2 & 1 & 1.13 \\
\hline & pursue mathematics & & & & \\
\hline & 7f) A teacher told me, that I am & 2.95 & 3 & 3 & 0.97 \\
\hline & strong in mathematics & & & & \\
\hline Family & pport & 1.79 & 1 & 1 & 1.05 \\
\hline & 7a) I have teachers in my family & 1.83 & 1 & 1 & 1.14 \\
\hline & 7c) Parent/ Grandparent & 2.11 & 2 & 1 & 1.14 \\
\hline & encouraged me to pursue & & & & \\
\hline & mathematics & & & & \\
\hline & 7d) Sibling / Cousin encouraged & 1.47 & 1 & 1 & 0.74 \\
\hline & me to pursue mathematics & & & & \\
\hline Peer I & tence & 2.27 & 2 & 1 & 1.13 \\
\hline & 7e) A friend / classmate & 1.75 & 1 & 1 & 0.88 \\
\hline & encouraged me to pursue & & & & \\
\hline & mathematics & & & & \\
\hline & 8f) My belief that teaching is a & 2.82 & 3 & 4 & 1.09 \\
\hline & respected career influenced my & & & & \\
\hline & choice & & & & \\
\hline
\end{tabular}


$\begin{array}{lllll}\text { Cognitive Influences } & 3.02 & 3 & 3 & 0.91\end{array}$

General Self-Efficacy

4a) Rank yourself in overall

Academic Performance

4e) Rank yourself in Artistic and

Creative

\section{Mathematical Self-Efficacy}

4b) Rank yourself in Problem

Solving

4c) Rank yourself in Critical

Thinking

4d) Rank yourself in Logic and

puzzles

8a) My interest in Mathematics

influenced my choice

8b) My skill in mathematics

influenced my choice

Mindset

5) Describe feelings when you

are faced with a challenging

problem

6) Describe your feelings when

you make a mistake.

8c) My enjoyment of puzzles

and problem solving influenced

my choice

\subsection{3}

3.19

2.48

3.31

3.41

3

3

0.80

3

3

3

0.74

2

2

0.72

3.00

3

3

0.65

3.24

3

3

0.76

3.46

4

4

0.78

3.46

4

4

0.71

2.99

3

3

0.87

3.21

3

3

0.63

2.52

3

3

0.93

3.24

3

3

0.84 


\section{Outcome Expectation}

8d) My belief that I will make a

good living influenced my

choice

8e) My belief that the benefits of

teaching are worthwhile

influenced my choice

8g) My belief that there is job

security and opportunity for

growth in teaching influenced

my choice
2.68

2.16

2

1

1.04

3

4

2.76

3

3

1.07

Next a clustered bar graph was created comparing the social and cognitive influences. The cognitive influences were significantly higher in median, mean and mode then the social influences. Furthermore, the standard deviation of the cognitive influences was lower than for the social influences.

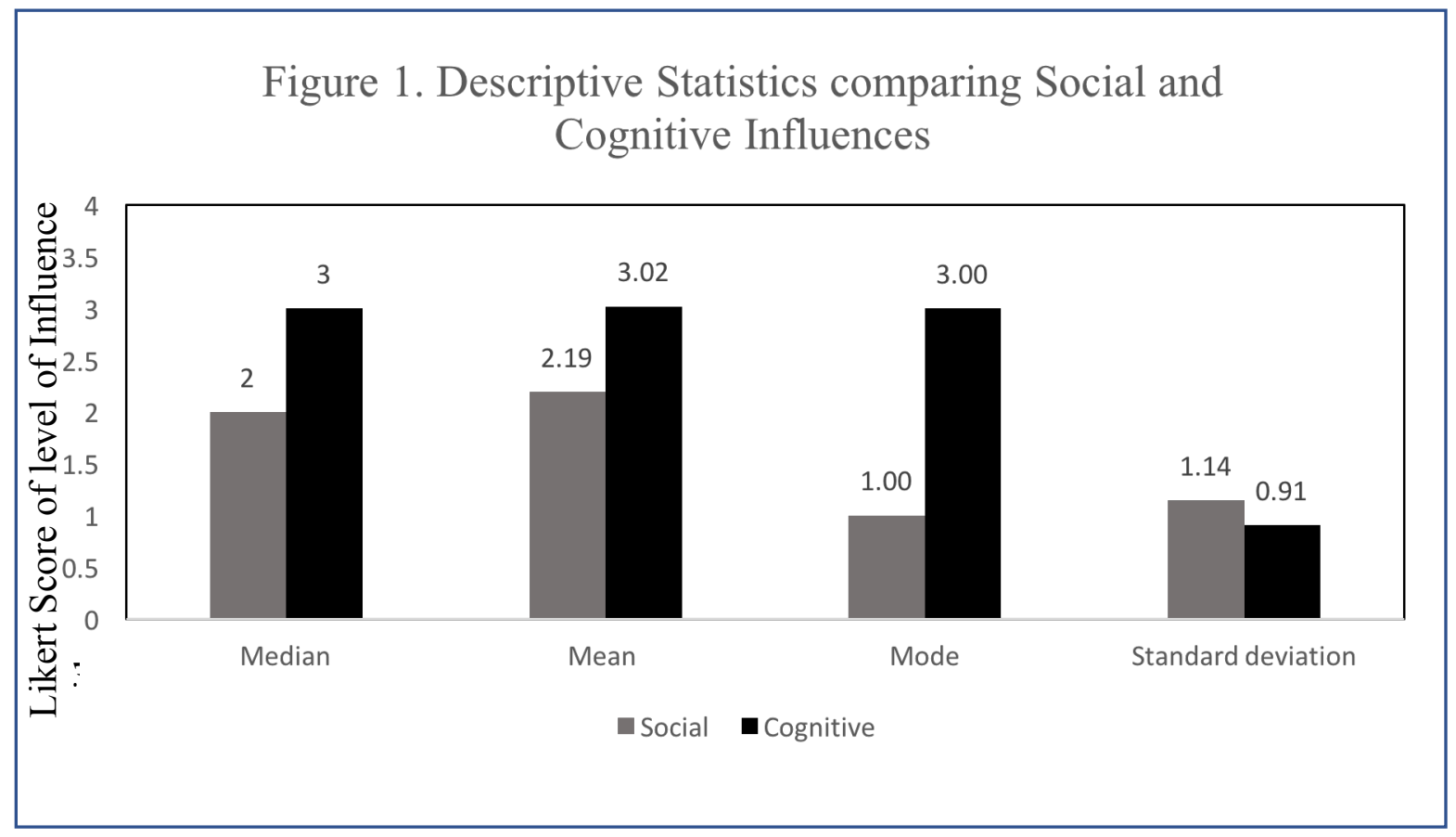


Next the data were broken down into the three social influences of teacher, family, and peer, followed by the three cognitive influences of growth mindset, selfefficacy, and outcome expectations. Bar graphs were created to show the mean for each variable in figure 2. (Field, 2013). Self-efficacy had a significantly stronger mean value then all the other influences. Of the social influences, teacher encouragement was significantly stronger. However, all of the cognitive influences were either equal or higher than the social influences.

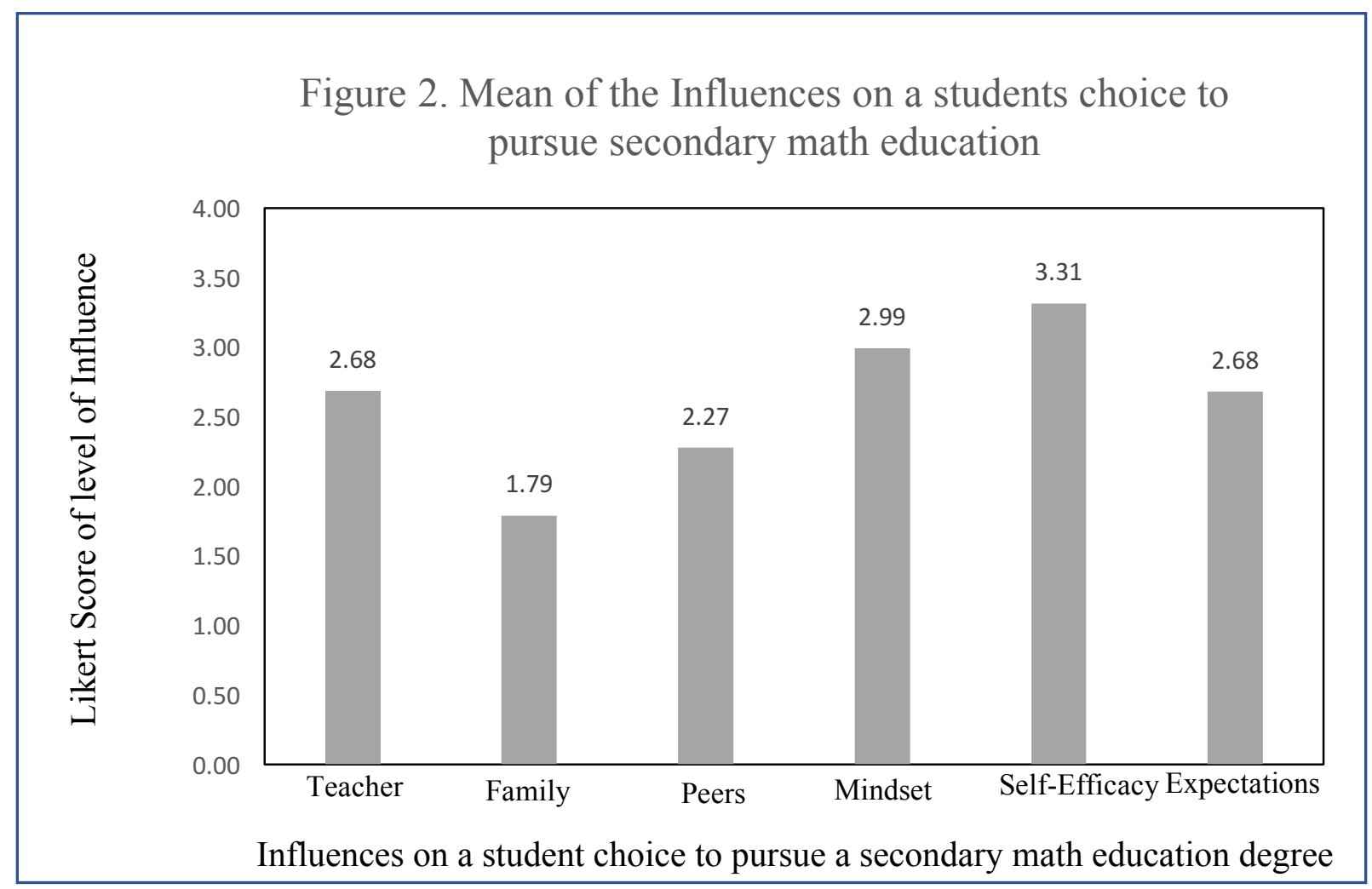

Figure 3 compares the median for the social and cognitive influences. The median was a three for teacher, mindset, self-efficacy and expectations. This states that over half the students surveyed found that all three cognitive influences and the teacher encouragement had a moderate to strong influence on their choice to pursue a secondary 
math education degree. Furthermore, more than half of the candidates stated that their family had no influence on their choice.

\section{Figure 3. Median of the Influences on a students choice to pursue secondary math education}

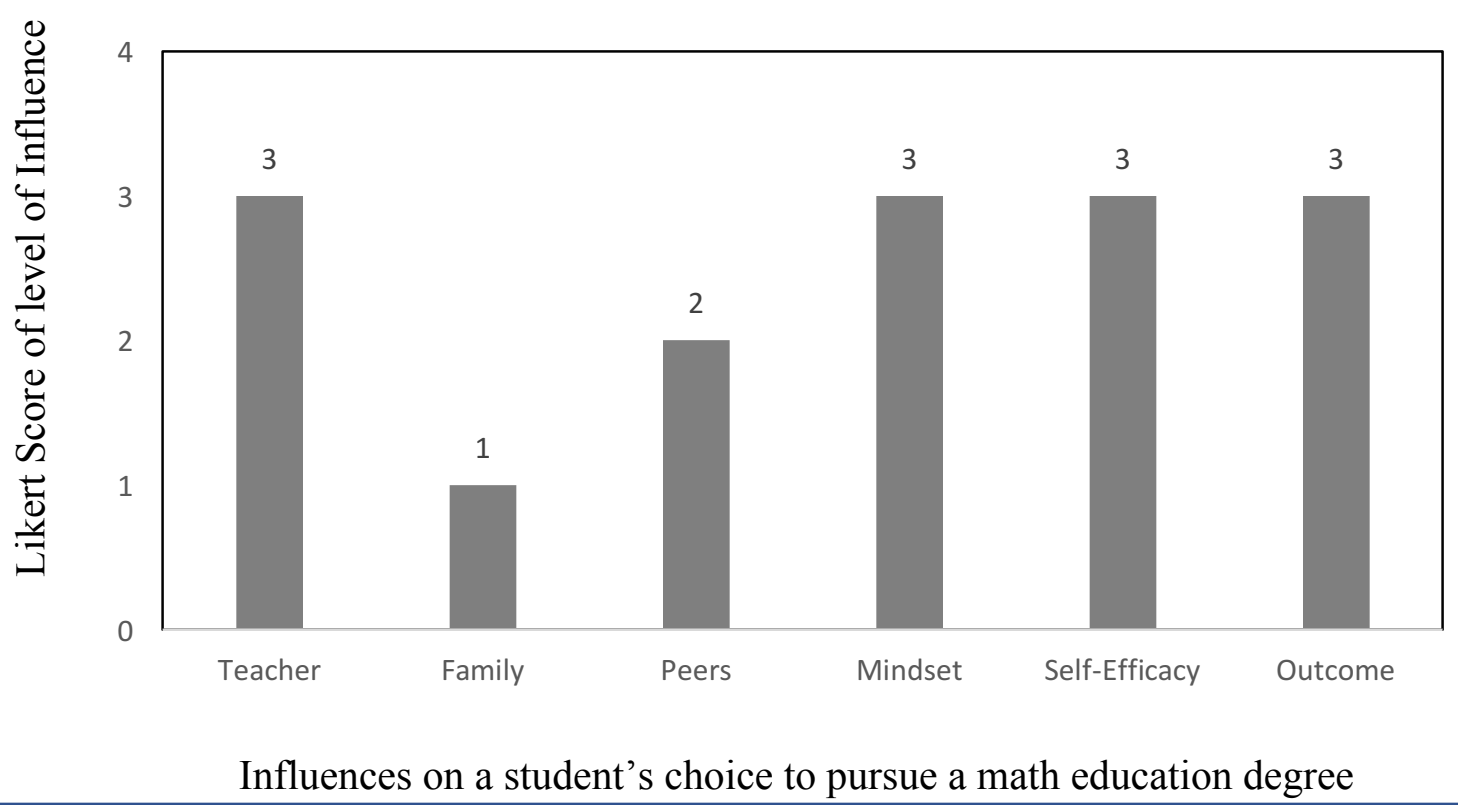

Figure 4 compares the mode for the social and cognitive influences. Self-efficacy has a mode of four, which means more students believe that their ability in mathematics has a strong influence on their choice pursue a secondary math education degree.

Moreover, family and peers have a mode of one. This means that more of the students believe that their family and peers have no influence on their choice. 


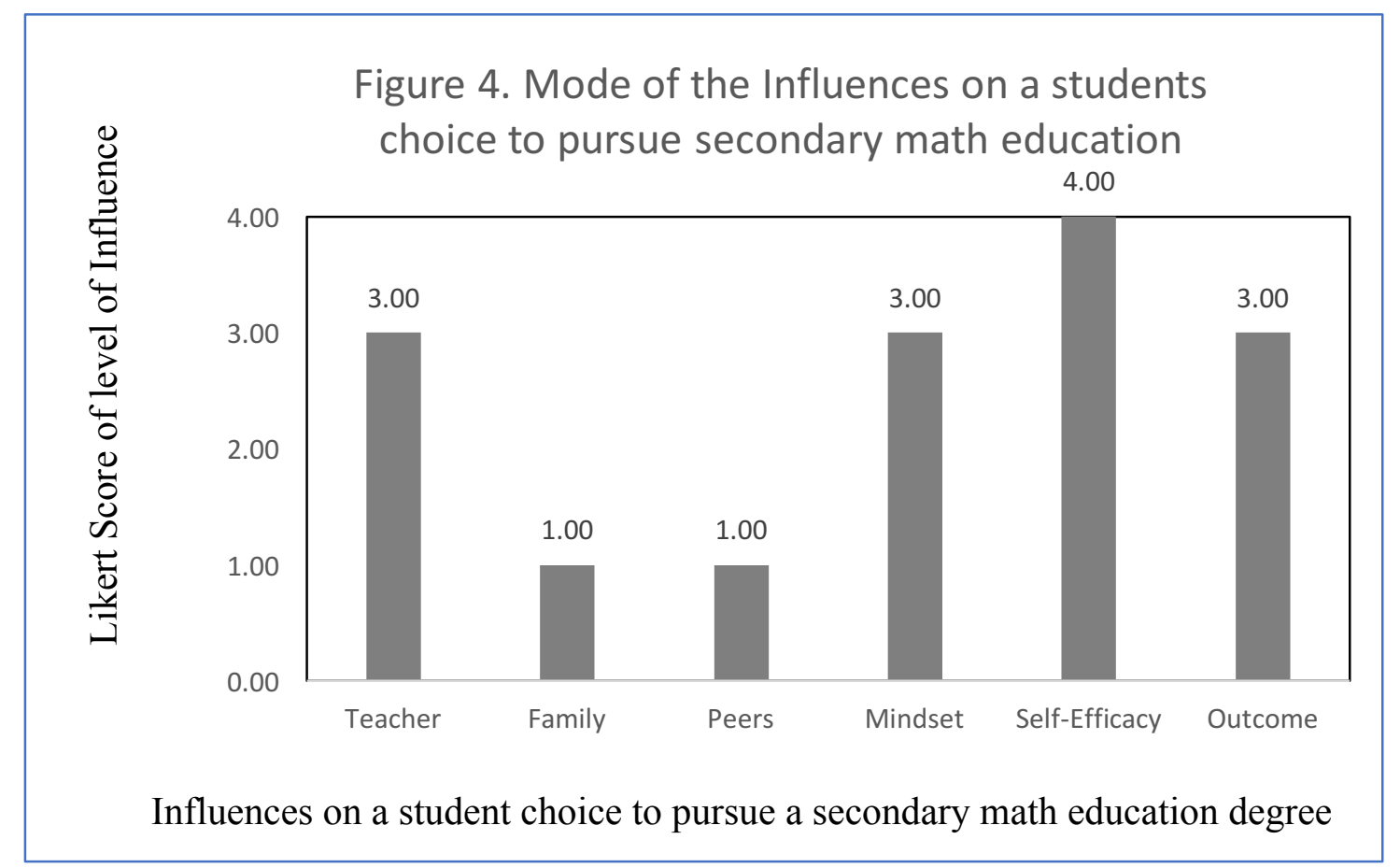

After the descriptive statistics were interpreted the data were evaluated for statistical differences using hypothesis mean paired $t$-tests. A $t$-test focuses on whether the difference between two groups' averages is because of random chance in sample selection or another factor. Statwing (2017) states that to get a meaningful difference one needs a large sample size, small standard deviation, and a large difference between averages. Our sample size was 63 giving us 62 degrees of freedom. The data is paired because the same participant answered both sets of questions that are being compared (Field, 2013).

Listed below are the null hypothesis tested to go with the research questions and their associated p-value. The p-value is the probability of the null hypothesis of being true. The null hypothesis can be rejected if the p-value is lower than 0.05 . Asterisks are 
used to show the level of significance $*$ for $\mathrm{p}<.05, * *$ for $\mathrm{p}<.01$, and $* * *$ for $\mathrm{p}<.001$. The mean difference was also calculated along with the test statistic. The test statistic is a standardized unit that compares the data to the null hypothesis.

The first research question was "Is there a difference between social and cognitive influences on a student's choice to pursue a degree in mathematics education?" so the corresponding null hypothesis is that there is no significant difference between the social and cognitive influences on a teacher candidate's choice to pursue a degree in mathematics education. After running the $t$-test the $\mathrm{p}$-value was $.0000^{* * *}$. This is less than 0.001 and therefore the null hypothesis was rejected. This low of a p value means that with $99.9 \%$ confidence we can state that the difference is not due to chance. This implies that there is a significant difference between the social and cognitive influences. The mean difference between the two was 0.84 with Cognitive being the larger. This implies that the cognitive influences on average scored 0.84 higher on the 4 point Likert scale of influence when compared to the social influences. The test statistic was 11.1 which is extremely high.

The second research question was "Is there a difference between the social influences (teacher encouragement, family support, and peer influence) on a student's choice to pursue a degree in mathematics education?" To compare the three variables, three null hypothesis statements were created and three $t$-tests were analyzed. All three $\mathrm{p}$ values were below .05 and so all three null hypotheses were rejected. This means that the difference between each influence is significant. Furthermore, two are below .001 that implies a $99.9 \%$ confidence level. The mean difference between teachers and family was .89 implying that students scored teachers as having more influence than their family by 
.89 points on the 4 point Likert scale. This is the equivalent of saying almost all students found the teachers to be moderately or strongly influential and their parents low to no influence.

Table 3. Hypothesis Mean $t$-test results for Social Influences

\begin{tabular}{llll}
\hline Social Influences being compared & p value & mean difference & test statistic \\
\hline Teacher vs Family & $.0000^{* * *}$ & .89 & 7.79 \\
Peers vs Family & $.0000^{* * *}$ & .49 & 4.46 \\
Teacher vs Peers & $.005^{* *}$ & .39 & 2.91 \\
\hline
\end{tabular}

Note. All null hypotheses were rejected. $* \mathrm{p}<.05, * * \mathrm{p}<.01, * * * \mathrm{p}<.001$.

The final research question was "Is there a difference between the cognitive influences (self-efficacy, mindset, and expectations) on a student's choice to pursue a degree in mathematics education?" To compare the three variables, three null hypothesis statements were created and three $t$-tests were analyzed. All three $\mathrm{p}$ values were below .05 and so all three null hypotheses were rejected. This means that the difference between each influence is significant. Furthermore, all three were below .001 that implies a 99.9\% confidence level. The mean difference between self-efficacy and expectations was 1.59 implying that students scored self-efficacy as having more influence than their outcome expectations by 1.59 points on the 4 point Likert scale. The test statistics involving the expectations were very large showing a significant difference between expectations and the other two groups. 
Table 4. Hypothesis Mean $t$-test results for Cognitive Influences

\begin{tabular}{lccc}
\hline Cognitive Influences being compared & $\mathrm{p}$ value & mean difference & test statistic \\
\hline Self-efficacy vs Mindset & $.0002^{* * *}$ & .34 & 4.04 \\
Self- efficacy vs Expectations & $.0000^{* * *}$ & 1.59 & 18.40 \\
Mindset vs Expectations & $.0000^{* * *}$ & 1.25 & 13.17 \\
& & & \\
\hline Note. All null hypotheses were rejected. ${ }^{*} \mathrm{p}<.05, * * \mathrm{p}<.01, * * * \mathrm{p}<.001$.
\end{tabular}

\section{Discussion}

Self-efficacy is the most significant factor that influences a student to select a secondary mathematics education degree? The SCCT emphasizes that students select careers based on their interests; and self-efficacy and outcome expectations are the most important factors in shaping interests (Lent et al., 1994). The data supports SCCT theory that self-efficacy is the most important but did not find that outcome expectations were as important of an influence. The data suggests that the top three are self-efficacy, growth mindset, and teacher influence. The mean for the variable of self-efficacy was the highest followed by mindset and teacher influence. Family support was the lowest followed by peer's influence. The sub-questions break down this question into more detail.

\section{Is there a difference between social and cognitive influences on a student's}

choice to pursue a degree in mathematics education? The mean, median, and mode of the cognitive influences were higher than the mean, median, and mode of the social influences, respectively. The standard deviation of the cognitive influences was smaller than the standard deviation of the social influences showing that the cognitive influences were more consistent across the candidates. The difference in the mode was extremely large with a 1 (no influence) being the most popular response for the social influences 
and a 3 (moderate influence) for the cognitive influences. The p-value for the t-test was very small showing that there was a significant difference between the two categories. Furthermore, self-efficacy had the largest influence on a student's choice, and it is a cognitive influence. The results of this study agree with other research like Volodina and Nagy's (2016) research on vocational choices of adolescence that found students based their choice on what they liked and disliked and Fouad \& Santana (2017) research on increasing interest in math careers through building mathematical self-efficacy.

Is there a difference between the social influences (teacher encouragement, family support, and peer influence) on a student's choice to pursue a degree in mathematics education? The teacher influence was the highest of the three social influences. This aligns with the research that stated that more than half of the American public believe teachers have the greatest influence on a student's learning (NEA, 1999). But contradicted other research that stated that career decisions are influenced by parent expectations and support (Guerra \& Braungart-Rieker, 1999; Hsiao \& Nova, 2016). One interesting discovery was the difference in the two questions on teacher influence. Both had higher means than the other categories but question $7 \mathrm{f}$ (when a teacher tells you that you are strong in mathematics) had a median and mode of 3 while question $7 \mathrm{~b}$ (when a teacher encourages you to pursue teaching) had a median of 2 and a mode of 1. Question $7 \mathrm{~b}$ also had a large standard deviation and a mean that was larger than the median. This makes one wonder if when candidates selected a 1 (no influence) did they really mean no teacher told me to go into math education or did their encouragement not matter. The mean higher than the median implies that there was a large number of 4's recorded 
meaning that it strongly influenced many candidates. So, are teachers just less likely to encourage a student to go into math education?

The questions on parental, sibling, and peer influence were significantly lower than teacher influence. This contradicted other research that stated that career decisions are influenced by parent expectations and support (Guerra \& Braungart-Rieker, 1999; Hsiao \& Nova, 2016). The large standard deviation of 1.13 for parental influence supported Alika's (2012) statement that the family expectations can have a large influence or a small influence depending on the relationship between student and family. The mode of one means that for many of the candidates parental, sibling and peer influences had no influence on their choice.

One surprising result was the two questions on peer influence. Candidates had marked on question 7 e their peers' encouragement had no influence (median $=1$, mean $=$ 1.75 , mode $=1)$. The literature research had suggested that teaching did not have a reputation for being well respected (Larabee, 2008). However, the candidates marked respect as having a moderate to strong influence on their choice to pursue math education $($ median $=3$, mean $=2.77$, mode $=4)$. Again, the question for 7 e does the 1 really mean no influence or does it mean that peers are not encouraging each other to go into math education? Pereira \& Garcia (2007) stated that the emotional support needed for a career choice comes from peers but how is that emotional support interpreted might need to be investigated further.

The null hypotheses were that all the variables were equivalent, however the data showed that all three statements can be rejected with exceptionally small p-values. Therefore, there is a significant difference between the social variables, and the teacher's 
influence was the largest. The mean difference was also very large between teacher and family influence. This is valuable information because it means that teachers need to be the leaders in bringing information about careers in math education to students. As Easley \& Wang (2017) stated they need to be the pipeline to funnel information and resources students.

Is there a difference between the cognitive influences (self-efficacy, mindset, and expectations) on a student's choice to pursue a degree in mathematics

education? The mathematical self-efficacy had the highest mean 3.3 and highest mode of 4 while all three were equal in median. Having a mode of 4 means that a large number of the candidates were strongly influenced by self-efficacy. Furthermore, self-efficacy had the smallest standard deviation showing that there was less variation within the candidates scores. Finally, the $t$-test was an important indicator on if there was a significant difference, and all 3 p-values were below .001. Therefore, the research suggest that Mathematical self-efficacy significantly has the largest impact on student's choice to pursue math education. This agrees with Wang's research (2013) that selfefficacy had the largest influence on students' choice to pursue STEM majors.

Specifically, two questions ( $8 \mathrm{a}$ and $8 \mathrm{~b}$ ) had a median and mode of 4 . The data suggest more than half of the candidates believe that their interest and skill in mathematics strongly influences their choice. This aligns with the social cognitive career theory belief that careers are selected based on our interests and our belief in our skills (Lent \& Brown, 2013). So, if we want more students to go into mathematics we need to build interest in mathematics and build student's belief in their mathematical skills. Personal motivation or personal belief in what someone is good at or enjoys guides 
behavior (Bandura, 1993). The third highest score came from their skill to solve problems. Based on the results of this study, the top three questions all come from mathematical self-efficacy, reinforcing the largest influence on a student's choice to pursue mathematics is mathematical self-efficacy.

There were a few surprising differences within categories. Within the mindset category, question 6 (How do you feel when making a mistake) had a lower mean than the other two questions. Furthermore, it was unusual that the mean was less than the median and mode. This indicates there were several candidates with score of a 1 . When broken down by gender, the mean for the females was 2.32 compared to 2.78 for the males. The research sample consisted of 35 females and 28 males and the mean difference between the genders for the other questions was 0.19 so most responses were very similar. However, the difference for this question on mindset was 0.46 . Math anxiety is more common in women than men (Beilock, Gunderson, Ramirez \& Levine, 2010; Peters, 2013) and the difference in the results could be connected to math anxiety. However, students with high math anxiety tend to avoid situations involving mathematics and are therefore less likely to pursue math related careers (Supekar, 2015; Beilock \& Willingham, 2014). This is an area that needs further research. Another surprising difference was the data suggests a good living had little to no influence (median $=2$, mean $=2.16$, mode $=1)$ while good benefits were of moderate to stronger influence $($ median $=$ 3 , mean $=3.11$, mode $=4$ ). This is a difference that could be explored in more depth with more research. 


\section{Limitations}

One limitation is the number of teacher candidates in the state of Missouri is not diverse in race or gender and so the sample was not diverse. Majority of teacher candidates are Caucasian and female (Estes, 2017). The survey did not ask what region of the state the candidates were from therefore, we do not know if the sample is diverse in the location of the state. Consequently, it may not accurately represent the whole population. Another limitation is some students interested in pursuing math education may have been kept out of college due to low entrance exams or financial strain. Therefore, this study is limited to those who qualify for the college. Finally, students often change their mind on what career to pursue, so there may be some teacher candidates who change their mind about math education before even having a chance to be surveyed.

\section{Implications for Practice and Contributions to Math Education}

Mathematical self-efficacy has the strongest influence on a student's choice to pursue a secondary mathematics education degree. There was a significant difference between self-efficacy and all the other influences. Therefore, building students' belief in their mathematical skills is the most important way to increase the number of future math teachers. This aligns with Bandura (1993) that personal belief in one's skill will guide their motivation, which will guide the classes they select and eventually the career they select. Furthermore, this study found that teacher influence was significantly larger than the other social influences. It is important for classroom teachers to be made aware of their influence over student's self-efficacy, mindset and future career choices. Administrators and directors of human resources in school districts can also increase the 
number of new secondary math teachers.

\section{Implications for Teachers}

To decrease the shortage of math teachers, current math teachers need to find ways to encourage more students to pursue math education. This research suggests that one way to do this is by increasing mathematical self-efficacy and growth mindset in the classroom. It is important to note that this study found that teachers have a statistically larger influence on a student's choice than their family. This significant difference is important because educators often leave the job of career advice up to the family. However, if teachers have the largest influence, then they need to be cognizant of ways they can make their influence positive. The students at most risk for implicit biased influence are the ones in the middle academically (Blanchard, \& Muller, 2014; Glock Krolak-Scwerdt, Klapproth, \& Bohmer, 2013; Nernberger, Nerb, Schmitz, Keller \& Sutterlin, 2016). Some possibilities for influence are teachers finding time to discuss students' future plans or becoming more aware of how their words and actions impact their students. Teachers that encourage students through affirmation of their academic abilities give students a sense of self-efficacy (Fries-Britt, Villlarreal, McAllister, \& Blacknall, 2012). Teachers need to use tactics to increase self-efficacy and growth mindsets in their classrooms.

\section{Self-efficacy}

Self-efficacy can be formed or destroyed in classrooms based on feedback given by the teacher and activities used for instruction. Bandura (1993) states that self-efficacy is not about the skills one has, but what one thinks they can do with the skills one possesses. Even when an activity is challenging, self-efficacy can be the factor that helps 
a student persevere (Pajares, 2003; Stevens, Olivarez, Lan, \& Tallent-Rummels, 2004).

Teachers that encourage students through affirmation of their academic abilities give students a sense of self-efficacy (Fries-Britt, Villlarreal, McAllister \& Blacknall, 2012). Research has found mathematics self-efficacy is increased when students experience academic success specific to math such as solving math problems (Campbell \& Hackett, 1986; Len, Brown, \& Hackett, 1994). Kirk (2018) lists four main ways of building selfefficacy. The most well recognized is mastery experiences where students feel they have completed a worthwhile task successfully (Kirk, 2018; Williams \& Williams, 2010). Observing a peer be successful is called vicarious experience and is believed to increase self-efficacy. Verbal persuasion is when a teacher uses positive feedback to motivate a student. Finally, emotional state or classroom climate can lower anxiety and therefore build self-efficacy in mathematics (Kirk, 2018; Peters, 2012).

Teachers have many tools they can use to build self-efficacy. The largest piece is that tasks need to be at the correct difficulty level (Margolis \& McCabe, 2006). If the task is too easy, it is boring and success is meaningless or even embarrassing. If the task is too difficult, students that do not feel capable of beginning and it will increase their low self-efficacy. Another thing to focus on is conceptual instead of the computational questions (Fenci \& Scheel, 2005). Conceptual tasks and questions are more likely to build a positive climate as the feedback is less right versus wrong and more descriptive about correcting connections in understanding. Other methods are allowing students to make their own choices within a task, use peer models to demonstrate problem solving, capitalize on students' interests when designing tasks, and give frequent and focused feedback that encourages students to keep trying (Margolis \& McCabe, 2006). 
Collaborative learning and inquiry based instruction have also been shown to improve self-efficacy (Fenci \& Scheel, 2005).

\section{Mindset}

Mindset is described as one's belief about learning and intelligence (Dweck, 2016). Students with a growth mindset view mistakes as a challenge and motivation to do work harder (Boaler, 2016). There are many techniques that can build growth mindsets in students. One small change that can be made is how praise is given. When students are praised for who they are as a person instead of what they have done, they get a fixed mindset about their abilities (Boaler, 2016). Another larger concept is in the power of mistakes. Research showed every time the brain experiences conflict between a correct response and an error there is increased electrical activity (brain growth) (Moser, Schroder, Heeter, Moran, \& Lee, 2011). Mistakes are when the brain grows the most because it is challenged and struggles (Boaler, 2016; Dweck, 2016). However, many classrooms are designed to give students work they will get correct, and teachers praise the students that do not make mistakes. When teachers flip this by encouraging students to be proud of their mistakes, they are in turn encouraging a growth mindset and brain growth (Boaler, 2016).

Interest in mathematics is connected to a growth mindset. "I strongly believe that if school math classrooms presented the true nature of the discipline, we would not have this nationwide dislike of math and widespread math underachievement" (Boaler, 2016, p. 22). The true nature of mathematics is the study of patterns and relationships, that relies on logic and creativity (Rutherford, 1990). Teachers often get caught up teaching curriculum that focuses on procedures and solving specific problems, that students begin 
to think that math is about getting the correct answer (Boaler, 2016). Wolfram (2010) suggests students should experience all four phases of math: posing a question, going from the real world to a mathematical model, performing the calculation, and then going back to the real world to verify the results. Boaler (2016) shares that rich mathematical tasks should include the " 5 C's curiosity, connection making, challenge, creativity, and collaboration" (p. 57).

\section{Implications for Administrators}

Administrators in school districts can encourage more students to pursue secondary math education degrees in many ways. One way is to provide professional development to current teachers on how to build self-efficacy and growth mindsets in their classrooms. There are several books and workshops offered around these topics. Another way is to hire teachers that contain a growth mindset so that they will positively influence their students. This can be done in the interview process by asking questions about why the candidate went into math education and how they perceive mistakes. Look for teachers that see mistakes as a chance to grow and learn (Boaler, 2016). A third thing is to give students opportunities to tutor their peers and younger students. This can be done through cadet teaching opportunities or class partners. Finally, when you have career speakers/career days do not forget to include teachers, coaches, school counselors and principals. On job shadow days, allow students to follow teachers and other staff. Overall school district administrators can encourage more students to pursue secondary math education.

\section{Implications for Human Resources}


Human resource representatives for school districts can make a large impact in encouraging students to pursue secondary mathematics education degrees. College Fairs are wonderful places to actively recruit new teachers with a growth mindset. Hiring teachers with a growth mindset will help develop the next generation of students with growth mindsets (Dweck, 2016). New teacher panels are also a place to showcase mindset, and passion for mathematics education. Moreover, the largest influence can be in a change of constructive feedback given throughout the district to faculty (Dweck, 2016). Growth mindset starts with everyone learning through mistakes and constructive feedback is a key part (Boaler 2016).

\section{Future Research}

The results from this study opened more questions for future research. This study was quantitative and so a qualitative study focused on the social and cognitive influences would fill in the gaps in literature. It should contain personal interviews and focus groups discussing what influenced their choice. Furthermore, it could contain teacher candidates that are disadvantaged minorities to help fill in the gap in the literature. Other questions also developed as the data were analyzed.

Is there a difference between males and females when it comes to growth mindset? Males had higher means than females, especially on the question about mistakes. Females report higher levels of math anxiety and lower levels of math selfconcept (Else-Quest, Minew, \& Higgins, 2013). High achieving girls are the most affected by the fixed mindset (Dweck, 2006). The high number of girls with a fixed mindset is one reason girls avoid careers in the STEM fields (Boaler, 2016). 
Is there a difference between the influence of earning a good living versus having good benefits on a students' choice to pursue the education profession? The data showed a mode of one (no influence) for a good living influencing their choice while good benefits had a mode of four (strong influence). Summers off and job flexibility could be positive influences to encourage students to pursue education (Allgretto, Corcoran, \& Mishel, 2004). However, the salary and working conditions are often the reason teachers leave the profession (Branch, 2001; Curtis, 2012; DeNisco, 2015).

What creates students' interest in mathematics? The last question of the survey was open ended, asking if there were any other influences. Two-thirds did not respond, but the ones that did gave a wide range of responses. "I really enjoyed math and problem solving growing up. I think the satisfaction of solving a difficult problem is another influential factor." Others mentioned things like observation, a teacher from their past, the movie Hidden Figures. Several students mentioned that tutoring influenced their choice. There seems a logical connection between self-efficacy, growth mindset, and tutoring. The personal stories of a qualitative study would give another level of insight into these influences. 


\section{REFERENCES}

Alika, H. (2012). Career choice in engineering: The influence of peers and parent's implication for counselling. College Student Journal, 46(3), 537-542.

Allegretto, S., Corcoran, S.P. \& Mishel, L. (2004). How does teacher pay compare?

Methodological challenges and answers. Retrieved from

www.epi.org/publication/books_teacher_pay

Ayotolah, A. Adedeji, T. (2009). The relationship between mathematics self-efficacy and achievement in mathematics. Procedia Social and Behavioral Sciences, 1, 953957.

Azar, F. S., \& Mahmoudi, L. (2014). Relationship between Mathematics, self-efficacy and students' performance in statistics: the meditational role of attitude toward Mathematics and Mathematics anxiety. Journal of Educational Sciences and Psychology, 4(1).

Bandura, A. (1993). Percieved self-efficacy in cognitive development and functioning. Educational Psychologis,. 28, 117-148.

Bandura, A. (2006). Toward a psychology of human agency. Perspectives on Psychological Science, 1, 164-180. doi:10.1111/j.1745-6916.2006.00011.

Bates, A. B., Latham, N., \& Kim, J. A. (2011). Linking preservice teachers' mathematics Self-Efficacy and mathematics teaching efficacy to their mathematical performance. School Science and Mathematics, 111(7), 325-333.

Beilock, S. L., Gunderson, E. A., Ramirez, G., \& Levine, S. C. (2010). Female teachers' 
math anxiety affects girls' math achievement. Proceedings of the National Academy of Sciences, 107(5), 1860-1863.

Beilock, S. L., \& Willingham, D. T. (2014). Math Anxiety: Can Teachers Help Students Reduce It? Ask the Cognitive Scientist. American educator, 38(2), 28.

Blanchard, S., Muller, C. (2014). Gatekeepers of the American dream: How teachers' perceptions shape the academic outcomes of immigrant and language-minority students. Social Science Research, 51, 262-275.

Boaler, J. (2016). Mathematical mindsets: Unleashing students' potential through creative math, inspiring messages and innovative teaching. San Francisco, CA: Jossey-Bass.

Branch, A. J. (2001). Increasing the numbers of teachers of color in K-12 public schools. The Educational Forum, 65, 254-261.

Brown, S.D. Lent, R.W. (2006). Preparing adolescents to make career decisions: A social cognitive perspective. Adolescence and education, 5, 201-223.

Campbell, N. K., Hackett, G. (1986). The effects of mathematics self-efficacy expectations on math self-efficacy and task interest. Journal of Vocational Behavior, 28, 149-162.

Creswell, J. W. (2014) Research design: Qualitative, quantitative, and mixed methods approaches $\left(4^{\text {th }}\right.$ ed $)$. Thousand Oaks, CA: Sage.

Curtis, C. (2012). Why do they choose to teach--and why do they leave? A study of middle school and high school mathematics teachers. Education, 132(4), 779-789.

DeNisco, A. (2015). Teacher shortage at 'crisis' levels: Salaries remain low, public school funding is down and some states have eliminated tenure protections. 
Retrieved from (http://www.districtadministration.com/article/teacher-shortage'crisis'-levels.)

Duckworth, A., \& Quinn, P. (2009). Development and validation of the short grit scale. Journal of Personality Assessment, 91(2), 166-174.

Dweck, C.S. (2016). The remarkable reach of growth mindsets. Scientific American Mind, doi:15552284, 27(1).

Eesley, C., \& Wang, Y. (2017). Social influence in career choice: Evidence from a randomized field experiment on entrepreneurial mentorship. Research Policy, 46(3), 636-650.

Else-Quest, N.M., Mineo, C. C., \& Higgins, A. (2013). Math and science attitudes and achievement at the intersection of gender and ethnicity. Psychology of Women Quarterly, 37(3), 293-309.

Estes, J. S. (2017). Preparing teacher candidates for diverse classrooms: The role of teacher preparation programs. In J. Keengwe (Ed.) Handbook of Research on Promoting Cross-Cultural Competence and Social Justice in Teacher Education (pp. 52-75). Hershey, PA: IGI Global. Doi:10.4018/978-1-5225-0897-7.ch003

Fenci, H., \& Scheel, K. (2005) Research and teaching: Engaging students—an examination of the effects of teaching strategies on self-efficacy and course in a nonmajors physics course. Journal of college science teaching, 35(1), 20-24.

Field, A. (2013). Discovering statistics using IBM SPSS statistics. Thousand Oaks, CA: Sage.

Fouad, A. N. Santana, M.C. (2017). SCCT and underrepresented populations in stem fields: Moving the needle. Journal of Career Assessment 25(1) 24-39. 
Fries-Britt, S., Villarreal, R., McAllister, D. E., \& Blacknall, T. (2012). K-12 teachers: Important bridges to success for African-American students. Journal of Women and Minorities in Science and Engineering, 18(4), 359-375. doi:10.1615/JWomenMinorScienEng.2013004406

Glock, S., Krolak-Scwerdt, S., Klapproth, F., and Bohmer, M. (2013). Beyond judgment bias: How students' ethnicity and academic profile consistency influences teachers' tracking judgment. Social Psychology Education, 16, 555-573.

Guerra, A. L., \& Braungart-Rieker, J. M. (1999). Predicting career indecision in college students: The roles of identity formation and parental relationship factors. The career development quarterly, 47(3), 255-266.

Hackett, G. Betz, N.E. (1989). An exploration of the mathematics selfefficacy/mathematics performance correspondence. Journal for Research in Mathematics Education 20 (3) 261-273.

Hsiao, J., \& Nova, S. P. D. C. C. (2016). Generational Approach to Factors Influencing Career Choice in Accounting. Revista Contabilidade \& Finanças, 27(72), 393407.

Hrabowski III, F. A. (2014). Institutional change in higher education: Innovation and collaboration, Peabody Journal of Education, 89(3), 291-304. doi: 10.1080/0161956X.2014.913440

Ingersoll, R. M., \& Perda, D. (2010). Is the supply of mathematics and science teachers sufficient? American Educational Research Journal, 47(3), 563-594.

Kirk, K. (2018) Self-efficacy: Helping students believe in themselves. Retrieved from https://serc.carleton.edu/NAGTWorkshops/affective/efficacy.html 
Labaree, D. F. (2008). An uneasy relationship: the history of teacher education in the university. In Cochran-Smith, S. Feiman-Nemser, \& J. McIntyre (with K.

Demers) (Eds), Handbook of Research on teacher education ( $3^{\text {rd }}$ ed., pp 290-306). New York: Routledge.

Lent, R. W., Brown, S.D. Hackett, G. (1994). Toward a unifying social cognitive theory of career and academic interest, choice, and performance. Journal of Vocational Behavior. 45, 79-122.

Lent, R. W., Brown, S.D. (2013). Social cognitive model of career self-management: Toward a unifying view of adaptive career behavior across the life span. Journal of Counseling Psychology, 60, 557-568.

Margolis, H., \& McCabe, P. (2006). Improving self-efficacy and motivation: What to do, what to say. Intervention in School and Clinic, 41(4), 218-227.

McCarthy, J. (2011). Why men are better than women at math. The Psychology of Wellbeing Retrieved from http://psychologyofwellbeing.com/201110/men-are$\underline{\text { better-at-math.htm }}$

Merriam, S. B., \& Tisdell, E. J. (2016). Qualitative research: a guide to design and implementation (4th ed.). San Francisco, CA: Jossey-Bass.

Moakler, M. W., Kim, M. M. (2014). College major choice in stem: Revisiting confidence and demographic factors. The Career Development Quarterly, 62, 128-142.

Moser, J.,Schroder, H.S., Heeter, C., Moran, T.P., \&Lee, Y. H. (2011). Mind your errors: Evidence for a neural mechanism linking growth mindset to adaptive post error adjustments. Psychological Science,22, 1484-1489. 
National Academy of Sciences. (2007). Is America falling off the flat earth?

Washington, DC: National Academies Press.

National Center for Educational Statistics (NCES) retrieved from

https://nces.ed.gov/programs/coe/indicator_tva.asp

National Science Board. (2005). 2020 vision for the National Science Foundation.

Arlington, VA: National Science Foundation.

National Education Association. (1999). Teacher quality. Legislative action center Retrieved from http://www.nea.org/lac/papers/quality.html

Nurnberger, M., Nerb, J., Schmitz, F., Keller, J. \& Sutterlin, S. (2016). Implicit gender stereotypes and essentialist beliefs predict preservice teachers' tracking recommendations. Journal of Experimental Education, 84(1), 152-174

Ostroff, C. (2017). Schools throughout the country are grappling with teacher shortage, data show. CNN: Health Retrieved from http://www.cnn.com/2017/08/21/health/teacher-shortage-data-trnd/index.html.

Pajares, F. (2003). Self-efficacy beliefs, motivation, and achievement in writing: A review of the literature. Reading \&Writing Quarterly, 19(2), 139-158.

Pereira, F. N., \& Garcia, A. (2007). Friendship and professional choice: influence or cooperation?. Brazilian Journal of Professional Guidance, 8(1), 71-86.

Peters, M. L. (2013). Examining the relationships among classroom climate, selfefficacy, and achievement in undergraduate mathematics: A multi-level analysis. International Journal of Science and Mathematics Education, 1-22.

Rutherford, F. J. (1990). Science for all Americans. American Association for the Advancement of Science 
Ryan, M. (2016). Districts tackle teacher shortages with higher salaries, mentoring. District Administration Retrieved from https://www.districtadministration.com/articles/districts-tackle-teacher-shortages

Stevens, T., Olivarez, A., Lan, W. Y., \& Tallent-Runnels, M. K. (2004). Role of mathematics self-efficacy and motivation in mathematics performance across ethnicity. The Journal of Educational Research, 97(4), 208-222

Supekar, K., Iuculano, T., Chen, L., \& Menon, V. (2015). Remediation of childhood math anxiety and associated neural circuits through cognitive tutoring. The Journal of Neuroscience, 35(36), 12574-12583.

Sutcher, L., Darling-Hammond, L., Carver-Thomas, D. (2016). A coming crisis in teaching? Teacher supply, demand and shortages in the U.S. Learning Policy Institute, Research. Action. Impact. Retrieved from (http://www/learningpolicyinstitute.org/products/coming-crisis-teaching. )

Wang, X. (2013). Why students choose STEM majors: Motivation, high school learning, and postsecondary context of support. American Educational Research Journal, 50(5), 1081-1121.

Wheelan, C. (2013). Naked statistics: stripping the dread from the data. WW Norton \& Company, New York.

Williams, T., \& Williams, K. (2010). Self-efficacy and performance in mathematics: Reciprocal determinism in 33 nations. Journal of educational Psychology, 102(2), 453.

Wolfram, C. (2010). Teaching kids real math with computers. TED talks. Retrieved from https://www.ted.com/talks/conrad wolfram teaching kids real math with comp uters 


\section{SECTION 6: SCHOLARLY PRACTITIONER REFLECTION}

This dissertation has influenced my practice as an educational leader and the process has changed me as a scholar. Over the past few years, my understanding of leadership and scholarship has drastically changed due to the course work and reading in this educational leadership cohort program. I have always known that teachers influence their students, but now I realize their influence affects their career choice as well as their learning. In this section, the dissertation results and process will be evaluated on how they influenced my practice as an educational leader and how they influenced scholarship.

\section{Dissertation Influencing Practice as an Educational Leader}

Education is at the heart of my leadership, as it is the primary goal for all activities and lessons. Adult learning theory applies to my leadership as most of the students I work with are 17 and 18 years old. They want to be treated as adults, are starting to feel the pressures of time management, and are beginning to question their adult leaders. Relationships built upon mutual respect are an important building block for a learning atmosphere (Merriam \& Bierema, 2014). They are not going to listen and learn from me if they do not value what I am saying or believe that I do not care about them. High school students often have a great deal of math anxiety and so a great deal of my time is spent on emotional support. This dissertation has taught me that I need to focus on my students' self-efficacy and growth mindset also. My research revealed the three largest influences on a student's choice to pursue math education are content selfefficacy, growth mindset, and teacher encouragement. Therefore, it is important for 
teachers (me specifically) to find ways to positively influence students toward mathematics.

\section{Changes in practice related to self-efficacy}

Self-efficacy can be formed or destroyed in classrooms based on feedback given by the teacher and activities used for instruction. Research has found mathematics selfefficacy is increased when students experience academic success specific to math such as solving math problems (Campbell \& Hackett, 1986; Len, Brown, \& Hackett, 1994). Kirk (2018) lists four main ways of building self-efficacy. The most well recognized is mastery experiences where students feel they have completed a worthwhile task successfully (Kirk, 2018; Williams \& Williams, 2010). Observing a peer be successful is called vicarious experience and is believed to increase self-efficacy. Verbal persuasion is when a teacher uses positive feedback to motivate a student. Finally, emotional state or classroom climate can lower anxiety and therefore build self-efficacy in mathematics (Kirk, 2018; Peters, 2012).

Through this research, I learned many tools I can use to build self-efficacy. The largest piece is that tasks need to be at the correct difficulty level (Margolis \& McCabe, 2006). If I assign tasks that are too easy, it is boring and success is meaningless or even embarrassing to my students. If the tasks are too difficult, my students do not feel capable of beginning and this will exascerbate their low self-efficacy. Another thing I need to focus on is conceptual questions instead of computational questions (Fenci \& Scheel, 2005). Conceptual tasks and questions are more likely to build a positive climate as the feedback is less right versus wrong and more descriptive about correcting connections in understanding. Other methods are allowing students to make their own 
choices within a task, use peer models to demonstrate problem solving, capitalize on students' interests when designing tasks, and give frequent and focused feedback that encourages students to keep trying (Margolis \& McCabe, 2006). Collaborative learning and inquiry based instruction have also been shown to improve self-efficacy (Fenci \& Scheel, 2005).

\section{Changes in practice related to growth mindset.}

Mindset is described as one's belief about learning and intelligence (Dweck, 2016). Students with a growth mindset view mistakes as a challenge and motivation to work harder (Boaler, 2016). There are many techniques that can build growth mindsets in students. One small change I can make is how I give praise. When I praise students for who they are as a person instead of what they have done, they get a fixed mindset about their abilities (Boaler, 2016). For example, I need to compliment their hardwork, their perseverance, or their willingness to share their ideas. Another change I have made is in my view of mistakes. Research showed that every time the brain experiences conflict between a correct response and an error there is increased electrical activity (brain growth) (Moser, Schroder, Heeter, Moran, \& Lee, 2011). Mistakes are when the brain grows the most because it is challenged and struggles (Boaler, 2016; Dweck, 2016). However, my classroom used to be designed to give students work that they will get correct and I rewarded the students that did not make mistakes. So, I need to be encouraging students to be proud of their mistakes, I need to give them more opportunities to try challenging problems in a safe environment where there is no pressure to be right. 
"I strongly believe that if school math classrooms presented the true nature of the discipline, we would not have this nationwide dislike of math and widespread math underachievement" (Boaler, 2016, p. 22). The true nature of mathematics is the study of patterns and relationships, that relies on logic and creativity (Rutherford, 1990). I used to get caught up teaching curriculum that focuses on procedures and solving specific problems. A majority of my students probably thought math was about getting the correct answer. Wolfram (2010) suggests that students should experience all four phases of math: posing a question, going from the real world to a mathematical model, performing the calculation, and then going back to the real world to verify the results. Boaler (2016) shares that rich mathematical tasks should include the " 5 C's curiosity, connection making, challenge, creativity and collaboration" (p. 57). I am currently working on curriculum for a course that will be fully about exploration, seeking patterns and the true uses of mathematics in the world. Students will be able to choose from different topics to explore and most importantly it will be about the true nature of mathematics.

\section{Dissertation Process Influencing Scholarship}

Through the research for the literature review and the discussions with mathematics professors, I found there was a need to find out what can be done to get more students to pursue math education. However, without research it was just my opinion compared to another's opinion, full of bias from my own experiences. The quantitative survey given to students across the state reaffirmed some of my beliefs, but 
also changed my perspective on others. Now it will influence scholarship as I work to publish and present the finding.

\section{Researcher as Learner}

"Human beings would not have survived without learning" (Merriam \& Bierema, 2014, p. 24). Learner was one of my strengths when I took the strengths quest questionnaire. This seemed logical, because as a teacher, I value life-time learning. Professionally, I want to learn to be a better instructor and leader. I attend professional development through my school, through our district, and at national conferences. I also read articles from teaching magazines and collaborate with other teachers to get new ideas. Nonaka (1994) discusses the importance of knowledge in our society is increasing and so our level of learning should also be increasing. Therefore, the three years of course work and research were filled with learning as I soaked in everything I could. Moreover, this graduate course has transformed my thinking as Merriam and Bierema (2014) state, it moved me from being the victim of my situation and passively watching the world, to realizing I can make a difference in the world.

Specifically, through the dissertation I have learned some ways that have influenced students to go into math education. One surprising realization was teachers have more influence then family or peers on a student's choice. I have always assumed that parents would be the key influence on a child's career choice and this research stated the opposite. Due to this new information, I now know I need to take time to discuss career choices with my students. Furthermore, the data showed that self-efficacy and growth mindset had more influence than outcome expectations. Therefore, I learned again teachers have the most influence as they are the ones selecting the tasks that help 
build or destroy these two factors. My next step was to research how to build those skills. Now I hope to increase the number of students pursuing math by sharing my findings with others and implementing new tactics in my own classroom.

\section{Researcher as Scholar}

One definition of leadership is "a process whereby an individual influences a group of individuals to achieve a common goal" (Northouse, 2011, p. 3). As a teacher, I enjoy sharing what I have learned with others. In the past, this meant sharing knowledge with my students and the fellow teachers in my building. However, through this coursework and the dissertation process, I am now planning on sharing what I have learned on a larger scale in a larger leadership role. I plan to present at a district wide professional development, and at a larger national conference for math teachers.

Furthermore, I plan to try to publish my results because they can make a large difference in the number of students entering into math education preparation programs.

Scholarship is not just adding publications, but it is filling in gaps in knowledge. There was a gap in the knowledge on what was influencing students to pursue math education. This research fills that gap with data telling us self-efficacy is the largest influence on the career choice and of the social influences, teachers have more influence than family. This supports the Social Cognitive Career Theory that emphasizes students select careers based on their interests; and those interest are based on self-efficacy (Lent et al, 1994). Now the next step can be taken to learn how one can increase self-efficacy and teacher influence. 


\section{Conclusion}

"If you continue to do things the way you've been doing them you'll continue to get the results you've been getting" as stated anonymously (Gill, 2010, p. 1). There has been a shortage of math teachers across the nation for several years and we need to start changing what we are doing if we want to see a change in this shortage. Based on the results of this study, teachers have several things they can do. They can use tasks and instructional strategies to build self-efficacy and growth mindsets. The data also indicates the encouraging words of a teacher have a large influence on a student's career choices. 


\section{REFERENCES}

Aaltonen, S. (2016). 'My mother thought upper secondary school was OK, but then my sibling said no'-Young People's Perceptions of the Involvement of Parents and Siblings in their Future Choices. Sociological Research Online, 21(1), 5.

Alika, H. (2012). Career choice in engineering: The influence of peers and parent's implication for counselling. College Student Journal, 46(3), 537-542.

Allegretto, S., Corcoran, S.P. \& Mishel, L. (2004). How does teacher pay compare? Methodological challenges and answers. Retrieved from www.epi.org/publication/books_teacher_pay

American Association for the Advancement of Science (1959) Recommendations for the preparation of high school teachers of science and mathematics-1959. School Science and Mathematics, 59, 281-89.

Aspinwall, L.G. (1998). Rethinking the role of positive affect in self-regulation. Motivation and Emotion, 22(1), 1-32.

Ayotolah, A. Adedeji, T. (2009). The relationship between mathematics self-efficacy and achievement in mathematics. Procedia Social and Behavioral Sciences, 1, 953957.

Azar, F. S., \& Mahmoudi, L. (2014). Relationship between Mathematics, self-efficacy and students' performance in statistics: the meditational role of attitude toward Mathematics and Mathematics anxiety. Journal of Educational Sciences and Psychology, 4(1).

Bahnik, S., \& Vranka, M. A. (2017). Growth mindset is not associated with scholastic 
aptitude in a large sample of university applicants. Personality and Individual Differences, 117, 139-143.

Ball, C., Huang, K., Cotton, S. R., Rikard, R. V., \& Coleman, L. O. (2016). Invaluable value: An expectancy-value theory analysis of youths' academic motivations and intentions. Information, Communication \& Society, 19(5) 618-638.

Bandura, A. (1993). Perceived self-efficacy in cognitive development and functioning. Educational Psychologist. 28, 117-148.

Bandura, A. (2006). Toward a psychology of human agency. Perspectives on Psychological Science, 1, 164-180. doi:10.1111/j.1745-6916.2006.00011.

Bates, A. B., Latham, N., \& Kim, J. A. (2011). Linking preservice teachers' mathematics Self-Efficacy and mathematics teaching efficacy to their mathematical performance. School Science and Mathematics, 111(7), 325-333.

Beilock, S. L., Gunderson, E. A., Ramirez, G., \& Levine, S. C. (2010). Female teachers' math anxiety affects girls' math achievement. Proceedings of the National Academy of Sciences, 107(5), 1860-1863.

Beilock, S. L., \& Willingham, D. T. (2014). Math Anxiety: Can Teachers Help Students Reduce It? Ask the Cognitive Scientist. American educator, 38(2), 28.

Blanchard, S., Muller, C. (2014). Gatekeepers of the American dream: How teachers' perceptions shape the academic outcomes of immigrant and language-minority students. Social Science Research, 51, 262-275.

Boaler, J. (2016). Mathematical mindsets: Unleashing students' potential through creative math, inspiring messages and innovative teaching. San Francisco, CA: Jossey-Bass. 
Bobo, L. (2001). Racial attitudes and relations at the close of the twentieth century. In N. J. Smelser, W.J. Wilson, \& F. Mitchell (Eds.), America becoming: Racial trends and heir consequences (pp. 264-301). Washington, D.C. National Academy Press.

Branch, A. J. (2001). Increasing the numbers of teachers of color in K-12 public schools. The Educational Forum, 65, 254-261.

Brock, J. (2012, December 26). Missouri raises the bar on teacher preparation. St. Louis Post Dispatch. Retrieved from https://dese.mo.gov/educator-quality/equitableaccess-excellent-education

Brown, S.D. Lent, R.W. (2006). Preparing adolescents to make career decisions: A social cognitive perspective. Adolescence and education, 5, 201-223.

Byars-Winston, A., Estrada, Y., Howard, C., Davis, D., \& Zalapa, J. (2010). Influence of social cognitive and ethnic variables on academic goals of underrepresented students in science and engineering: a multiple-groups analysis. Journal of counseling psychology, 57(2), 205.

Campbell, N. K., Hackett, G. (1986). The effects of mathematics self-efficacy expectations on math self-efficacy and task interest. Journal of Vocational Behavior, 28, 149-162.

Commission on the Training and Utilization of Advanced Students in Mathematics. (1935) Report on the training of teacher of mathematics. American Mathematical Monthly. 42(5) 263-277.

Committee on the Undergraduate Program in Mathematics, Panel on Teacher Training. (1961) Recommendations for the training of teachers of mathematics. Berkeley, CA: Auther. revised Edition 1966. 
Committee on the Undergraduate Program in Mathematics, Panel on Teacher Training. (1983) Recommendations for the mathematical preparation of teachers. Washington, DC: Mathematical Association of America.

Cowan, N., Morey, C. C., Chen, Z., Gilchrist, A. L., Saults, J. S. (2008). Theory and measurement of working memory capacity limits. The Psychology of Learning and Motivation, 49 49-104. DOI 10.1016/S0079-7421(08)00002-9.

Creswell, J. W. (2014) Research design: Qualitative, quantitative, and mixed methods approaches $\left(4^{\text {th }}\right.$ ed $)$. Thousand Oaks, CA: Sage.

Curtis, C. (2012). Why do they choose to teach--and why do they leave? A study of middle school and high school mathematics teachers. Education, 132(4), 779-789.

Dee, T. S. (2004). Teachers, race, and student achievement in a randomized experiment. The review of economics and Statistics, 86(1), 195-210.

DeNisco, A. (2015). Teacher shortage at 'crisis' levels: Salaries remain low, public school funding is down and some states have eliminated tenure protections. Retrieved from (http://www.districtadministration.com/article/teacher-shortage‘crisis'-levels.)

Diemer, M. A., Marchand, A. D., McKellar, S. E. \& Malanchuk, O. (2016). Promotive and corrosive factors in African American students' math beliefs and achievement. $J$ Youth Adolescence doi:10.1007/s10964-01600439-9

Duckworth, A., \&Quinn, P. (2009). Development and validation of the short gritscale. Journal of Personality Assessment, 91(2), 166-174.

Duncan, A. (2010). Teacher preparation: Reforming the uncertain profession. The Education Digest, 75(5), 13. 
Dweck, C.S. (2016). The remarkable reach of growth mindsets. Scientific American Mind, doi:15552284, 27(1).

Dweck, C.S. (2006). Is math a gift? Beliefs that put females at risk. In W.W.S.J.Cesi(Ed.), Why aren't more women in science? Top researchers debate the evidence.Washington, DC: American Psychological Association. Education in Missouri (2017) Retrieved from https://en.wikipedia.org/wiki/Education in Missouri

Eesley, C., \& Wang, Y. (2017). Social influence in career choice: Evidence from a randomized field experiment on entrepreneurial mentorship. Research Policy, 46(3), 636-650.

Else-Quest, N.M., Mineo, C. C., \& Higgins, A. (2013). Math and science attitudes and achievement at the intersection of gender and ethnicity. Psychology of Women Quarterly, 37(3), 293-309.

Eglash, R., gilbert, J.E., Taylor, V. \& Grier, S. R. (2013). Culturally responsive computing in urban after-school contexts: Two approaches. Urban Education, 48(5), 629-656.

Estes, J. S. (2017). Preparing teacher candidates for diverse classrooms: The role of teacher preparation programs. In J. Keengwe (Ed.) Handbook of Research on Promoting Cross-Cultural Competence and Social Justice in Teacher Education (pp. 52-75). Hershey, PA: IGI Global. Doi:10.4018/978-1-5225-0897-7.ch003

Fabian, E. S. (2000). Social cognitive theory of careers and individuals with serious mental health disorders: Implications for psychiatric rehabilitation programs. Psychiatric Rehabilitation Journal, 23(3), 262. 
Feiman-Nemser, S. (1990). Teacher preparation: Structural and conceptual alternatives. Handbook of research in teacher education. New York: Macmillian.

Fenci, H., \& Scheel, K. (2005) Research and teaching: Engaging students—an examination of the effects of teaching strategies on self-efficacy and course in a nonmajors physics course. Journal of college science teaching, 35(1), 20-24.

Ferrini-Mundy, J. \&Findell, B. (2010). The mathematical education of prospective teacher of secondary school mathematics: Old assumptions, new challenges. Committee on the Undergraduate Program in Mathematics (Eds.), CUPM discussion papers about mathematics and the mathematical sciences, 31-41.

Fetler, M. (1999). High school staff characteristics and mathematics test results. education policy analysis archives, 7, 9.

Field, A. (2013). Discovering statistics using IBM SPSS statistics. Thousand Oaks, CA: Sage.

Fink, A. (2017). How to conduct surveys: A step-by-step guide (6th ed). Thousand Oaks, CA: Sage.

Fouad, A. N. Santana, M.C. (2017). SCCT and underrepresented populations in stem fields: Moving the needle. Journal of Career Assessment 25(1) 24-39.

French, J. R. P., \& Raven, B. (2005). The basis of social power. In J. M. Shafritz, J. S. Ott, \& Y. S. Jang (Eds.), Classics of organizational theory (pp. 311-320). Belmont, CA: Wadsworth. (Reprinted from Studies in social power, ed. D. P. Cartwright, pp. 150-167, 1959, Ann Arbor, MI: Institute of Social Research, University of Michigan).

Fries-Britt, S., Villarreal, R., McAllister, D. E., \& Blacknall, T. (2012). K-12 teachers: 
Important bridges to success for african-american students. Journal of Women and Minorities in Science and Engineering, 18(4), 359-375.

doi:10.1615/JWomenMinorScienEng.2013004406

Fryer, R. G., Jr., \& Torelli, P. (2010). An empirical analysis of "acting White." Journal of Public Econoics, 94, 380-396. Doi:10.1016/j.jpubeco.2009.10.011

Glock, S., Krolak-Scwerdt, S., Klapproth, F., and Bohmer, M. (2013). Beyond judgment bias: How students' ethnicity and academic profile consistency influences teachers' tracking judgment. Social Psychology Education, 16, 555-573.

Graham, K. J., Li, Y., \& Buck, J. C. (2000) Characteristics of mathematics teacher preparation programs in the United States: An exploratory study. The Mathematics Educator, 5, 5-31.

Guerra, A. L., \& Braungart-Rieker, J. M. (1999). Predicting career indecision in college students: The roles of identity formation and parental relationship factors. The career development quarterly, 47(3), 255-266.

Hackett, G. Betz, N.E. (1989). An exploration of the mathematics selfefficacy/mathematics performance correspondence. Journal for Research in Mathematics Education 20 (3) 261-273.

Harackiewicz, J. M., Canning, E. A., Tibbetts, Y., Priniski, S.J., \& Hyde, J. S. (2015). Closing achievement gaps with a utility-value intervention: Disentangling race and social class. Journal of Personality and Social Psychology. Advance online publication. http://dx.doi.org/10.1037/pspp0000075

Harper, N. W., \& Daane, C. J. (1998). Causes and reduction of math anxiety in preservice elementary teachers. Action in Teacher Education, 19(4), 29-38. 
Hsiao, J., \& Nova, S. P. D. C. C. (2016). Generational Approach to Factors Influencing Career Choice in Accounting. Revista Contabilidade \& Finanças, 27(72), 393407.

Hrabowski III, F. A. (2014). Institutional change in higher education: Innovation and collaboration, Peabody Journal of Education, 89(3), 291-304. doi: 10.1080/0161956X.2014.913440

Ingersoll, R. M., \& Perda, D. (2010). Is the supply of mathematics and science teachers sufficient? American Educational Research Journal, 47(3), 563-594.

International Commission on the Teaching of Mathematics. (1911) The training of teachers of elementary and secondary mathematics. Committee no. 5. United States Bureau of Education Bulletin 1911, no 12. Washington DC: Government Printing Office.

Irwin, S. \& Elley, S. (2012). Parents hopes and expectations for their children's future occupation. The Sociological Review 61(1), 111-130.

Jansson, N. (2013). Organizational change as practice: a critical analysis. Journal of Organizational Change Management, 26(6), 1003-1019.

Jussim, L., Harber, K.D. (2005). Teacher expectations and self-fulfilling prophecies: Knowns and unknowns, resolved and unresolved controversies. Personality and Social Psychology Review, 9(2), 131-155.

Kettley, N. C., \& Whitehead, J. M. (2012). Remapping the "landscape of choice": patterns of social class convergence in the psycho-social factors shaping the higher education choice process. Educational Review, 64(4), 493-510.

King, R.B., McInerney, D.M., Fraide, A. G., Villarosa, J. B. (2015). Positive affect 
catalyzes academic engagement: Cross-sectional, longitudinal, and experimental evidence. Learning and Individual Differences, 39, 64-72.

Kirk, K. (2018) Self-efficacy: Helping students believe in themselves. Retrieved from https://serc.carleton.edu/NAGTWorkshops/affective/efficacy.html

Klein, D. (2003). A brief history of American K-12 mathematics education in the $20^{\text {th }}$ century. Mathematical Cognition, 175-259.

Labaree, D. F. (2008). An uneasy relationship: the history of teacher education in the university. In Cochran-Smith, S. Feiman-Nemser, \& J. McIntyre (with K. Demers) (Eds), Handbook of Research on teacher education ( $3^{\text {rd }}$ ed., pp 290-306). New York: Routledge.

Lent, R. W., Brown, S.D., \& Gore Jr, P. A. (1997). Discriminant and predictive validity of academic self-concept, academic self-efficacy and mathematics-specific selfefficacy. Journal of Counseling Psychology, 44(3), 307.

Lent, R. W., Brown, S.D. Hackett, G. (1994). Toward a unifying social cognitive theory of career and academic interest, choice, and performance. Journal of Vocational Behavior. 45, 79-122.

Lent, R. W., Brown, S.D. (2013). Social cognitive model of career self-management: Toward a unifying view of adaptive career behavior across the life span. Journal of Counseling Psychology, 60, 557-568.

Lent, R. W., Brown, S. D., Talleyrand, R., McPartland, E. B., Davis, T., Chopra, S. B., \& Chai, C. M. (2002). Career choice barriers, supports, and coping strategies: College students' experiences. Journal of Vocational Behavior, 60(1), 61-72.

Leslie, S.J., Cimpian, A., Meyer, M., \& Freeland, E. (2015). Expectations of brilliance 
underlie gender distributions across academic disciplines. Science,347 (6219), $262-265$.

Levi, D. (2015) Group dynamics for teams. Thousand Oaks, CA: Sage.

Margolis, H., \& McCabe, P. (2006). Improving self-efficacy and motivation: What to do, what to say. Intervention in School and Clinic, 41(4), 218-227.

Math Teacher Education (2017). Math Teacher Edu.org. Retrieved from (http://www.mathteacheredu.org/)

McCarthy, J. (2011). Why men are better than women at math. The Psychology of Wellbeing Retrieved from http://psychologyofwellbeing.com/201110/men-arebetter-at-math.htm

McKown, C., \& Weinstein, R. S. (2008). Teacher expectations, classroom context, and the achievement gap. Journal of school psychology, 46(3), 235-261.

Merriam, S. B., \& Bierema, L. L. (2014). Adult learning: Linking theory and practice. San Francisco: Jossey-Bass.

Merriam, S. B., \& Tisdell, E. J. (2016). Qualitative research: a guide to design and implementation (4th ed.). San Francisco, CA: Jossey-Bass.

Missouri Department of Elementary and Secondary Education (MDESE) October 5, 2017, retrieved from https://dese.mo.gov/educator-quality/equitable-accessexcellent-education

Missouri Department of Higher Education (MDHE) June $1^{\text {st }}$ 2017. Retrieved from http://dhe.mo.gov/public-and-independent-colleges.php

Moakler, M. W., Kim, M. M. (2014). College major choice in stem: Revisiting confidence and demographic factors. The Career Development Quarterly, 62, 
128-142.

Morrow, S. L., Gore Jr, P. A., \& Campbell, B. W. (1996). The application of a sociocognitive framework to the career development of lesbian women and gay men. Journal of Vocational Behavior, 48(2), 136-148.

Moser, J.,Schroder, H.S., Heeter, C., Moran, T.P., \&Lee, Y. H. (2011). Mind your errors: Evidence for a neural mechanism linking growth mindset to adaptive post error adjustments. Psychological Science,22, 1484-1489.

National Academy of Sciences. (2007). Is America falling off the flat earth?

Washington, DC: National Academies Press.

National Center for Educational Statistics (NCES) retrieved from $\underline{\text { https://nces.ed.gov/programs/coe/indicator tva.asp }}$

National Council of Teachers of Mathematics, Secondary Curriculum Committee. (1959).

The secondary mathematics curriculum. Mathematics Teacher, 52, 389-417.

National Council of Teachers of Mathematics. (1980). An agenda for action:Recommendations for school mathematics of the 1980's. Reston, VA:NCTM.

National Education Association. (1999). Teacher quality. Legislative action center Retrieved from http://www.nea.org/lac/papers/quality.html

National Science Board. (2005). 2020 vision for the National Science Foundation. Arlington, VA: National Science Foundation.

National Science Foundation, National Center for Science and Engineering Statistics. 
(2015). Women, minorities and persons with disabilities in science and engineering: 2015 (Special Report NSF 15-311). Arlingtion, VA. Retrieved from http://www.nsf.gov/statistics /wmpd/

National Science Board. (2005). 2020 vision for the National Science Foundation. Arlington, VA: National Science Foundation.

Nonaka, I. (1994). A dynamic theory of organizational knowledge creation. Organization Science, 5(1), 14-37.

Northouse, P.G. (2011). Leadership: Theory and practice (5th ed.). Thousand Oaks, CA: Sage Publications.

Nurnberger, M., Nerb, J., Schmitz, F., Keller, J. \& Sutterlin, S. (2016). Implicit gender stereotypes and essentialist beliefs predict preservice teachers' tracking recommendations. Journal of Experimental Education, 84(1), 152-174

Ostroff, C. (2017). Schools throughout the country are grappling with teacher shortage, data show. CNN: Health Retrieved from http://www.cnn.com/2017/08/21/health/teacher-shortage-data-trnd/index.html.

Pajares, F. (2003). Self-efficacy beliefs, motivation, and achievement in writing: A review of the literature. Reading \&Writing Quarterly, 19(2), 139-158.

Payne, R. K. (2005) A framework for understanding poverty.

Pereira, F. N., \& Garcia, A. (2007). Friendship and professional choice: influence or cooperation?. Brazilian Journal of Professional Guidance, 8(1), 71-86.

Peters, M. L. (2013). Examining the relationships among classroom climate, selfefficacy, and achievement in undergraduate mathematics: A multi-level analysis. International Journal of Science and Mathematics Education, 1-22. 
Rattan, A., Good, C., \& Dweck, C. S. (2012). "It's ok-Not everyone can be good at math": Instructors with an entity theory comfort (and demotivate) students. Journal of Experimental Social Psychology, 48(3), 731-737.

Reay, D., Davies, J., David, M., \& Ball, S. J. (2001). Choices of degree or degrees of choice? Class, race, and the higher education choice process. Sociology, 35(4), 855-874.

Rosenthal, R., Jacobson, L. (1968). Pygmalion in the classroom: Teacher expectations and pupil's intellectual development. Holt, Rinehart, \& Winston, New York.

Rutherford, F. J. (1990). Science for all Americans. American Association for the Advancement of Science

Ryan, M. (2016). Districts tackle teacher shortages with higher salaries, mentoring. District Administration Retrieved from https://www.districtadministration.com/articles/districts-tackle-teacher-shortages

Schmitz, S.A., Nourse, S.W., Ross, M.E. (2012). Increasing teacher diversity: Growing your own through partnerships. Education, 133(1), 181-187.

Scott, A., \& Martin, A. (2014). Percieved barriers to higher education in science, technology, engineering and mathematics. Journal of Women and Minorities in Science and Engineering, 20(3), 235-256.

Segen's Medical Dictionary. (2011). Retrieved October 62017 from https://medical-dictionary.thefreedictionary.com/math+anxiety

Stevens, T., Olivarez, A., Lan, W. Y., \& Tallent-Runnels, M. K. (2004). Role of mathematics self-efficacy and motivation in mathematics performance across ethnicity. The Journal of Educational Research, 97(4), 208-222 
Stodolsky, S. S., \& Grossman, P. L. (2000). Changing Students, Changing Teaching. Teachers College Record, 102(1), 125-72.

Supekar, K., Iuculano, T., Chen, L., \& Menon, V. (2015). Remediation of childhood math anxiety and associated neural circuits through cognitive tutoring. The Journal of Neuroscience, 35(36), 12574-12583.

Sutcher, L., Darling-Hammond, L., Carver-Thomas, D. (2016). A coming crisis in teaching? Teacher supply, demand and shortages in the U.S. Learning Policy Institute, Research. Action. Impact. Retrieved from (http://www/learningpolicyinstitute.org/products/coming-crisis-teaching. )

Tartari, V., Perkmann, M., \& Salter, A. (2014). In good company: The influence of peers on industry engagement by academic scientists. Research Policy, 43(7), 11891203.

Toland, M.D., Usher, E. L. (2016). Assessing mathematics self-efficacy: How many categories do we really need. Journal of Early Adolescence 36 (7), 932-960.

Tolven-Lindsey, B., Levis-fitzgerald, M., Barber, P. H., Hasson, T. (2015). Increasing persistence in undergraduate science majors: A model for institutional support of underrepresented students. Life Science Education, 14, 1-12.

Tyack, D. B. (1967) Turning points in American educational history. Waltha,, MA: Blaisdell Publishing Company.

US Census Bureau (2017, June 1 ${ }^{\text {st }}$ ). Quick facts: Missouri. Retrieved from https://www.census.gov/quickfacts/table/PST045215/29

Vergolini, L. Vlach, E. (2017). Family background and educational path of Italian graduates. Higher Educ 73, 245-259. DOI 10.1007/s10734-016-0011-2 
Villavicencio, F.T., Bernardo, A.B.I. (2015, July). Beyond math anxiety: Positive emotions predict mathematics achievement, self-regulation, and self-efficacy. Asia-Pacific Education Researcher, 25(3), 415-422.

Volodina, A., \& Nagy, G. (2016). Vocational choices in adolescence: The role of gender, school achievement, self-concepts, and vocational interests. Journal of Vocational Behavior, 95, 58-73.

Wang, X. (2013). Why students choose STEM majors: Motivation, high school learning, and postsecondary context of support. American Educational Research Journal, 50(5), 1081-1121.

Wheelan, C. (2013). Naked statistics: stripping the dread from the data. WW Norton \& Company, New York.

Whitford, B. L. \& Villaume, S. K. (2014). Clinical teacher preparation: A retrospective. Peabody Journal of Education 89 (4) 423-435, DOI:

10.1080/0161956X.2014.938590.

Williams, T., \& Williams, K. (2010). Self-efficacy and performance in mathematics: Reciprocal determinism in 33 nations. Journal of educational Psychology, 102(2), 453.

Wolfram, C. (2010). Teaching kids real math with computers. TED talks. Retrieved from https://www.ted.com/talks/conrad wolfram teaching kids real math with comp uters 


\section{APPENDIX A: SURVEY QUESTIONS}

1. Which gender do you identify with?

Female

Male

2. What is the highest level of school your father completed or the highest degree he received?

$\begin{array}{ll}\text { Less than high school degree } & \text { Bachelor degree } \\ \text { High school degree or equivalent (e.g., GED) } & \text { Graduate degree } \\ \text { Some college but no degree } & \text { Unknown } \\ \text { Associate degree } & \end{array}$

3. What is the highest level of school your mother completed or the highest degree she received?

$\begin{array}{ll}\text { Less than high school degree } & \text { Bachelor degree } \\ \text { High school degree or equivalent (e.g., GED) } & \text { Graduate degree } \\ \text { Some college but no degree } & \text { Unknown } \\ \text { Associate degree } & \end{array}$

* 4. Rank yourself in the following areas in comparison to your peers from high school

Overall Academic
performance
Mathematical problem
solving
Critical thinking ability
Ability in logic and
solving puzzels
Artistic and creative
ability

\section{*5. When I am faced with a challenging problem}

I avoid it

I am hesitant but will attempt it

I am willing to work on it

I am excited to work on it 


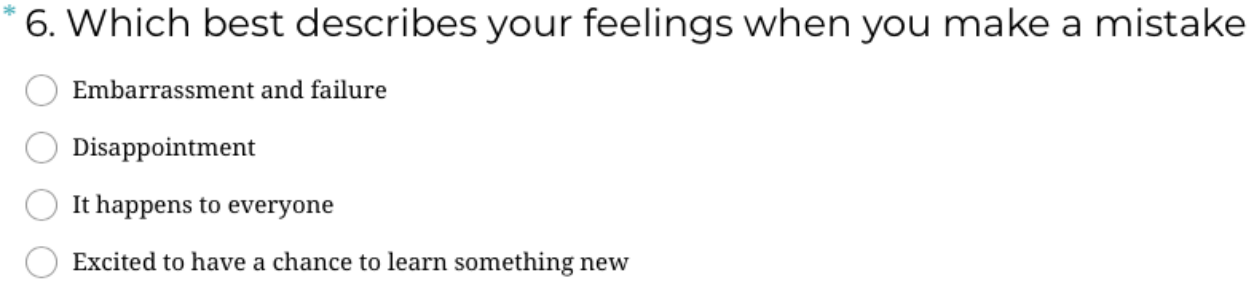

* 7. For each statement mark the level of influence on your choice to pursue education

I have teachers in my
family
A teacher encouraged
me to pursue math
education
A parent or grandparent
encouraged me to
pursue math education
A sibling or a cousin
encouraged me to
pursue math education
A friend or classmate
encourage me to pursue
math education
A teacher told me I was
strong in mathematics

* 8. For each statement mark the level of influence on your choice to pursue education

My interest in
mathematics
I am skilled in
mathematics
I enjoy puzzles and
problem solving
I believe I will make a
good living teaching
I believe the benefits of
teaching are worthwhile
Teaching is a respected
career
I feel there is job
security and
opportunity for growth
in education




\section{APPENDIX B: RECRUITMENT LETTER FOR FACULTY \\ Project: Social and Cognitive Influences on Teacher Candidates Choice to Pursue Math Education.}

To:

From: Jennifer Wall <JWALL@nwmissouri.edu>

Subject: Doctoral Study Participation

Cc: Rebecca Callaway <rebecca.callaway@nkcschools.org>

Bcc:

Hello, my name is Rebecca Callaway and I am a Doctoral Student at the University of Missouri-Columbia through the Northwest Missouri State University cohort. I am currently working on my dissertation, "Social and Cognitive Influences on Teacher Candidates choice to pursue Math Education."

This research is being conducted to investigate the factors that influence a teacher candidate to select math education. There is currently a teacher shortage in the field of math education and finding theses influences can guide future actions to eliminate this shortage.

The research consists of students in their first two years of teacher preparation completing an online survey about what influenced their choice. I need your help contacting these students. As a leader in your teacher preparation program would you be willing to share this survey with your students. Attached you will find an email that it would be much appreciated if you passed on to your students.

The survey link is https://www.surveymonkey.com/r/QK2WMNH

I would greatly appreciate, if you would encourage your students to participate. The more participation, the more accurate the results will be. I will share my results with you.

Thank you so much for your time.

Sincerely, Rebecca Callaway rebecca.callaway@nkcschools.org (816) 233-9380 (Cell) 


\section{APPENDIX C. RECRUITMENT LETTER FOR STUDENTS \\ Project: Social and Cognitive Influences on Teacher Candidates Choice to Pursue Math Education.}

To:

From:

Subject: Please complete this Survey

Ce:

Bcc:

Hello, my name is Rebecca Callaway and I am a Doctoral Student at the University of Missouri-Columbia through the Northwest Missouri State University cohort. I am currently working on my dissertation, "Social and Cognitive Influences on Teacher Candidates choice to pursue Math Education."

This research is being conducted to investigate the factors that influence a teacher candidate to select math education. There is currently a teacher shortage in the field of math education and finding theses influences can guide future actions to eliminate this shortage.

Would you please take a few minutes to answer 9 questions about what influenced your choice to pursue math education? Please click on the link below to get to the survey. https://www.surveymonkey.com/r/QK2WMNH

Thank you so much for your time.

Sincerely,

Rebecca Callaway

rebecca.callaway@nkcschools.org

(816) 233-938 
Rebecca Ruth Grier Callaway is a math teacher at Winnetonka High School in North Kansas City, Missouri. She is a wife and best friend to Jason Callaway of 18 years. She is mother to 4 amazing children: Jasmine-16, Jase- 13, Jamin-9 and Jane-3. She is the daughter to Amy and Stacy Grier who taught her to work hard. She is the youngest sister to Sara Buck, Beth Berry and Fred Grier who set the bar high and pushed her be the best she could be. She is a student at heart.

Rebecca earned a BA in mathematics from Central Methodist College where her professors (Linda Lembke and Tiger Gordon) first put the love of mathematics in her. She then earned a Masters in Applied Mathematics from Iowa State University. While at ISU, she discovered her passion for teaching mathematics. Then she moved to St. Joseph Missouri, where she earned a teaching certificate from Missouri Western State University while beginning to teach at Central High School. While in St. Joseph she became National Board Certified, earned a Teacher of the Year award and several other teaching awards. She also sponsored many clubs that taught her the power of building relationships. Now she has moved school districts and increased her passion for building student self-efficacy and focus on student thinking. 